NBER WORKING PAPER SERIES

\title{
THE ECONOMICS OF SOVEREIGN DEBT, BAILOUTS \\ AND THE EUROZONE CRISIS
}

Pierre-Olivier Gourinchas

Philippe Martin

Todd E. Messer

Working Paper 27403

http://www.nber.org/papers/w27403

\author{
NATIONAL BUREAU OF ECONOMIC RESEARCH \\ 1050 Massachusetts Avenue \\ Cambridge, MA 02138 \\ June 2020
}

The first draft of this paper was written while P-O. Gourinchas was visiting Harvard University, whose hospitality is gratefully acknowledged. We thank the Fondation Banque de France and the Banque de France-Sciences Po partnership for its financial support. The views expressed herein are those of the authors and do not necessarily reflect the views of the National Bureau of Economic Research.

NBER working papers are circulated for discussion and comment purposes. They have not been peer-reviewed or been subject to the review by the NBER Board of Directors that accompanies official NBER publications.

(C) 2020 by Pierre-Olivier Gourinchas, Philippe Martin, and Todd E. Messer. All rights reserved. Short sections of text, not to exceed two paragraphs, may be quoted without explicit permission provided that full credit, including $(\odot$ notice, is given to the source. 
The Economics of Sovereign Debt, Bailouts and the Eurozone Crisis

Pierre-Olivier Gourinchas, Philippe Martin, and Todd E. Messer

NBER Working Paper No. 27403

June 2020

JEL No. F34,F45

\begin{abstract}
$\underline{\text { ABSTRACT }}$
Despite a formal 'no-bailout clause', we estimate significant net present value transfers from the European Union to Cyprus, Greece, Ireland, Portugal and Spain, ranging from roughly 0.5\% (Ireland) to $43 \%$ (Greece) of 2011 output during the recent Eurozone crisis. We propose a model to analyze and understand bailouts in a monetary union, and the large observed differences across countries. We characterize bailout size and likelihood as a function of the economic fundamentals (economic activity, debt-to-gdp ratio, default costs). Our model embeds a 'Southern view' of the crisis (transfers did not help) and a 'Northern view' (transfers weaken fiscal discipline). While a stronger no-bailout commitment reduces risk-shifting, it may not be optimal from the perspective of the creditor country, even ex-ante, if it increases the risk of immediate insolvency for high debt countries. Hence, the model provides a potential justification for the often decried policy of 'kicking the can down the road'.

Pierre-Olivier Gourinchas

Department of Economics

University of California, Berkeley

530 Evans Hall \#3880

Berkeley, CA 94720-3880

and CEPR

and also NBER

pog@econ.berkeley.edu

Philippe Martin

SciencesPo

28, rue des Saints-Peres

75007 Paris

and CEPR

philippe.martin@sciencespo.fr

Todd E. Messer

University of California at Berkeley

530 Evans Hall \#3880

Berkeley, CA 94720-3880

messertodd@berkeley.edu
\end{abstract}




\section{Introduction.}

The markets are deluding themselves when they think at a certain point the other member states will put their hands on their wallets to save Greece.

ECB Executive Board member, Júrgen Stark (Reuters, 2010, January 10)

The euro-region treaties don't foresee any help for insolvent countries, but in reality the other states would have to rescue those running into difficulty.

German finance minister Peer Steinbrueck (The Financial Times, 2009, February 18)

No, Greece will not default. Please. In the euro area, the default does not exist.

Economics Commissioner Joaquin Almunia (Reuters, 2009, January 29)

The above quotes illustrate the uncertainties and disagreements on the possibility of sovereign defaults in the European Monetary Union (Eurozone), as well as the distance between words and deeds. This paper explores theoretically and empirically the conditions under which a member of a Monetary Union might choose to default on its sovereign contractual obligations, and the conditions under which other members of the Monetary Union prefer to bail it out.

As the Eurozone crisis of 2010-2015 highlighted, a potential default on government debt inside a monetary union comprised of sovereign members involves some unique features that affect the potential costs and benefits to debtor and creditor countries. First, a monetary union facilitates financial integration. With larger within-union cross-border holdings of financial assets, including government debt held by banks, the exposure of creditor countries inside the union to sovereign risk is high. In addition, monetary and economic unions usually go hand in hand, fostering real integration. Should a country experience a severe fiscal crisis, this has the potential to disproportionately disrupt its trading partners inside the union. Further, a sovereign default could be the first step towards a potential exit from the monetary union, potentially impairing the credibility of other members or of the monetary union as a whole. For creditor countries inside the union, there is significant direct and indirect exposure if a fiscally weak member defaults.

Should these costs for the group of creditor countries exceed the resources the debtor country needs to avoid a default, a unilateral transfer -in the form of a bailout- might be a preferred outcome for the union, helping to achieve (ex-post) efficiency. It follows that a monetary union, through the direct and collateral linkages it generates between members, creates conditions where creditor countries may desire (ex-post) to bail-out weaker members. For the defaulting country, not surprisingly, the possibility of future bailouts distorts (ex-ante) incentives to issue debt by softening the debtor's budget constraint. This results in excessive debt issuance that can weaken the union. 
The founders of the European Monetary Union well understood this trade-off and sought explicitly to limit the potential for excessive debt issuance. For instance, Article 125 of the Treaty on the Functioning of the European Union (TFEU), often referred to as the no-bailout clause, prevents any form of liability of the Union or Member States for another Member's debt obligations. ${ }^{1}$ A distinctive additional feature of a monetary union is the way in which debt monetization affects member countries. While the benefits and costs of inflation are borne by all members, their distribution is not uniform. Surprise inflation reduces the ex-post real value of debt for all members. This benefits disproportionately highly indebted countries, while the costs of inflation are more uniformly distributed. Article 123 of the same treaty sought to address this by expressly prohibiting the European Central Bank from directly purchasing member countries' public debt. ${ }^{2}$

Yet the same European Treaty did not close the door entirely on the possibility of (ex-post) financial assistance. For instance, Article 122 of the TFEU allows the Union or other Member States to provide assistance to other members, under exceptional circumstances. ${ }^{3}$ Indeed, at various points during the Eurozone sovereign debt crisis, Greece, Ireland, Portugal, Spain and Cyprus lost market access and had to ask for the support of other eurozone members, in order to avoid a default or a collapse of their domestic banking sector. This financial support was mainly provided through the creation of the European Financial Stability Facility (EFSF) and its successor, the European Stability Mechanism (ESM), who lent large amounts to these countries. More recently, discussions about unilateral transfers in the Eurozone have been revived in the context of the COVID-19 crisis (Bénassy-Quéré et al., 2020).

This raises two critical questions, one empirical and one theoretical. The empirical question is whether fragile Eurozone countries received unilateral support during the crisis, and if so how much as a share of the recipient country's economy? The theoretical question is who benefits from these transfers, and under which conditions it might be (ex-ante) preferable for the creditor members of the union to bail-out a debtor member? This paper answers both questions. First, we document large and sizable implicit transfers in the context of the Eurozone debt crisis of 2010-2015. Second, we present a model that captures the trade-off between ex-post bailout and ex-ante borrowing incentives. The

\footnotetext{
${ }^{1}$ Article 125 stipulates that 'The Union shall not be liable for or assume the commitments of central governments, regional, local or other public authorities, other bodies governed by public law, or public undertakings of any Member State, without prejudice to mutual financial guarantees for the joint execution of a specific project. A Member State shall not be liable for or assume the commitments of central governments, regional, local or other public authorities, other bodies governed by public law, or public undertakings of another Member State, without prejudice to mutual financial guarantees for the joint execution of a specific project' EU (2012b).

${ }^{2}$ Article 123 stipulates 'Overdraft facilities or any other type of credit facility with the European Central Bank or with the central banks of the Member States (hereinafter referred to as 'national central banks') in favour of Union institutions, bodies, offices or agencies, central governments, regional, local or other public authorities, other bodies governed by public law, or public undertakings of Member States shall be prohibited, as shall the purchase directly from them by the European Central Bank or national central banks of debt instruments.' EU (2012b)

${ }^{3}$ Article 122 stipulates "..Where a Member State is in difficulties or is seriously threatened with severe difficulties caused by natural disasters or exceptional occurrences beyond its control, the Council, on a proposal from the Commission, may grant, under certain conditions, Union financial assistance to the Member State concerned.' EU (2012b)
} 
model allows us to characterize the likelihood and size of bailouts in equilibrium, as a function of country characteristics. It also explores under which conditions it is beneficial (ex-ante) for the creditor country to allow for the possibility of (ex-post) bailouts.

How much, if any, of a given financial assistance program constitutes a transfer to the recipient country? The answer depends on the risk profile of the program and the interest rate charged by the lending institution. If the ESM or EFSF are providing risk-free funding at the market risk-free rate, there is no implicit subsidy. If instead the ESM charges a rate that is below the risk-adjusted market rate, i.e. the rate that reflects the risk-profile of the program, then there is an expected transfer component. We provide estimates of the implicit transfers arising from official European Union financing to five eurozone crisis countries: Cyprus, Greece, Ireland, Portugal and Spain. The key assumption necessary to construct our estimates is the choice of a relevant risk-adjusted market rate. It should not be the market rate since often official lending will have a much lower risk profile. This paper uses instead the internal rate of return on the International Monetary Fund (IMF) lending to these countries. ${ }^{4}$ This assumption is justified by the evidence that IMF programs almost always get repaid and do not incorporate a substantial transfer component, except for concessional lending to poor and highly indebted countries (Joshi and Zettelmeyer, 2005). Importantly, this assumption yields a lower bound on the size of the transfers from the European Union to the recipient countries for three reasons. First IMF programs are relatively short term (between three and nine years) compared to ESM and EFSF programs with duration ranging from 10 years to 30 years. Adjusting the IMF internal rate for a term-premia would increase estimates of the transfers. Second, IMF programs are super-senior, even to the European Union institutions. Therefore the proper risk-adjusted rate for European Union programs is likely to be higher than the IMF. Lastly, we ignore any potential transfer component arising from European Central Bank policies (namely the Security Market Program, or the Asset Purchase Program).

Our estimates indicate substantial variation in the implicit transfers received by the fiscally weak Eurozone countries, from roughly 0.4 percent of output for Ireland or Spain, to roughly 3 percent of output for Cyprus and Portugal and a very substantial 43.7 percent of output for Greece. By contrast, non-eurozone program countries such as Hungary, Latvia or Romania did not receive any measurable direct transfer from the European Union. It is clear, based on these estimates, that unilateral transfers did happen, or said differently, that the no-bail out clause did not apply.

Next, we present a two-period model that captures the trade-off between ex-post bailout and ex-ante borrowing incentives inside a monetary union. The model features two countries that are members of a monetary union, one fiscally strong and one fiscally fragile, and a third country that represents the rest of the world, outside the union. Each region issues sovereign debt and private portfolio holdings are determined endogenously. A sovereign default inflicts direct costs on bondholders, but also indirect

\footnotetext{
${ }^{4}$ Spain did not have an IMF program, so we use an average of the IMF's internal rate of return for the other four countries.
} 
costs on both the defaulting country and its partner within the monetary union. The structure of these collateral costs, together with the realization of output and the composition of portfolios, determines the conditions under which the fiscally strong country may prefer to bailout its fiscally weak partner. We show that while the bailout allows the union to achieve (ex-post) efficiency, it does so by transferring all the surplus to the fiscally strong country, leaving the debtor country no better off with a bailout (and no default) than with a default (and no bailout). We call this the 'Southern view' of the crisis: financial assistance may come, but it does not really help the afflicted country. That financial assistance to a country that is close to default does not improve its fate may seem surprising. However, in absence of political integration, there is no reason creditor countries would offer more than the minimal transfer required that leaves the debtor country indifferent between default and no default. Seen through the lens of our model, even if Greece receives a transfer equal to 43 percent of its output, ex-post this does not make Greece better off.

What the possibility of a bailout does, however, is distort the ex-ante incentives of the fiscally weak country and generate excessive borrowing. We establish this result with both a risk neutral lender and borrower, so the incentive to borrow arises exclusively from the expected ex-post transfer. A higher likelihood of transfer lowers the cost of borrowing for the fiscally weak country below the risk free rate, at the expense of the fiscally strong country. The debtor country then trades-off the increased riskiness of debt against the likelihood of a bailout. We call this the 'Northern view' of the crisis: the ability to obtain a bailout weakens fiscal discipline. In the context of the Eurozone crisis, this position has been articulated many times by the German Treasury and other who have pointed to fiscal laxity in some of the crisis countries.

Our analysis very naturally reconciles the 'Northern' and 'Southern' views of the crisis as the two sides of the same coin: risk shifting by the debtor country occurs in the first period because of the transfer, even if ex-post the creditor country captures all the efficiency gains from avoiding a default. This suggests a simple fix: if the creditor country could credibly commit to a no bail-out clause, this would eliminate ex-ante risk shifting and over-borrowing. Yet we show that such ex-ante commitment may not be optimal, even from the perspective of the creditor country. Instead, we find that, under certain conditions, the creditor country may prefer an imperfect commitment to the no-bailout clause. This is more likely to be the case if the debtor country has an elevated level of debt that needs to be rolled over. Under a strong no-bailout clause, the debtor country may become immediately insolvent. Instead, if a future bailout is possible, the debtor country might be able to roll-over its debt in the initial period. Of course, this can lead to some risk shifting and excessive borrowing, but the scope for excessive borrowing is less significant the larger is the initial debt to roll-over. Hence the creditor country faces a meaningful trade-off between immediate insolvency and the possibility of a future default. Interpreted in this fashion, our model provides conditions under which it is optimal for creditor countries to 'gamble 
for resurrection' or 'kick the can down the road' in official EU parlance, by remaining evasive about the strength of the no-bailout clause. This part of the model captures well what happened between 2000 and 2008 when spreads on sovereign debts were severely compressed.

We consider two important extensions. In the first extension, we allow for two separate decisions by fiscally weak countries: whether to default on sovereign debt and whether to exit the monetary union. This extension is motivated by the fact that Greece received the largest transfer from EU institutions in 2012 , i.e. the year it defaulted on its debt. This would not happen in our baseline model where creditors would only offer a bailout if it were sufficient to avoid a default. Yet, it can happen in our extended model: our model suggest that the 2012 bailout was not intended to prevent a default on public debt -seen as inevitable, but instead to was necessary to ensure that Greece would remain in the Eurozone. As in our baseline model, however, the ex-post welfare gains from that transfer accrue entirely to the creditor countries inside the Eurozone.

In our second extension, we also consider the possibility of debt monetization -through higher inflation- by the common central bank of the monetary union. Debt monetization differs from transfers in the sense that the distortion cost is borne by all Member States. We first show that if debt monetization generates a surplus for the monetary union, it is captured by creditor countries. As in the case of bailouts, the common central bank may prefer, ex-post, to monetize the debt rather than let a default occur. Yet because in our model inflation is more distortionary than a direct bailout, we derive a pecking order in terms of policies : direct fiscal transfers should come first before debt monetization. A contrario, the model suggests that the central bank of a common currency can become 'overburdened' and pushed to monetize the debt if excessively tight restrictions on direct fiscal bailouts are adopted.

Our paper relates to several literatures. The theoretical literature on sovereign debt crisis has focused on the following question: why do countries repay their debt? Two different approaches have emerged (see the recent survey by Bulow and Rogoff (2015)). On the one hand, Eaton and Gersovitz (1981) focus on the reputation cost of default for countries that value access to international capital markets to smooth consumption. On the other hand, Cohen and Sachs (1986), Bulow and Rogoff (1989b), Bulow and Rogoff (1989a) and Fernandez and Rosenthal (1990) focus on the direct costs of default in terms of disruption of trade for example. Our model clearly belongs to this second family of models as we emphasize output loss for the country that defaults which comes from trade and financial disruptions but also which may come from the risk of exit of the eurozone. Empirically, Rose (2005) shows that debt renegotiation entail a decline in bilateral trade of around 8 percent a year which persists for around 15 years.

Collateral damage of a sovereign default plays an important role in our analysis of the euro crisis and the existence of efficient ex post transfers. We are not the first to make this point. A related argument can be found in Bulow and Rogoff (1989a) who show that because protracted debt renegotiation 
can harm third parties, the debtor country and its lenders can extract side-payments. Mengus (2014) shows that if the creditor's government has limited information on individual domestic portfolios, direct transfers to residents cannot be perfectly targeted so that it may be better off honoring the debtor's liabilities. Tirole (2015) investigates ex ante and ex post forms of solidarity. As in our paper, the impacted countries may stand by the troubled country because they want to avoid the collateral damage inflicted by the latter. A related paper is Farhi and Tirole (2018) which adds a second layer of bailout in the form of domestic bailouts of the banking system by the sovereign to analyze the 'deadly embrace' or two-way link between sovereign and financial balance sheets. The main differences with our paper are that the first paper focuses on the determination of the optimal debt contract, that both rule out strategic default as well as legacy debt and possible debt monetization. Dovis and Kirpalani (2020) also analyze how expected bailouts change the incentives of governments to borrow but concentrate on the conditions under which fiscal rules can correct these incentives in a reputation model. Niepmann and Schmidt-Eisenlohr (2013) analyze how bank bailouts are affected by cross-border contagion costs. Broner et al. (2014) analyze the eurozone sovereign crisis through a model which features home bias in sovereign debt holdings and creditor discrimination. Our model shares with Broner et al. (2014) the first feature but not the second. In their model, creditor discrimination provides incentives for domestic purchases of debt which itself generate inefficient crowding-out of productive private investment. Uhlig (2014) analyzes the interplay between banks holdings of domestic sovereign debt, bank regulation, sovereign default risk and central bank guarantees in a monetary union. Contrary to this paper, we do not model banks explicitly but the home bias in sovereign bonds plays an important role in the incentive to default. A related paper is also Dellas and Niepelt (2016) who show that higher exposure to official lenders improves incentives to repay due to more severe sanctions but that it is also costly because it lowers the value of the sovereign's default option. Our model does not distinguish private and official lenders. Our model also relates to Corsetti, Erce and Uy (2018) who introduce offcial lending institutions in a model of sovereign debt and default motivated by the euro crisis but focus on different questions as they analyze how official lending and its conditions (maturity and rates) may restore debt sustainability and affect a government's decision to default.

Since the seminal paper of Calvo (1988), a large part of the literature on sovereign default has focused on an analysis of crisis as driven by self-fulfilling expectations (see for example Cole and Kehoe (2000)). This view has been very influential to analyze the euro crisis: this is the case for example of de Grauwe (2012), Aguiar et al. (2015) and Corsetti and Dedola (2016)) for whom the crisis can be interpreted as a rollover crisis where some governments (Spain for example) experienced a liquidity crisis. In this framework, the crisis abates once the ECB agrees to backstop the sovereign debt of eurozone members. For example, Corsetti and Dedola (2016) ) analyze a model of sovereign default driven by either self-fulfilling expectations, or weak fundamentals, and analyze the mechanisms by which either conventional or unconventional monetary policy can rule out the former. We depart from 
this literature and do not focus on situations with potential multiple equilibria and on liquidity issues. This is not because we believe that such mechanisms have been absent but in a framework where the crisis is solely driven by self-fulfilling expectations, the bad equilibrium can be eliminated by a credible financial backstop and transfers should remain "off the equilibrium path". However, we will show in the next section that transfers (from the EFSF/ESM) to the periphery countries have been substantial and not only to Greece. An important difference between Aguiar et al. (2015) and our work is that they exclude the possibility of transfers and concentrate on the lack of commitment on monetary policy that makes the central bank vulnerable to the temptation to inflate away the real value of its members' nominal debt. We view the lack of commitment on transfers as an distinctive feature of a monetary union and analyze the interaction between the monetary policy and transfers in a situation of possible sovereign default.

The remaining of the paper is organized as follows. In Section 2, we review how bailouts unfolded during the eurozone debt crisis in the different countries and estimate transfers implicit in lending from European countries to Greece, Ireland, Portugal, Cyprus and Spain. The possibility of such transfers is a key element of our theoretical model which we present in Section 3. Section 4 analyzes the incentives for defaults and bailouts and Section 5 studies how these incentives shape optimal debt issuance. Section Section 6 then extends the model into two directions: first, the possibility that a country could default but still remain in the eurozone and second the possibility that the ECB monetises the debt. Section Section 7 concludes.

\section{Implicit Transfers During the Euro area crisis}

This section briefly describes the financial assistance programs for the major crisis countries (Cyprus, Greece, Ireland, Portugal, and Spain). We also review the terms of EU financial assistance programs to three non-Eurozone members of the European Union (Hungary, Latvia and Romania). We refer the reader to the Online Appendix and to Corsetti, Erce and Uy (2017) for a more detailed analysis and description of the development of a euro area crisis resolution framework.

\subsection{Historical Overview}

Lenders. Financial assistance to distressed countries in the Eurozone was provided by the so-called "Troika", a tripartite group consisting of the International Monetary Fund (IMF), the European Commission (EC), and the European Central Bank (ECB). This paper, for reasons that will become clear shortly, focuses on the first two legs of the Troika: the IMF and the EC. ${ }^{5}$ The latter provided financial support using different lending institutions, including the European Financial Stability Mechanism (EFSM), the

\footnotetext{
${ }^{5}$ The role of the ECB has been discussed at length in, for example, Shambaugh (2012) or Giannone et al. (2012).
} 
European Financial Stability Facility (EFSF) the European Stability Mechanism (ESM), the Greek Loan Facility (GLF), and the Balance of Payments (BoP) facility.

Since the crisis countries are all high-income, IMF loans came through non-concessional Stand-by Arrangements or Extended Fund Facilities, subject to structural reforms and macroeconomic conditionality. Loans were medium-term, with maximum maturities of up to 10 years. ${ }^{6}$ Under normal access, the maximum amount that countries can borrow depends on their IMF quota. ${ }^{7}$ Many countries were given "exceptional access," allowing them to override the borrowing limit. The lending rate on all nonconcessional facilities is tied to the 'Basic Rate of Charge,' which is the SDR rate (revised weekly) plus a margin depending on the size of the loan relative to a country's quota. ${ }^{8}$

At the beginning of the crisis, the EC had few tools with which to manage debt crises within the Eurozone. The March 2010 program for Greece, through the newly created GLF, marked the beginning of large-scale EC lending. In June 2010, the EC created the EFSF, which would provide support to Greece, Ireland, and Portugal. In 2011, the EC further created the European Financial Stability Mechanism (EFSM) which provided assistance to Ireland and Portugal. Finally, the in September 2012, the EC created the ESM, a permanent facility to replace the EFSF and to continue providing support to Greece, Spain, and Cyprus. With the exception of the GLF which uses bilateral loans from Eurozone members, all EC programmes typically use an on-lending scheme in which the lender borrows first from financial markets. As with the IMF, lending from the EC comes with structural and macroeconomic conditionality. Lending rates for these facilities typically followed the same structure as the IMF, with a variable interest rate given by the cost of funding plus some margin.For non-Eurozone countries, the EC used its Balance of Payments assistance facility under Article 143 of the TFEU. This facility also funds itself through an on-lending scheme and was used by Hungary, Latvia, and Romania.

Greek Financial Assistance Programmes. Greece was by far the largest recipient of financial assistance during the European sovereign debt crisis. We describe the Greek financial assistance programmes in some detail and relegate the details of the other Eurozone countries programmes to the online-appendix. The country entered the first of three successive programmes following sharp rises in government yields and revelations that the Greek government had materially understated its public debt and deficit figures in late 2009. ${ }^{9}$ Programme 1 resulted in assistance from the EC via the Greek

\footnotetext{
${ }^{6}$ Early programs were mostly medium-term maturity Stand-By Arrangements, with repayment typically due within 3-5 years. Later programs were designed under the Extended Fund Facility (EFF), with slightly longer maturity of 4-10 years.

${ }^{7}$ Both SBA and EFF loans stipulate that, under normal access, the maximum amount a country can borrow is $145 \%$ of a their quota annually or $435 \%$ over the lifetime of a program.

${ }^{8}$ The margin is $100 \mathrm{bp}$ for loans less than $187.5 \%$ of quota, $200 \mathrm{bp}$ for credit above $187.5 \%$ of quota, and $300 \mathrm{bp}$ for credit above $187.5 \%$ of quota for more than 51 months. There is also a service charge of $50 \mathrm{bp}$ and commitment fees of up to $60 \mathrm{bp}$. (IMF, 2016b, 2017)

${ }^{9}$ There is by now a substantial literature discussing the unfolding of the Greek crisis. See Zettelmeyer, Trebesch and Gulati (2013), Blustein (2015), Schumacher and Mauro (2015), Gourinchas, Philippon and Vayanos (2017), and ChodorowReich, Karabarbounis and Kekre (2019) among others.
} 
Lending Facility (GLF) and the IMF in the period 2010-2011. Programme 2 resulted in assistance from the EFSF and the IMF in 2012-2015. Programme 3 resulted in assistance from the ESM in 2015-2018.

The size of Programme 1 was approximately $€ 110$ bn with $€ 80$ bn coming from the GLF and $€ 30$ bn from an IMF's SBA program. Actual disbursements by the IMF totaled $€ 20.1$ bn in six tranches between May 2010 and December 2011. Actual disbursements from the EC totaled $€ 52.9$ bn also over six tranches between May 2010 and December 2011. The disbursements were apportioned to each European country, with Germany (€15.17 bn), France (€11.39 bn), and Italy (€10.00 bn) contributing the bulk of the funding (EC, 2014). ${ }^{10}$ The maximum maturity was initially set to 5 years with a 3-year grace period (EC, 2010). The bilateral loans were pooled by the European Commission then disbursed to Greece with a variable lending rate originally based on the 3-month Euribor, representative of borrowing costs, plus a margin of 300 basis points for the first three years and 400 basis points thereafter. Three amendments to this loan agreement altered the grace period, the maturity structure, and the interest rates resulting in an extension of the weighted average maturity to 30 years and a lowering of the interest rate margin to only $50 \mathrm{bp} .{ }^{11}$

Towards the end of Programme 1, it became apparent that the financial assistance and structural reforms were not sufficient to restore growth and financial market access. The IMF and the EC agreed to a second programme, with the latter operating through the EFSF, coinciding with a restructuring of Greek debt. ${ }^{12}$ This programme included the un-disbursed amount from Programme 1, plus an additional $€ 130 \mathrm{bn}$, for a total of almost $€ 180 \mathrm{bn}$ (EC, 2012b). Actual disbursements by the IMF for Programme 2 totalled around $€ 11.6$ bn out of a total planned contribution of $€ 28$ bn (IMF, 2014). These loans were now given through the EFF, beginning with the first tranche in March 2012 and the last in June 2014. The EFSF committed a total of $€ 144.7 \mathrm{bn}$ of which approximately $€ 141.8 \mathrm{bn}$ was disbursed (EC, 2012b). ${ }^{13}$ Lending rates were calculated as the EFSF cost of funding plus two fees: a guarantee commitment fee and a service fee. ${ }^{14}$ (EC, 2012c) In January 2017, the maturity of the loans was lengthened to "update" the weighted average maturity back to the maximum permitted 32.5 years. ${ }^{15}$

Programme 2 was interrupted at the end of 2014 by Greek elections. Following the election of Syriza and six months of failed negotiations, Programme 2 was allowed to expire in June 2015 during the fifth review. That August, Greece and the EC, through the ESM, agreed to a third programme, this time

\footnotetext{
${ }^{10}$ Originally, Ireland and Portugal were also slated to contribute to Programme 1. However, their own fiscal struggles caused them to eventually drop out.

${ }^{11}$ The three amendments occurred in June 2011, February 2012, and December 2012 (EFSF, 2014, 2015; ESM, 2017).

${ }^{12}$ See Zettelmeyer, Trebesch and Gulati (2013) for a summary of the restructuring.

${ }^{13}$ There is a net outstanding amount of $€ 130.9 \mathrm{bn}$ as of October 2018 , due to the return of $€ 10.9 \mathrm{bn}$. The $€ 10.9 \mathrm{bn}$ returned consisted of bonds that were to be used to recapitalize Greek banks through the Hellenic Financial Stability Fund.

${ }^{14}$ Originally, interest payments on the debt buyback scheme were to be subject to a margin of 200bps per annum beginning in January 2017 (the "Step-Up" Scheme). This was waived temporarily in January 2017, and has since been waived annually. This rate can be reduced to zero by an ESM board decision each half year until 2022. (ESM, 2019a)

${ }^{15}$ The agreement also reduced interest rate risk via bond exchanges, swap arrangements, and matched funding. Note that we do not take this second factor into account in our calculation of transfers.
} 
without the IMF, which was concluded in August 2018. ${ }^{16}$ Programme 3 consisted of new loans by the ESM only, who committed $€ 86$ bn to Greece and disbursed $€ 61.9$ bn in total.

Other Eurozone Financial Assistance Programmes. Three of the other four Eurozone crisis countries, Cyprus, Ireland, and Portugal, had similar, although less extreme patterns of financial assistance by the IMF and the European Union. Ireland and Portugal both received assistance in late 2010 and early 2011, respectively, before both receiving debt relief measures in 2013. Cyprus received assistance in 2013 with no debt relief measures institutes since. Finally, Spain received assistance in 2012 from the ESM only.

Ireland request for financial assistance in November 2010 was approved in December 2010. Total commitments were $€ 85 \mathrm{bn}$, with $€ 67.5 \mathrm{bn}$ committed externally. ${ }^{17}$ Such external funding comprised $€ 17.7 \mathrm{bn}$ from the EFSF, $€ 22.5 \mathrm{bn}$ from the EFSM, $€ 22.5 \mathrm{bn}$ from the IMF, and $€ 4.8$ bn from Bilateral Loans (United Kingdom, Sweden, and Denmark). ${ }^{18}$ All committed funds were eventually disbursed. IMF support came through the EFF between January 2011 and December 2013.(IMF, 2013) EFSF support was given over the same time period, with interest payments initially given by the EFSF cost of funding.(EFSF, 2012a) The maximum average maturity was initially set to fifteen years, but later extended to 22 years.(EFSF, 2013b) EFSM support was given between January 2011 and March 2014. While interest payments were originally set to the EFSM cost of funding plus a margin of 292.5bps, in October 2011 all EFSM margins were cancelled (EU, 2011e). The weighted average maturity of both EFSF and EFSM loans, initially set to 7.5 years, were eventually extended to 19.5 years (EU, 2013).

Portugal received financial assistance from the EC via the EFSF and the EFSM, as well as the IMF between May 2011 and June 2014. Portugal allowed the programme to lapse without taking the final tranche of funding available. The three groups each committed approximately $€ 26$ bn for a total of $€ 78$ bn (EC, 2016). The EFSF disbursed the full €26 bn with lending rates equal to the EFSF Cost of Funding. The EFSM disbursed $€ 24.3$ bn of its commitment. The original agreement in May 2011 stipulated the loans would have an average maturity of 7.5 years and a margin of 215bp on top of the EU's cost of funding. In 2011, the average maturities of Portugal's EFSM loan were extended to 12.5 years and margins were eliminated(EU, 2011b). In 2013, the average maturities were again extended to 19.5 years (EU, 2011a). The IMF lent through the EFF nearly all of its $€ 26$ bn but the final disbursement did not occur.

Cyprus officially asked for assistance in 2012 and was approved for a joint IMF/ESM programme in April/May 2013. Cyprus officially exited its programme in March 2016. The program's total approved

\footnotetext{
${ }^{16}$ Greece received one bridge loan from the European Financial Stability Mechanism (EFSM) when it missed a payment on its loans to the IMF in July 2015. This was a three-month loan for $€ 7.16$ bn given to allow Greece time to transition to Programme 3 and receive assistance from the ESM.

${ }^{17}$ Ireland had to commit $€ 17.5 \mathrm{bn}$ itself. This money came from, among other sources, their pension program.

${ }^{18}$ Sweden provided $€ 600$ million, the United Kingdom provided $€ 3,830$ million ( $£ 3.23$ million), and Denmark provided $€ 400$ million.
} 
financing was $€ 10 \mathrm{bn}$, with the ESM committing $€ 9$ bn and the IMF approximately $€ 1$ bn. The ESM disbursed only $€ 6.3$ bn between May 2013 and October 2015, with expected repayment between 2025 and 2031. The IMF disbursed a little less than its commitment through the EFF. Expected repayment is between 2020 and 2026, although Cyprus made one early repayment in July 2017 to take advantage of declining market-based financing.(IMF, 2018b)

Spain received assistance from the ESM only, with no assistance from the IMF. ${ }^{19}$ A total of $€ 100$ bn was committed in July 2012. Only €41.3 bn were disbursed in December 2012 and February 2013. The assistance was used to recapitalize the banking sector. Expected repayment should take place between 2022 and 2027, although Spain has made voluntary early repayments on these loans. Table 1 summarizes the financial assistance measures to all Eurozone countries.

Other European Bailout Programmes. Financial assistance was also offered to three European Union countries outside of the monetary union: Hungary, Latvia, and Romania. Assistance was primarily made under the EC's medium-term Balance of Payment (BoP) assistance programme and by the IMF through SBAs. Assistance was granted to Hungary in November 2008 and lasted through the end of 2009. The total amount available was $€ 6.5 \mathrm{bn}$ in assistance from the EC and approximately $€ 12.5$ bn from the IMF. ${ }^{20}$ However, only $€ 5.5$ bn was disbursed by the EC. ${ }^{21}$ The realized EC loans comprised three installments given over the course of December 2008 to July 2009, each with a maturity between three and six years. For the IMF, approximately $€ 8.7$ bn (SDR7.6 bn) was disbursed between November 2008 and September 2009 and was repaid between February 2012 and August 2013. Latvia received assistance in January 2009. A total of $€ 7.5$ bn was made available, with $€ 3.1 \mathrm{bn}$ from the EC and approximately $€ 1.7 \mathrm{bn}$ from the IMF. ${ }^{22}$ For the EC, realized financial assistance came in four installments of $€ 2.9$ bn between February 2009 and October 2010. The IMF disbursed approximately SDR1 bn between 2008 and 2010 and was repaid in 2013. Finally, assistance to Romania was granted in May 2009. A total of $€ 20$ bn was made available, comprised of $€ 5$ bn from the EC and approximately $€ 12.95$ bn from the IMF. ${ }^{23}$

\footnotetext{
${ }^{19}$ Technically, Spain agreed to a programme with the EFSF. The ESM was set up before any disbursements were given, and so the assistance was transferred.

${ }^{20}$ The World Bank made approximately $€ 1$ bn available as well.

${ }^{21}$ We focus on actual disbursements, so the second round of assistance in July 2012, which did not result in any assistance, is excluded from our analysis.

${ }^{22}$ Additionally, $€ 1.9$ bn were made available by Nordic countries (Sweden, Denmark, Finland, Estonia, and Norway), the World Bank, the European Bank of Reconstruction and Development, the Czech Republic, and Poland.

${ }^{23}$ Additionally, there was $€ 1$ bn from the World Bank, and $€ 0.5$ bn each from the European Investment Bank (EIB) and the European Bank for Reconstruction and Development (EBRD)
} 


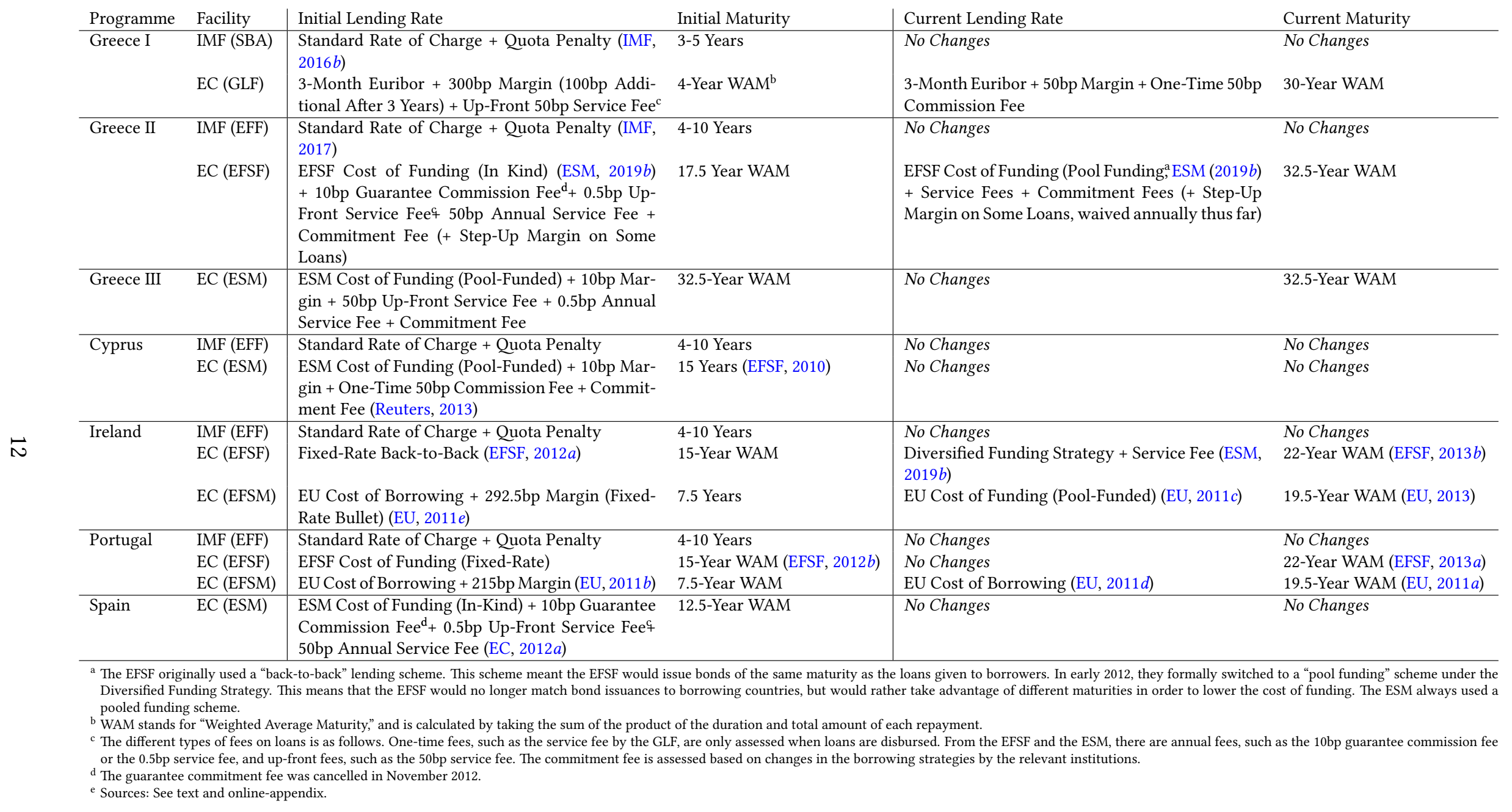

Table 1: Debt Relief Summary 


\subsection{Transfers estimates}

\subsubsection{Motivation and Methodology}

To estimate the implicit transfers in financial assistance for the programmes described above, we follow Joshi and Zettelmeyer (2005) who perform a similar exercise for transfers implicit in IMF programs. A first estimate of transfers was attempted by the ESM itself (see ESM (2014) and ESM (2015) reports). The discount rate used was the market interest rate that crisis countries would have paid had they been able to cover their financing needs from private investors. Using these market rates, however, overlooks the fact that public loans may have a very different risk profile than private loans. To put this point in sharp relief, imagine that ESM loans are risk free and that the ESM charges the risk-free rate. In that case, there is no implicit transfer from lenders to the borrowers, regardless of the market rate on risky loans. Using the private sector (risky) interest rate to discount public sector (risk-less) loans would erroneously conclude that there is a large concessional component in these programs. What is needed instead, is an estimate of the risk-adjusted discount rate on public assistance programs to crisis countries.

Our approach consists in assuming that the default risk on EU funding is similar or higher than the default risk of IMF loans to these same countries, during the same period. Importantly, we do not need to assume that the IMF loans themselves are risk-free. As long as the risk profile of IMF loans and EU loans are similar, then we can use the internal rate of return on IMF programs to each country to discount the term sheet of European loans to that same country. ${ }^{24}$

The IMF interest rate is an attractive choice for three reasons. First and most importantly, while both IMF and EC lending are expected to enjoy preferred creditor status, IMF loans are legally senior to loans from the EFSF and the ESM. ${ }^{25}$ The fact that IMF loans have more seniority implies that the risk of default on IMF loans is lower than that of European loans. Therefore, the correct discount rate on European loans should be even higher than the IMF's internal rate. This biases downwards our bailout estimates. Second, European loans are time-varying, based on the cost of funds. The relevant benchmark rate must also be time-varying in order to account for changes in global lending conditions. As discussed above, IMF loans are time-varying, with an interest rate related to the IMF's cost of funding and to the size of the loan relative to the country's quota. Third, IMF programs tend to be have a medium term maturity (3 to 9 years) while while European loans have a longer duration (10 to 30 years). To the extent that there is a positive term premium, this also biases downward our bailout estimates.

One concern with our methodology is that the IMF programs themselves may include a transfer component. We do not consider that this is a serious issue for two reasons. First, Joshi and Zettelmeyer (2005), estimating the realized transfers in IMF lending from 1973 to 2003 find no evidence of a signifi-

\footnotetext{
${ }^{24}$ The internal rate of return is the standard discount rate that sets the net present value of cash flows equal to zero.

${ }^{25}$ Article 13 of the ESM Treaty states "ESM loans will enjoy preferred creditor status in a similar fashion to those of the IMF, while accepting preferred creditor status of the IMF over the ESM" EU (2012a).
} 
cant transfer component for high and middle income countries, unlike low income countries or Highly Indebted Poor Countries. Second, one might still be concerned that IMF lending to European countries during the Eurozone crisis may have adopted lending criteria that deviated from past practice, resulting in a potential concessional component from IMF lending. In that case, however, using the IMF interest rate would again bias downwards our transfer estimates from EC programs.

To summarize, our estimated transfers provide a lower bound on the true transfer for three reasons: because EC programs are riskier than the IMFs; because they have longer maturity; and because IMF programs themselves may be subsidized. Conversely, our estimates would be biased upwards if either EC lending was senior to the IMF, was shorter maturity or if the IMF was lending at a penalty rate. For reasons argued above, we do not view these scenarios as serious possibilities.

To estimate the NPV of total transfers, $T r_{t}^{i, j}$, for borrower $i$ and creditor $j$ at time $t$, we calculate the difference between the present value of the sequence of net transfers discounted at our benchmark IMF internal rate of return and the present value of the sequence of net transfers discounted at its actual internal rate of return. By definition, this latter term is zero, and so we can write the NPV of transfers as

$$
\operatorname{Tr}_{t_{0}}^{i, j}=\sum_{t=t_{0}}^{T} \frac{1}{\left(1+\bar{r}^{i}\right)^{t}} N T_{t}^{i, j},
$$

in which $t_{0}$ refers to year 2010 and $T$ is the date of the last net transfer flow (always a repayment). As explained above we use the internal rate of return on the IMF's lending for borrower $i$ during the Eurozone crisis, $\bar{r}^{i}$, as the discount rate for country $i . N T_{t}^{i, j}$ are net transfers from lender $j$ to borrower $i$ at time $t$, constructed as:

$$
N T_{t}^{i, j}=D_{t}^{i, j}-R_{t}^{i, j}-\sum_{\tau=1} i_{t-\tau}^{i, j} D_{r, t-\tau}^{i, j}
$$

where $R_{t}^{i, j}$ are principal repayments from $j$ to $i$ at time $t$, and $D_{t}^{i, j}$ denotes disbursements from $i$ to $j$ at time $t$. $\tau$ denotes the maturity of each disbursement and $D_{r, t-\tau}^{i, j}$ is the outstanding principal balance remaining at time $t$ on a disbursement effected at time $t-\tau$, and $i_{t-\tau}^{i, j} D_{r, t-\tau}^{i, j}$ the corresponding interest payments at time $t$. The internal rate of return $i r r^{i, j}$ is the value that sets the sequence of net transfers to zero.

We compile data on disbursements, repayments, and interest payments for the eight borrowing countries and five official international lenders described above. We make two key assumptions. First we assume that the most current specification of future repayments and interest rates coincides with future realized outcome. This assumes that there will be no more debt renegotiations in the future. Any changes to the current agreement, such as delaying interest payments or extending the overall maturity, could only make the terms more favorable for the borrower and would result in a larger transfer than we estimate. Second, for loans with variable interest rates, we construct a proxy for future interest 


\begin{tabular}{ll|ccccc|cc}
\hline \hline Borrower $i$ & Lender $j$ & $i r r^{i, j}$ & $\bar{r}^{i}$ & $\Delta i r r^{i, j}$ & $d^{i, j}$ & $\sum D^{i, j}$ & $\operatorname{Tr}^{i, j}$ & $\operatorname{Tr}^{i, j} / G D P^{i}$ \\
$(1)$ & $(2)$ & $(3)$ & $(4)$ & $(5)$ & $(6)$ & $(7)$ \\
\hline Cyprus & ESM & 0.82 & 1.73 & 0.90 & 15.48 & 6.30 & 0.74 & $3.62 \%$ \\
& IMF & 1.73 & 1.73 & & 7.26 & 0.95 & & \\
Greece & EC & 0.68 & 3.26 & 2.58 & 20.66 & 52.90 & 18.49 & $8.18 \%$ \\
& EFSF & 1.16 & 3.26 & 2.11 & 37.20 & 171.20 & 66.82 & $28.19 \%$ \\
& ESM & 1.83 & 3.26 & 1.43 & 33.81 & 61.90 & 16.64 & $7.30 \%$ \\
& IMF & 3.26 & 3.26 & & 6.70 & 31.99 & & \\
Ireland & EFSF & 1.83 & 2.66 & 0.83 & 21.98 & 17.70 & 2.22 & $1.29 \%$ \\
& EFSM & 3.23 & 2.66 & -0.57 & 16.04 & 22.50 & -1.51 & $-0.88 \%$ \\
& IMF & 2.66 & 2.66 & & 4.59 & 22.61 & & \\
& PFrtugal & 1.78 & 3.25 & 1.46 & 21.92 & 26.00 & 5.47 & $2.93 \%$ \\
& EFSM & 3.10 & 3.25 & 0.14 & 15.64 & 24.30 & 0.38 & $0.21 \%$ \\
& IMF & 3.25 & 3.25 & & 5.65 & 26.39 & & \\
\hline \hline
\end{tabular}

Table 2: Implicit Transfers from Eurozone Funding Programs

The table reports the internal rate of return $\left(\mathrm{irr}^{i, j}\right)$ for each recipient country $i$ and funding agency $j$, the duration of the program $\left(d^{i, j}\right)$, the total (nominal) amount disbursed $\left(\sum D^{i, j}\right)$, the implicit transfer $\operatorname{Tr}^{i, j}$ in billions of euros and scaled by 2010 nominal GDP.

rates by adding an estimate of the term premium to the current interest rate. ${ }^{26}$

\subsubsection{Results}

Table 2 reports our results for Eurozone borrowers. Column (1) reports the calculated internal rate of return for each given borrower-lender pair $i, j, i r r^{i, j}$. Column (2) reports the IMF internal rate of return for borrower $i, \bar{r}^{i}$, which is used as the discount rate. Note that this is simply repeated for reference from the IMF row by country. ${ }^{27}$ Column (3) calculates the difference between the IMF internal rate of return and the loan's internal rate of return (Column (2) minus Column (1)). With the notable exception of the EFSM loan to Ireland, the IMF internal rate of return is always higher, which implies a transfer element from European institutions.

The IMF internal rate varies from $1.73 \%$ for Cyprus to $3.26 \%$ for Greece. There are at least two reasons for this variation across countries. First, countries borrowed at different points in time. Greece's IMF program started in May 2010, while Cyprus' program started in May 2013 (see Table A.1). Over that

\footnotetext{
${ }^{26} \mathrm{We}$ construct this term premium at various maturity from the difference between forward 3-month Euribor rate and the current 3-month Euribor. See the Online Appendix for details.

${ }^{27}$ For Spain, who did not receive any IMF loans, we take the simple average of the other IMF internal rates for the other countries.
} 


\begin{tabular}{ll|ccccc|cc}
\hline \hline Borrower $i$ & Lender $j$ & $i r r^{i, j}$ & $i r r^{i, I M F}$ & $\Delta i r r^{i, j}$ & $d^{i, j}$ & $\sum D^{i, j}$ & $\operatorname{Tr}^{i, j}$ & $\operatorname{Tr}^{i, j} / G D P^{i}$ \\
\hline Hungary & BoP & 3.56 & 2.42 & -1.13 & 5.24 & 5.50 & -0.28 & $-0.31 \%$ \\
& IMF & 2.42 & 2.42 & & 4.22 & 8.75 & & \\
Latvia & BoP & 3.09 & 2.55 & -0.53 & 6.92 & 2.90 & -0.09 & $-0.49 \%$ \\
& IMF & 2.55 & 2.55 & & 3.85 & 1.11 & & \\
Romania & BoP & 3.00 & 2.70 & -0.30 & 7.96 & 5.00 & -0.10 & $-0.08 \%$ \\
& IMF & 2.70 & 2.70 & & 4.65 & 11.87 & & \\
\hline \hline
\end{tabular}

Table 3: Implicit Transfers from non-Eurozone Funding Programs

The table reports the internal rate of return $\left(\mathrm{irr}^{i, j}\right)$ for each recipient country $i$ and funding agency $j$, the duration of the program $\left(d^{i, j}\right)$, the total (nominal) amount disbursed $\left(\sum D^{i, j}\right)$, the implicit transfer $T r^{i, j}$ in billions of euros and scaled by 2010 nominal GDP.

period, the IMF's basic rate of charge decreased from $1.25 \%$ to $1.06 \%{ }^{28}$ Second, countries borrowed various fraction of their quotas, with a corresponding penalty adjustment in their borrowing rate (see Table A.2). Greece, which borrowed 3,374\% of its 2010 quota, faced a higher rate than Cyprus which borrowed 'only' $547 \%$ of its 2010 quota. ${ }^{29}$ As discussed above, these differences can be interpreted as risk premia on IMF lending, and do not affect our calculations as long as EC lending remained less senior than IMF lending to that country. ${ }^{30}$

Column (4) displays the duration of the lending cycle, $d$, following the methodology in Joshi and Zettelmeyer (2005). The duration of the lending cycle between borrower $i$ and lender $j, d^{i, j}$, is calculated as:

$$
d^{i, j}=\sum_{t=1}^{T} \frac{R_{t}^{i, j}}{\sum_{s} R_{s}^{i, j}} \cdot t
$$

where $R_{t}^{i, j}$ are the principal repayments from country $i$ to lender $j$ at time $t$. The duration of IMF programs, between 4.59 years (Ireland) and 7.26 years (Cyprus), is much shorter than the duration of EC programs, between 9.14 years (Spain) and 33.81 years (Greece, ESM). As discussed above, these duration differences suggest a transfer element.

Column (5) shows the sum of all nominal disbursements $\sum D^{i, j}$, in $€$ billion. They vary between 7.25 $€$ billion for Cyprus representing 36\% of its 2010 GDP, to $317.82 €$ billion for Greece, representing $140 \%$ of its 2010 GDP. Columns (6) and (7) of Table 2 show our estimates of the net present value of transfers, calculated according to Eq. (1), first in 2010 billions of Euros and then as a percentage of the country's 2010 GDP. There are striking differences in the estimated transfers across countries. Two countries stand out. First, we find that the size of Ireland's transfer was positive but very small, at 0.69€billion,

\footnotetext{
${ }^{28}$ The IMF's historical basic rate of charge is available at https://www.imf.org/external/np/fin/data/query.aspx.

${ }^{29}$ Given the size of its program, Cyprus also spent a lot less time above its quota, at a penalty rate, relative to Greece.

${ }^{30}$ In addition, since we use the realized IMF schedule of disbursements, repayments, and interest rates, countries like Ireland, which repaid their IMF debt early mechanically faced a lower IMF internal rate of return.
} 
representing $0.41 \%$ of its 2010 GDP. At the other extreme, Greece received a very substantial transfer of 98.6 €billion, representing 42.3\% of its 2010 GDP. For Portugal and Cyprus the transfer is positive and quite sizable, between 3.14 and 3.62\% of GDP. In the case of Spain, where lending was directed towards bank recapitalization and therefore of a different nature from the other countries, the transfer is less than $0.5 \%$ of GDP. ${ }^{31}$

We also calculate the transfer component included in the financial assistance programs that the European Commission extended to three EU members outside the Eurozone: Hungary, Latvia and Romania. ${ }^{32}$ All three countries benefitted also from a concurrent IMF program. Table 3 reports the results. Since these countries were not in the Eurozone, they constitute an interesting control group with which to compare the Eurozone bailouts. We highlight three important results. First, the internal rates of return for the EC programs - between $3.00 \%$ and $3.56 \%$ - are never lower than the IMF internal rate of return - between $2.42 \%$ and $2.70 \%$. Second, the IMF loans are again always shorter, even though in some cases the IMF lent more than the EC. Finally, in the last two columns, we see that the transfer is always negative, between $-0.08 \%$ (Romania) and $-0.49 \%$ (Latvia). Taken together, we interpret this result as saying there was no transfer element embedded in the EC lending to these countries.

We draw the following conclusions from our empirical analysis. First, we estimate implicit transfers of very different sizes to different eurozone countries during the euro crisis. They vary from small (Ireland) to extremely large (Greece). We view these transfers as a central part of the crisis resolution. Second, non-eurozone EU countries did not receive any significant transfer from the EC: sizable transfers are tied to membership in the monetary union, not to membership of the European Union.

\section{Model}

We now present a simple model to help us think about the conditions under which a monetary union might agree to bail out one of its members and characterize the determinants of that transfer. The model emphasizes the collateral cost of default and/or exit from the monetary union in case of default on the other members of the union.

\subsection{Assumptions}

The baseline model we consider is a simple extension of Calvo (1988). Consider a world with 2 periods, $t=0,1$, and three countries. We label the countries $g, i$ and $u$. Countries $g$ and $i$ belong to a monetary union while country $u$ does not. Countries $g$ and $u$ are fiscally strong, in the sense that their government debt is risk-free. Instead, country $i$ is fiscally fragile: its government may be unable or unwilling to

\footnotetext{
${ }^{31}$ As noted above, our calculation for Spain is a bit less precise since the country did not have an IMF program and we are using an average of the IMF internal rate of return for the other countries.

${ }^{32}$ Latvia adopted the Euro on January 1, 2014.
} 
repay its debts either in period 0 or period 1 . Countries can have different sizes, and we denote $\omega^{j}$ the relative size of country $j$, with $\sum_{j} \omega^{j}=1$.

Each country/region $j$ receives an exogenous per capita endowment in period $t$ denoted $y_{t}^{j}$. This endowment represents the maximum fiscal resources available in each period and region. The only source of uncertainty is the realization of the endowment in country $i$ in period $1, y_{1}^{i}$. We define expected output $\bar{y}_{1}^{i} \equiv E\left[y_{1}^{i}\right]$, where $E[$.$] denotes the expectation operator, and \epsilon_{1}^{i}=y_{1}^{i} / \bar{y}_{1}^{i}$ is an endowment shock that satisfies $E\left[\epsilon_{1}^{i}\right]=1$. $\epsilon_{1}^{i}$ is distributed according to a cumulative distribution function $G(\epsilon)$ with pdf $g(\epsilon)$, over a bounded support $\left[\epsilon_{\min }, \epsilon_{\max }\right]$, with $0<\epsilon_{\min } \leq \epsilon_{\max }<\infty$.

The only traded financial assets are sovereign bonds issued by each country. In country $j$, a representative agent -representing a composite of the country's households and banks- has preferences defined over aggregate consumption sequences $\left\{c_{0}^{j}, c_{1}^{j}\right\}$ and over holdings of sovereign bonds, as follows:

$$
U^{j}=c_{0}^{j}+\beta E\left[c_{1}^{j}\right]+\omega^{j}\left(\lambda^{s} \ln b_{1}^{s, j}+\lambda^{i, j} \ln b_{1}^{i, j}\right)
$$

In Eq. (2), $b_{1}^{k, j}$ denotes the face value of debt issued at $t=0$ by country $k$, held by agent $j$. The first part of these preferences is straightforward: households are risk neutral over consumption sequences. In addition, we assume that government bonds provide 'money-like' liquidity services that are valued by households. We model these liquidity services in a very simple way, by including the face value of bonds maturing next period directly in the utility function, as in Krishnamurthy and Vissing-Jorgensen (2012). ${ }^{33}$

Crucially, we assume that bonds from different countries provide different levels of liquidity services, depending on how 'money-like' these government bonds are perceived to be by different investors. Specifically, we assume that sovereign bonds from countries $u$ and $g$ are perfect substitutes and provide identical liquidity services. This is a natural assumption, since both countries are fiscally sound, so their debt is risk free. It follows that we can consider the total demand for safe assets by households in country $j$, denoted $b_{1}^{s, j}=b_{1}^{g, j}+b_{1}^{u, j}$. The liquidity services provided by these 'safe assets' is the same in all countries, hence $\lambda^{s, j}=\lambda^{s}$.

Since country $i$ is fiscally fragile, its debt is not necessarily safe and we should expect $\lambda^{s} \geq \lambda^{i, j}$. Moreover, the liquidity services from holding $i$ 's government debt may vary across investors. In what follows, we assume that $i$-bonds provide higher liquidity services to $i$-investors, then $g$-investors, then $u$-investors: $\lambda^{i, i}>\lambda^{i, g}>\lambda^{i, u}$.

We view this assumption as reasonable. First, $i$-investors are likely to perceive $i$-debt as more liq-

\footnotetext{
${ }^{33} \mathrm{~A}$ number of recent models have introduced bonds in the utility function. This captures, in a simple reduced form, the demand for safe stores of value that would arise in presence of idiosyncratic risk. For a discussion, see Kaplan and Violante (2018).
} 
uid/safe than other investors if risk-shifting leads them to ignore the states of the world where both they and their government default. $i$-investors may also be coerced into holding debt of their own sovereign, through moral suasion or outright financial repression. In our set-up, this would be captured by a higher $\lambda^{i, i}$. Second, collateral policy (i.e which government debt is accepted for collateral and at which haircut) inside the monetary union may make $i$-debt more desirable for foreign investors also located inside the monetary union (i.e. $g$-investors) than for investors located outside the monetary union (i.e. $u$-investors). In the Eurozone, for instance, the Eurosystem collateral framework was criticized before the crisis by Buiter and Sibert (2005) for reducing risk premia and thereby contributing to the insufficient differentiation of sovereign risk. ${ }^{34}$ During the crisis, the ECB implemented numerous changes to its collateral framework, including in the application of its minimum rating threshold. ${ }^{35}$ For the time being, these liquidity services are taken as given but will discuss how changes in collateral policy can affect the equilibrium bailouts.

In order to simplify a number of expressions, we will often consider the bondless limit that obtains when $\lambda^{s} \rightarrow 0$ and $\lambda^{i, j} \rightarrow 0$, while keeping the ratios $\omega^{j} \lambda^{i, j} / \sum_{k} \omega^{k} \lambda^{i, k}$ constant. ${ }^{36}$ In this limit, as we will see, the bond portfolios remain well defined, but the liquidity services become vanishingly small, so the level of debt does not affect utility.

As mentioned above, countries $i$ and $g$ differ in their fiscal strength. While $g$ is fiscally sound, $i$ is fiscally fragile: it needs to refinance maturing debt $b_{0}^{i}$ in period $t=0$, and can decide to default in either period. Should a default occur, we follow the literature and assume that $i$ suffers an output loss in the period of default equal to $\Phi y_{t}^{i}$, with $0 \leq \Phi \leq 1$. This output loss captures the disruption to the domestic economy caused by the default event. With a default cost increasing in output, a default is more costly, and therefore less likely, when the economy is doing well. There are many possible dimensions to the economic cost of a default. In particular, for country $i$, a default may force the country to exit the monetary union. One way to capture this is to write $\Phi=\Phi_{d}+\Phi_{e}$ where $\Phi_{d}$ is the share of output lost if the country defaults but remains in the currency union, while $\Phi_{e}$ is the additional share of output lost from a potential exit, conditional on a default. While $\Phi_{d}$ might be low, $\Phi_{e}$ could be much larger. ${ }^{37}$

In the event of a default, we assume that creditors can recover an amount $\rho y_{t}^{i}$ where $0 \leq \rho<1$ on their original claims. This assumption captures the fact that country $i$ 's decision not to repay its debt does not generally result in a full expropriation of outstanding creditor claims. Importantly, the

\footnotetext{
${ }^{34}$ see Bindseil et al. (2017) for a description of the Eurosystem collateral framework.

${ }^{35}$ Before the crisis only high-rated government debt (A- at minimum) were accepted as collateral with a haircut of $3 \%$ (for a residual maturity of 5-7 years). Lower-rated government bonds (BBB- and above) became eligible on October 2008 with a haircut of $8 \%$. In September 2013, these haircuts were changed to $2 \%$ and $10 \%$ respectively for high-rated and lower-rated government bonds. Furthermore, the ECB often waived the minimum rating threshold for low grade sovereign bonds. See Bindseil et al. (2017).

${ }^{36}$ The terminology here is by analogy with Woodford (1998)'s 'cashless limit' where the direct utility gains from money holdings become vanishingly small.

${ }^{37}$ Section 6.2 considers separately the possibility of a sovereign default and an exit from the currency union.
} 
recovery amount is proportional to output, and not to the outstanding debt. Hence, $\rho y_{t}^{i}$ is economically equivalent to the implicit collateral value of the outstanding debt. The recovery payment is distributed pari passu among all creditors, domestic or foreign, in proportion to their claims. We restrict our analysis to the case where $\Phi+\rho<1$ so that the country always has enough resources for the recovery amount, in the event of default.

A default in $i$ creates direct economic losses on foreign bondholders (both $g$ and $u$ ), through their portfolio holdings of $i$ 's debt, $b_{1}^{i, j}$. In addition to this direct portfolio exposure, we assume that country $g$ also suffers a collateral output loss when country $i$ defaults, equal to $\kappa y_{t}^{g}$, with $0 \leq \kappa<1$. Country $u$, by contrast, does not suffer any collateral damage. This assumption captures the idea that, since $i$ and $g$ belong to a monetary union, their economies are deeply intertwined. It is reasonable to expect that a default in country $i$ would severely disrupt economic activity in country $g$ as well, to a greater extent than in country $u$. This contagion cost could be especially high if, as a consequence of its default decision, country $i$ was forced to exit the common currency. By analogy with the cost of default for $i$, we can re-write $\kappa=\kappa_{d}+\kappa_{e}$, where $\kappa_{e}$ captures the cost of an exit by $i$ on $g$, conditional on a default in $i$. Countries outside the monetary union do not face similarly high levels of economic disruption caused by a collapse of the monetary union.

As in Tirole (2015), both the direct exposure and the collateral cost for country $g$ create a soft budget constraint for country $i$. Our interpretation is that this soft budget constraint was at the heart of the discussions regarding bailout decisions in the Eurozone. For instance, the decision to bail-out Greece in May 2010 and avoid a debt restructuring was directly influenced by the perception that a default event could have quickly spread the sovereign debt crisis to other vulnerable economies in the Eurozone, such as Spain, Italy, Portugal or Ireland, disrupting their economies. ${ }^{38}$ It was also argued that a Greek restructuring could have hurt France or Germany through the exposure of their banking system to Greek sovereign debt. Implicitly, a common perception at the time was that bailing out Greece -so that the Greek government could in turn repay foreign creditors, including French and German banks- was preferable to a restructuring that would have forced the German and French governments to directly recapitalize the losses of domestic banks on their Greek portfolio holdings.

Finally, we allow for voluntary transfers from $g$ to $i$ in either period, denoted $\tau_{t}$. Crucially, we consider an environment where $g$ can make ex-post transfers conditional on the realization of output, and therefore on $i$ 's default decision. These transfers are voluntary and therefore must satisfy: $\tau_{t} \geq 0$. There is no reason for $g$ to make a transfer to $i$ in case of default, so the optimal transfer in that case is zero. $^{39}$

\footnotetext{
${ }^{38}$ See Constâncio (2012).

${ }^{39}$ While we allow for unilateral transfers from $g$ to $i$, we do not need to consider transfers from $u$ to $i$. There are two reasons for this. First, $g$ has more exposure to $i$ 's default than $u$, both through larger direct portfolio holdings and indirectly through the collateral damage. Therefore, $g$ has a stronger incentive than $u$ to bailout $i$. Conditional on a bailout from $g, u$
} 


\subsection{Budget Constraints and Market Clearing}

The government of country $j$ issues one-period bonds with face value $b_{1}^{j}$ in period $t=0$. It also raises aggregate lump-sum taxes $T_{t}^{j}$ on domestic residents in period $t$. We begin by writing down the budget constraints of the representative household in country $i$, assuming that no default occurs at $t=0$ :

$$
c_{0}^{i}+b_{1}^{i, i} / R^{i}+b_{1}^{s, i} / R^{*}=y_{0}^{i}-T_{0}^{i}+b_{0}^{i, i}+b_{0}^{s, i} .
$$

Country $i$ 's representative household consumes $c_{0}^{i}$, invests in domestic and safe debt, $b_{1}^{i, i}$ and $b_{1}^{s, i}$, with respective yields $R^{i}$ and $R^{*}$. Its resources consist of after tax income $y_{0}^{i}-T_{0}^{i}$ and the face-value of maturing debt claims $b_{0}^{i, i}$ and $b_{0}^{s, i}$.

In period $t=1$, the household consumes:

$$
\left\{\begin{array}{rlrl}
c_{1}^{i} & =y_{1}^{i}-T_{1}^{i}(r)+b_{1}^{i, i}+b_{1}^{s, i} & & \text { if } i \text { repays }(\mathrm{r}) \\
c_{1}^{i}=y_{1}^{i}(1-\Phi)-T_{1}^{i}(d)+\rho y_{1}^{i} \frac{b_{1}^{i, i}}{b_{1}^{i}}+b_{1}^{s, i} & & \text { if } i \text { defaults }(\mathrm{d}) .
\end{array}\right.
$$

The household consumes after tax income, and liquidates its bond portfolio. In case of default, it suffers the direct cost $\Phi y_{1}^{i}$ and recovers only $\rho y_{1}^{i} / b_{1}^{i}$ per unit of domestic bond purchased. Note that period 1 taxes $T_{1}^{i}$ are state dependent and will depend on the realization of output and the decision to default or repay.

Now consider $g$ 's household. Using similar notation, the budget constraint in period $t=0$ is

$$
c_{0}^{g}+b_{1}^{i, g} / R^{i}+b_{1}^{s, g} / R^{*}=y_{0}^{g}-T_{0}^{g}+b_{0}^{i, g}+b_{0}^{s, g},
$$

while period $t=1$ consumption satisfies

$$
\left\{\begin{array}{rlrl}
c_{1}^{g} & =y_{1}^{g}-T_{1}^{g}(r)+b_{1}^{i, g}+b_{1}^{s, g} & & \text { if } i \text { repays (r) } \\
c_{1}^{g}=y_{1}^{g}(1-\kappa)-T_{1}^{g}(d)+\rho y_{1}^{i} \frac{b_{1}^{i, g}}{b_{1}^{i}}+b_{1}^{s, g} & & \text { if } i \text { defaults (d). }
\end{array}\right.
$$

In the case of default, $g$ 's representative household suffers an output loss $\kappa y_{1}^{g}$. As in the case of $i$, taxes raised in $t=1, T_{1}^{g}$, are state contingent and may depend on whether $g$ offers a bailout to $i$. A similar set of budget constraints hold for households in the rest of the world.

We now write the budget constraints of the governments in $i$ and $g$. The budget constraints for $i$ 's

does not need to intervene since a default is already prevented. Second, in the event that $g$ declines to intervene, we will see that $u$ will have no incentive to intervene either, given its lower exposure. We implicitly rule out the case where $u$ and $g$ could coordinate their bailout efforts. This last assumption is plausible and does not preclude IMF-style programs, as long as these do not include a concessional component. 
government in periods $t=0$ and $t=1$ are:

$$
T_{0}^{i}+b_{1}^{i} / R^{i}+\tau_{0}=b_{0}^{i}
$$

and

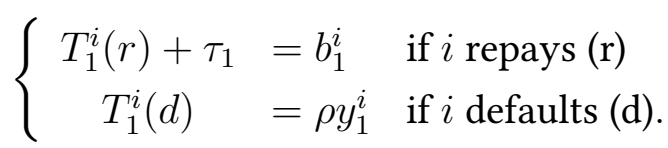

In these expressions, $\tau_{t}$ denotes the direct unilateral transfer from $g$ 's government to $i$ 's government in period $t$. As discussed previously, these transfers can be made conditional on the decision to default by $i$ in the same period, or ex-ante, so as to reduce $i$ 's debt overhang. That is, $g$ can make a transfer $\tau_{0}$ either to avoid a default in the current period or to influence default decisions in the second period.

The budget constraints for $g$ 's government are derived similarly:

$$
T_{0}^{g}+b_{1}^{g} / R^{*}=b_{0}^{g}+\tau_{0}
$$

and

$$
\left\{\begin{array}{lll}
T_{1}^{g}(r)=b_{1}^{g}+\tau_{1} & \text { if } i \text { repays }(\mathrm{r}) \\
T_{1}^{g}(d)=b_{1}^{g} & \text { if } i \text { defaults (d). }
\end{array}\right.
$$

Finally, the markets for safe bonds and $i$-bonds clear:

$$
\sum_{j} b_{1}^{s, j}=b_{1}^{s} \quad ; \quad \sum_{j} b_{1}^{i, j}=b_{1}^{i}
$$

\subsection{Optimal Portfolios}

Denote $\mathcal{P}^{j} \leq 1$ the expected payment per unit of $i$ 's sovereign debt for $j$ 's household, given the optimal default decision at $t=1$. If $i$ cannot discriminate between different types of bondholders when defaulting, this expected payoff is the same for all investors: $\mathcal{P}^{j} \equiv \mathcal{P}$. The optimal bond portfolio maximizing $U^{j}$ satisfies:

$$
\frac{1}{R^{i}}-\beta \mathcal{P}=\frac{\omega^{j} \lambda^{i, j}}{b_{1}^{i, j}}, \quad \quad \frac{1}{R^{*}}-\beta=\frac{\omega^{j} \lambda^{s}}{b_{1}^{s, j}}
$$

The first equation characterizes the demand for $i$ bonds. The left-hand side of that equation represents the expected monetary cost from purchasing one more unit of $i$ 's debt: a cost $1 / R^{i}$ and an expected discounted return $\beta \mathcal{P}$. The right hand side of that equation represents the additional liquid-

ity benefit. The second equation characterizes the demand for safe bonds. Denote $\bar{\lambda}^{i} \equiv \sum_{k} \omega^{k} \lambda^{i, k}$ the weighted average of liquidity services provided by $i$-debt. Combining the equilibrium condition Eq. (12) and the bond market clearing condition Eq. (11), the aggregate share $\alpha^{i, j}$ of $i$ 's debt held by country $j$ 
satisfies:

$$
\alpha^{i, j} \equiv \frac{b_{1}^{i, j}}{b_{1}^{i}}=\frac{\omega^{j} \lambda^{i, j}}{\bar{\lambda}^{i}} .
$$

In the absence of selective default, the model implies that equilibrium portfolio shares are proportional to the relative liquidity benefits of $i$-debt across investor classes. To understand the intuition for this result, observe that all investors expect the same payment per unit of debt, $\beta \mathcal{P}$, and pay the same price, $1 / R^{i}$. Hence, difference in equilibrium portfolios must arise entirely from differences in the relative liquidity services provided by the bonds, i.e. $\omega^{j} \lambda^{i, j} / \bar{\lambda}^{i}$. These shares don't depend on the riskiness of $i$ 's debt and remain well defined in the bondless limit.

Similarly derivations for safe bonds yield:

$$
\alpha^{s, j} \equiv \frac{b_{1}^{s, j}}{b_{1}^{s}}=\omega^{j}
$$

For safe assets, liquidity services are the same, up to size differences. It follows that equilibrium portfolios only reflect size differences with larger countries holding a larger share of safe assets. ${ }^{40}$

Substituting Eqs. (13) and (14) into Eq. (12), we can rewrite the equilibrium conditions as:

$$
R^{*}=\left(\beta+\frac{\lambda^{s}}{b_{1}^{s}}\right)^{-1} \quad ; \quad R^{i}=\left(\beta \mathcal{P}+\frac{\bar{\lambda}^{i}}{b_{1}^{i}}\right)^{-1}
$$

The first expression indicates that the yield on safe debt can be lower than the inverse of the discount rate $1 / \beta$ because of a liquidity premium $\lambda^{s} / b_{1}^{s}$. As the supply of safe assets increases, this liquidity premium decreases, as documented empirically by Krishnamurthy and Vissing-Jorgensen (2012). Similarly, the yield on $i$ 's debt decreases with its liquidity premium equal to $\bar{\lambda}^{i} / b_{1}^{i}$, but increases with default risk, i.e. as the expected payoff per unit of $i$ 's debt $\mathcal{P}$ decreases.

In the bondless limit, $\lambda^{i, j} \rightarrow 0, \lambda^{s} \rightarrow 0$, and we obtain:

$$
R^{*}=\beta^{-1} ; R^{i}=(\beta \mathcal{P})^{-1} .
$$

In that limit case, portfolio holdings remain determined by Eq. (13) and Eq. (14) but the liquidity pre-

\footnotetext{
${ }^{40}$ Since equilibrium portfolios are constant regardless of the riskiness of the bonds, our benchmark portfolio allocation cannot replicate the large shifts in cross-border bond holdings observed first after the introduction of the Euro (globalization of bond portfolios), then following the sovereign debt crisis (re-nationalization of bond portfolios). See Broner et al. (2014) for a description and a model of this portfolio rebalancing based on creditor discrimination. In the benchmark version of the model, this re-nationalization can only occur if the liquidity services provided by $i$ 's debt to $i$ 's banks $\left(\lambda^{i, i}\right)$ increases, or if the liquidity services provided by $i$ 's debt to foreign investors $\left(\lambda^{i, g}\right.$ or $\left.\lambda^{i, u}\right)$ decrease. A possible extension, left for future work, would allow for either discrimination in default or differential bailout policies, so that $\mathcal{P}^{i}$ becomes different from $\mathcal{P}^{j}$.
} 
mium on safe debt disappears and the premium on $i$ 's debt reflects entirely default risk $(\mathcal{P} \leq 1)$. We summarize these results in the following proposition.

Proposition 1 (Optimal Portfolios and Equilibrium Yields). In the absence of selective default, and given an expected repayment $\mathcal{P}$ per unit of $i$-debt,

- Equilibrium bond portfolios are independent from yields and reflect relative liquidity services:

$$
\alpha^{i, j}=\frac{\omega^{j} \lambda^{i, j}}{\bar{\lambda}^{i}} \quad ; \quad \alpha^{s, j}=\omega^{j}
$$

- In the bond-less limit, equilibrium yields satisfy:

$$
R^{*}=\beta^{-1} \quad ; \quad R^{i}=(\beta \mathcal{P})^{-1} .
$$

Proof. See text.

\section{Ex-Post Defaults and Bailouts}

We solve the model by backward induction, starting from the final period $t=1$. In that period, $i$ 's government can unilaterally decide to repay its debt or default, after observing the realization of the income shock $\epsilon_{1}^{i}$, and taking as given the transfer $\tau_{1}$ it receives from $g$ 's government in the event it does not default. Consolidating the budget constraint of $i$ 's government and households Eqs. (4) and (8), a government maximizing the welfare of domestic agents will decide to repay its debts when:

$$
y_{1}^{i}\left[\Phi+\rho\left(1-\alpha^{i, i}\right)\right]+\tau_{1} \geq b_{1}^{i}\left(1-\alpha^{i, i}\right)
$$

This equation has a natural interpretation. The left hand side captures the cost of default for $i$ 's government. This cost has three components. First there is the direct disruption to the domestic economy captured by $\Phi y_{1}^{i}$. Second, when a default occurs the country has to repay a fraction $\rho$ of output to foreign investors. These foreign investors hold a fraction $\left(1-\alpha^{i, i}\right)$ of marketable debt, hence will receive $\rho y_{1}^{i}\left(1-\alpha^{i, i}\right)$. Lastly $i$ will forego the unilateral transfer from $g, \tau_{1}$. Against these costs, the benefit of default consists in not repaying the outstanding debt to foreign investors, both inside the monetary union and in the rest of the world: $b_{1}^{i}\left(1-\alpha^{i, i}\right)$. Intuitively, default is more likely if the direct cost of default $\Phi$ is low, the recovery rate $\rho$ is low, transfers $\tau$ are low, and a larger fraction of the public debt is held abroad (low $\left.\alpha^{i, i}\right)$.

Condition (17) defines the minimum transfer $\underline{\tau}_{1}$ necessary to avoid a default:

$$
\underline{\tau}_{1} \equiv b_{1}^{i}\left(1-\alpha^{i, i}\right)-y_{1}^{i}\left[\Phi+\rho\left(1-\alpha^{i, i}\right)\right] .
$$


Since transfers are voluntary (i.e. $\tau_{1} \geq 0$ ), equation (18) defines a minimum realization of the output shock $\epsilon_{1}^{i}$, which we denote $\bar{\epsilon}$, such that repayment is optimal even in the absence of transfer when $\epsilon \geq \bar{\epsilon}$ :

$$
\bar{\epsilon} \equiv \frac{\left(1-\alpha^{i, i}\right) b_{1}^{i} / \bar{y}_{1}^{i}}{\Phi+\rho\left(1-\alpha^{i, i}\right)} .
$$

Intuitively, $\bar{\epsilon}$ increases, i.e. default without bailout becomes more likely, with the amount of debt owed to foreigners relative to expected resources, $\left(1-\alpha^{i, i}\right) b_{1}^{i} / \bar{y}_{1}^{i}$, and decreases with the cost of default $\Phi$ or the recovery rate $\rho$. A larger fraction of $i$-debt held by $i$-investors makes default less appealing to $i$ 's government since a default becomes a neutral transfer from domestic bondholders to domestic taxpayers. In the limit where $i$-debt is entirely held domestically, $\alpha^{i, i}=1$, and there is never any incentive to default regardless of the realization of output: $\bar{\epsilon}=0<\epsilon_{\min }$.

This result indicates one important benefit of the 're-nationalization' of bond markets: everything else equal, it decreases the ex-post incentive to default as emphasized by Tenreyro (2019). In our model there is no deadly embrace or doom-loop between sovereigns and bondholders, unlike Farhi and Tirole (2018). In that paper, the deadly embrace arises from the distorted incentives of domestic banks to hold debt issued by their own sovereign, creating an enhanced contagion channel from banks to sovereigns and vice-versa. This channel is absent in our model.

Let's now consider the choice of optimal ex-post transfers $\tau_{1}$ by $g$ 's government. When $\epsilon_{1}^{i}<\bar{\epsilon}$, a transfer becomes necessary to avoid default. Given our assumptions, $g$ will make the minimum transfer required to avoid a default: $\tau_{1}=\underline{\tau}_{1}{ }^{41}$ Substituting $\underline{\tau}_{1}$ from Eq. (18) into $g$ 's consolidated budget constraint Eqs. (6) and (10), $g$ 's government prefers to make a transfer as long as:

$$
\Phi y_{1}^{i}+\kappa y_{1}^{g} \geq \alpha^{i, u}\left(b_{1}^{i}-\rho y_{1}^{i}\right) .
$$

The left hand side of Eq. (20) measures the output loss from default for the monetary union as a whole. It consists of the sum of the direct cost $\Phi y_{1}^{i}$ for $i$ and the contagion cost $\kappa y_{1}^{g}$ for $g$. The right hand side measures the overall benefit of default: from the point of view of the monetary union, the benefits of default consists in not repaying the rest of the world, a gain of $\alpha^{i, u}\left(b_{1}^{i}-\rho y_{1}^{i}\right)$.

Eq. (20) makes clear that $g$ 's ex-post bailout restores joint ex-post efficiency from the perspective of the monetary union. The difference between the left and right hand side of Eq. (20) represents the surplus from avoiding a default. Moreover, under our assumption that $g$ makes a unilateral take-it-orleave-it offer to $i, g$ is able to appropriate the entirety of this ex-post surplus. ${ }^{42}$

We can solve Eq. (20) for the minimum realization of $\epsilon_{1}^{i}$ such that a transfer (and no-default) is

\footnotetext{
${ }^{41} \mathrm{We}$ assume that if $i$ is indifferent between default and no-default, it chooses not to default.

${ }^{42} \mathrm{An}$ alternative arrangement is to assume that $i$ and $g$ bargain over the surplus from avoiding default. We analyze this extension in Section 6.1.
} 
optimal. This defines a threshold, $\underline{\epsilon}$, such that a default is jointly optimal when $\epsilon_{1}^{i} \leq \underline{\epsilon}$ :

$$
\underline{\epsilon} \equiv \frac{\alpha^{i, u} b_{1}^{i} / \bar{y}_{1}^{i}-\kappa y_{1}^{g} / \bar{y}_{1}^{i}}{\Phi+\rho \alpha^{i, u}} \equiv \underline{\epsilon}
$$

Based on the discussion above, we can make the following observations about equation Eq. (21). First, it can be immediately checked that $\underline{\epsilon} \leq \bar{\epsilon}$ as long as $\alpha^{i, g} \geq 0$ and/or $\kappa \geq 0$. In other words, as long as $g$ is exposed directly (through its portfolio) or indirectly (through contagion) to $i$ 's default, it has an incentive to offer ex-post bailouts to $i$. It follows immediately that an ex-ante no-transfer policy - such as a no-bailout clause- is not renegotiation proof and therefore may prove difficult to enforce. It is also immediate from Eq. (21) that $g$ will always be willing to bailout $i$ regardless of its debt level if $\alpha^{i, u}=0$ since in that case $\underline{\epsilon} \leq 0<\epsilon_{\min }$. In other words, if all of $i$ 's debt is held within the monetary union and $i$ 's default is costly for either country, it is ex-post efficient for $g$ to offer a full bailout. ${ }^{43}$ The threat of collateral and direct damage to $g$ from $i$ 's default relaxes ex-post $i$ 's budget constraint, a point emphasized also by Tirole (2015). Lastly, because $g$ offers the minimum transfer $\underline{\tau}_{1}$ to avoid a default, $i$ receives a positive transfer but achieves the same utility as under default. When $\underline{\epsilon} \leq \epsilon_{1}^{i}<\bar{\epsilon}$, $i$ 's consumption in period $t=1$ is given by:

$$
c_{1}^{i}=y_{1}^{i}\left(1-\left(\Phi+\rho\left(1-\alpha^{i, i}\right)\right)\right)+b_{1}^{s, i} .
$$

This result captures what we call the Southern view of the crisis: the ex-post support that $i$ receives from $g$ does not make $i$ better off, relative to default. It avoids the deadweight losses imposed by a default, but $g$ captures all the corresponding efficiency gains. We summarize these results in the following proposition.

Proposition 2 (Optimal ex-post bailout under discretion). Given debt level $b_{1}^{i}$, the following output thresholds fully characterize the optimal ex-post bailout and default policy under discretion:

$$
\underline{\epsilon}=\frac{\alpha^{i, u} b_{1}^{i} / \bar{y}_{1}^{i}-\kappa y_{1}^{g} / \bar{y}_{1}^{i}}{\Phi+\rho \alpha^{i, u}} \leq \bar{\epsilon}=\frac{\left(1-\alpha^{i, i}\right) b_{1}^{i} / \bar{y}_{1}^{i}}{\Phi+\rho\left(1-\alpha^{i, i}\right)}
$$

1. When output is high, i.e. $\epsilon_{1}^{i} \geq \bar{\epsilon}$, country $i$ does not default and receives no bailout, $\tau_{1}=0$

2. When output is intermediate, i.e. $\underline{\epsilon} \leq \epsilon_{1}^{i}<\bar{\epsilon}$, country $i$ receives the minimal bailout $\underline{\tau}_{1}$ to avoid a default:

$$
\tau_{1}=\underline{\tau}_{1} \equiv b_{1}^{i}\left(1-\alpha^{i, i}\right)-y_{1}^{i}\left[\Phi+\rho\left(1-\alpha^{i, i}\right)\right]
$$

3. When output is low, i.e. $\epsilon_{1}^{i}<\underline{\epsilon}$, country $i$ defaults and receives no transfer, $\tau_{1}=0$.

\footnotetext{
${ }^{43}$ Of course, anticipating on the results from the next section, in that case $i$ would want to issue so much debt in period $t=0$ that this would eventually threaten $g$ 's own fiscal capacity. In what follows we always assume that $\alpha^{i, u}>0$ and that $g$ has sufficient fiscal capacity to make the necessary transfers.
} 
Proof. See text.

Observe that the optimal bailout $\tau_{1}$ is non-monotonous in $i$ 's output: there is no bailout when either output is very low or very high. The optimal bailout is also discontinuous at $\epsilon_{1}^{i}=\underline{\epsilon}$. The reason is that $i$ 's gain from default is stronger at lower levels of output, and therefore avoiding a default requires a larger transfer. At the lower threshold $\underline{\epsilon}$, the joint surplus from avoiding default falls to zero, while the incentive to default is strongest for $i$, requiring the largest possible transfer.

\subsection{Debt Re-Nationalization, Concentration Limits and Conditionality}

The size and thresholds of bailouts are affected by the decisions of European institutions. For example, reforms of collateral rules by the ECB during the crisis changed the liquidity services provided by crisis government bonds to banks in the eurozone. In our framework, this can be modeled as a change of parameters $\lambda^{i, i}$ and $\lambda^{i, g}$ which themselves affect bond portfolio shares according to Proposition 1. As described by Bindseil et al. (2017) "Greece (2010), Ireland (2011), Portugal (2011) and Cyprus (2013) saw the suspension of the rating threshold for debt instruments issued or guaranteed by the respective governments, based on the positive assessment of the EU/IMF programs that were ongoing at the time. However, once developments had not hinted at the successful conclusion of the program, such waivers were lifted, as in the case of Greece and Cyprus on several occasions.” The waiver allowed Eurozone banks to pledge the sovereign bonds of these countries, despite a below-investment grade credit rating. Intuitively, this increases the attractiveness of $i$ bonds for $i$ and $g$ investors, relative to $u$ investors and translates, according to Eq. (13), into a decrease in the equilibrium share of $i$ bonds held outside the union, $\alpha^{i, u}$. In turn, the decrease in $\alpha^{i, u}$ lowers $\underline{\epsilon}$, reducing the possibility of default according to Proposition 2. This is intuitive: as more $i$ bonds are held inside the union, there is less of a benefit to default on $u$ investors. This results illustrates that -with discretionary bailout- the degree of re-nationalization of debt within the union, i.e. the distribution of $\alpha^{i, i}$ and $\alpha^{i, g}$ for a given $\alpha^{i, u}$, is irrelevant to default outcomes. The latter are influenced by the concentration of debt holdings between the monetary union and the rest of the world as measured by $\alpha^{i, u}$.

The degree of home bias of bond holdings within the union does matter for the size of the bailout $\underline{\tau}_{1}$ and the probability of bailouts, according to Proposition 2. Some ECB measures, such as the Long Term Refinancing Operations of December 2011 and February 2012 were designed to provide longterm liquidity support to eurozone bank lending. They significantly increased the liquidity services of domestic debt to domestic banks, i.e. $\lambda^{i, i}$ (see Acharya and Steffen, 2015). Under Propositions 1 and 2, this increases $\alpha^{i, i}$, lowering $\bar{\epsilon}$ and $\underline{\tau}_{1}$ : it reduces both the probability and the size of a bailout. Conversely, the waiver of the rating threshold described in Bindseil et al. (2017) could have contributed to a larger increase in $\lambda^{i, g}$ than $\lambda^{i, i}$, especially if domestic banks could already obtain liquidity against 
below-grade domestic sovereign bonds via Emergency Liquidity Assistance (ELA). ${ }^{44}$ The waiver would decrease $\alpha^{i, i}$ relative to $\alpha^{i, g}$, increasing both the probability and size of a bailout. Similar effects obtain if a policy -such as concentration limits- mandates an increase in $g$ 's holdings of $i$ 's debt.

We summarize these results in the following corollary.

Corollary 1 (Debt Re-Nationalization and Concentration Limit). For a given debt level $b_{1}^{i}$,

- [Debt Re-nationalization] Higher liquidity services of domestic debt for domestic residents, $\lambda^{i, i}:(a)$ increase the share of $i$ debt held by $i$ investors, $\alpha^{i, i}$, while reducing $\alpha^{i, g}$ and $\alpha^{i, u}$; (b) lowers the expost default threshold $\underline{\epsilon}$, reducing the probability of default; (c) lowers the ex-post bailout threshold $\bar{\epsilon}$, reducing the probability of a bailout and $(d)$ reduces the size of the bailout $\underline{\tau}_{1}$.

- [Concentration Limit] Higher liquidity services of $i$ debt for $g$ residents, or concentration limits: (a) increase the share of $i$ debt held by $g$ investors, $\alpha^{i, g}$, while decreasing $\alpha^{i, u}$ and $\alpha^{i, i}$; (b) lowers the expost default threshold $\underline{\epsilon}$, reducing the probability of default; (c) increases the ex-post bailout threshold $\bar{\epsilon}$, increasing the probability of a bailout and $(d)$ increases the size of the bailout $\underline{\tau}_{1}$.

Proof. Immediate from Propositions 1 and 2

The quote from Bindseil et al. (2017) states that the lifting of the rating thresholds was linked to the negotiation of the terms of the bailout. This suggests a trade-off between more generous support and stricter conditionality. This trade-off is potentially complex since the benefits of reform efforts can be diluted by excessive debt (debt overhang) but also stimulated, if they allow the country to escape default altogether. We analyse this question with the following variation on our main model. Suppose, to simplify things, that there is no recovery in case of default $(\rho=0)$. Further, assume that, at the beginning of period 1 once debt $b_{1}^{i}$ has been issued but before the output shocks $\epsilon_{1}^{i}$ is realized, the government of country $i$ can implement a 'reform' effort $e_{1}$ that increases average output according to $\bar{y}_{1}^{i}=f\left(e_{1}\right)$ where $f($.$) is increasing and concave, i.e. f^{\prime}()>$.0 and $f^{\prime \prime}()<$.0 . The cost of this effort is $\psi\left(e_{1}\right)$, which is convex to the origin with $\psi^{\prime}()>$.0 and $\psi^{\prime \prime}()>$.0 . Country $i$, in choosing its reform effort internalizes the likelihood of default and bailouts. ${ }^{45}$ Substituting the optimal default and bailout

\footnotetext{
${ }^{44}$ From Bindseil et al. (2017), "Euro area credit institutions can receive central bank credit not only through monetary policy operations but exceptionally also through emergency liquidity assistance (ELA). ELA means the provision by a Eurosystem national central bank (NCB) of: (a) central bank money and/or (b) any other assistance that may lead to an increase in central bank money to a solvent financial institution, or group of solvent financial institutions, that is facing temporary liquidity problems, without such operation being part of the single monetary policy. Responsibility for the provision of ELA lies with the $\mathrm{NCB}(\mathrm{s})$ concerned. This means that any costs of, and the risks arising from, the provision of ELA are incurred by the relevant NCB."

${ }^{45}$ Note here we are considering an ex-ante reform effort, before the decision to default/bailout is made. If country $i$ could choose its reform effort after output is observed, all the benefits from additional reform efforts would be captured by country $g$ in the form of a lower transfer.
} 
decisions from Proposition 2, and the definition of $\bar{\epsilon}$ from Eq. (19) into Eq. (4), reform effort solves:

$$
\max _{e_{1}} f\left(e_{1}\right)\left[1-\Phi \int_{\epsilon_{\min }}^{\bar{\epsilon}} \epsilon d G(\epsilon)+\Phi \bar{\epsilon}(1-G(\bar{\epsilon}))\right]-\psi\left(e_{1}\right)
$$

The term in bracket represents the impact of the debt overhang on net output. When default or a bailout occurs, the country loses a fraction $\Phi$ of output. Instead, when it repays its debts, it loses $\left(1-\alpha^{i i}\right) b_{1}$. Importantly, because optimal bailouts leave the country indifferent between default or repayment, the debt overhang is the same in both cases (i.e. as long as $\epsilon<\bar{\epsilon}$ ). Another way to see this is to observe that, according to Eq. (18), the optimal bailout $\underline{\tau}_{1}$ decreases in the output level $y_{1}^{i}$ at rate $\Phi$, i.e. the same dilution rate as under default. The optimal choice of effort $e_{1}$ satisfies:

$$
f^{\prime}\left(e_{1}\right)\left[1-\Phi \int_{\epsilon_{\min }}^{\bar{\epsilon}} \epsilon d G(\epsilon)\right]=\psi^{\prime}\left(e_{1}\right)
$$

Denote $\mathcal{J}(\bar{\epsilon})$ the term in brackets. It captures the dilution of the reform effort induced by the prospect of default or bailout. ${ }^{46}$ Under the assumption that the second order condition of Eq. (23) is satisfied, the effect of bond portfolios, or debt levels, on reform effort are summarized by $\mathcal{J}^{\prime}(\epsilon)$, which satisfies: ${ }^{47} \mathcal{J}^{\prime}(\epsilon)=-\Phi \epsilon g(\epsilon) \leq 0$. A higher $\bar{\epsilon}$, meaning a higher likelihood of default or bailout, is associated with a lower $\mathcal{J}$, i.e. higher dilution, which reduces reform effort levels. This is a standard debt-overhang effect. When $\bar{\epsilon}<\epsilon_{\min }$, default or bailouts cannot occur and there is no dilution, $\mathcal{J}=1$, and country $i$ chooses the first-best reform effort $e_{1}^{*}$ such that $f^{\prime}\left(e_{1}^{*}\right)=\psi^{\prime}\left(e_{1}^{*}\right)$. When $\epsilon_{\min }<\bar{\epsilon}$, defaults or bailouts are possible, reform benefits are diluted, $\mathcal{J}<1$ and the reform effort level declines: $e_{1}<e_{1}^{*}$.

As mentioned above, the optimal reform effort is unaffected by the bailout policy. Another way to state this same result is that bailouts do not, per se, increase the benefit of a reform for country $i$, despite the fact that country $i$ receives financial assistance that helps it avoid default. This captures another aspect of the 'Southern' view: despite receiving financial assistance, the marginal benefit of reforms is unchanged. At the margin, reforms are seen as benefiting the creditor country.

A second implication is that the optimal reform effort varies with the distribution of $i$ 's debt inside the monetary union, as captured by $\bar{\epsilon}$. Debt-renationalization, interpreted as an increase in $\lambda^{i, i}$, increases $\alpha^{i, i}$, reducing $\bar{\epsilon}$ and the likelihood of default. This increases the optimal effort level $e_{1}$. Conversely, the waiver of rating thresholds (interpreted as an increase in $\lambda^{i, g}$ ), concentration limits (interpreted as a floor on $\alpha^{i, g}$ ), or increases in outstanding debt levels have the opposite effects: they reduce

\footnotetext{
${ }^{46}$ Note that the effect of the reform effort on the bailout cutoff $\bar{\epsilon}$ does not appear in this expression because of the envelope theorem: $\bar{\epsilon}$ is chosen optimally by country $i$.

${ }^{47}$ The second-order condition is satisfied if $\mathcal{S}\left(e_{1}\right) \equiv f^{\prime \prime}\left(e_{1}\right)-\Psi^{\prime \prime}(e)+f^{\prime}\left(e_{1}\right) \mathcal{J}^{\prime}(\bar{\epsilon}) \partial \bar{\epsilon} / \partial e_{1}<0$. Since $\partial \bar{\epsilon} / \partial e_{1}<0$, and $\mathcal{J}^{\prime}()<$.0 , the second-order condition can always be satisfied by assuming sufficient concavity (resp. convexity) of $f($.$) (resp. \Psi($.$) ). Full differentiation then implies that a change x$ that affects $\bar{\epsilon}$ will impact $e_{1}$ according to $d e_{1} / d x=$ $\left(-1 / \mathcal{S}\left(e_{1}\right)\right) f^{\prime}\left(e_{1}\right) \mathcal{J}^{\prime}(\bar{\epsilon}) \partial \bar{\epsilon} / \partial x$.
} 
reform effort by exacerbating the debt overhang effect. In both cases, part of the reform effort benefits $g$ since it reduces the optimal bailout $\tau_{1}$. We summarize these results in the following corollary.

Corollary 2 (Optimal Reform Effort, Debt Overhang and Home Bias). Given a reform benefit function $f\left(e_{1}\right)$ and cost $\psi\left(e_{1}\right)$ as specified above,

- The output cost of default $\Phi$ creates a debt overhang, reducing reform efforts below their first-best level when $\epsilon_{\min }<\bar{\epsilon}: e_{1}<e_{1}^{*}$.

- Optimal ex-post bailouts do not affect the optimal reform effort which remains inefficiently low: the benefits of reform are diluted via lower expected bailouts (Southern view).

- Optimal reform effort depends on the extent of portfolio home bias. Collateral or liquidity policies that increase debt re-nationalization increase reform efforts. Conversely, concentration limits or liquidity policies that reduce debt home bias reduce reform effort.

Proof. See the text.

These results help understand why the ECB may have conditioned the waiver of rating thresholds with the continued implementation of reforms. In the absence of such conditionality, Corollaries 1 and 2 indicate that waving the rating thresholds could have simultaneously reduces the probability of default, increased the likelihood and size of a bailout, but also reduced reform effort in country $i$.

\subsection{No-Bailout Clauses}

We already noted that the transfer $\tau_{1}$ is ex-post optimal from the point of view of $g$. However, it is important to recognize that it may be difficult for $g$ to implement such transfers. For instance, the institutional framework inside the monetary union may forbid direct transfers from one country to another under so called 'no -bailout' clauses. While direct transfers may be ruled out, indirect transfers, via common institutions -such as the common central bank- may still be possible, albeit difficult to implement in practice. ${ }^{48}$

These 'no-bailout' clauses have repeatedly been invoked and played an important role in shaping the response to the Eurozone crisis. In particular, the legality of proposed bailout programs has often been questioned and referred to the German federal constitutional court (commonly called the Karlsruhe court), or the European Court of Justice. For instance, on September 12, 2012, in a landmark decision, the Karlsruhe court ruled that the European Stability Mechanism (ESM) did not violate German law, allowing for the ESM statutes to be signed into law by the German president. However, the German

\footnotetext{
${ }^{48}$ We explore this possibility in more details in section 6.3 .
} 


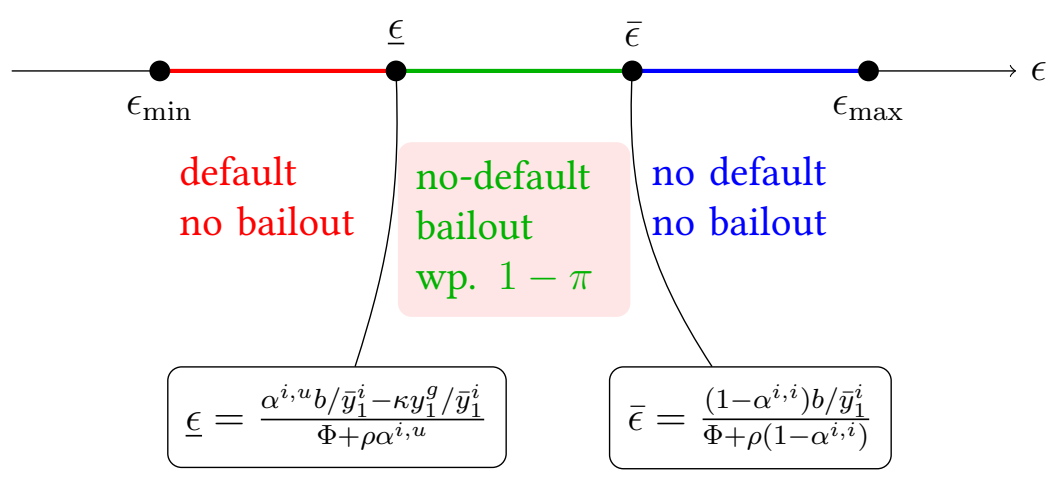

Figure 1: Optimal Ex-Post Bailout Policy.

The figure reports the endogenous thresholds $\underline{\epsilon}$ and $\bar{\epsilon}$ that separate the default, bailout, and no-default regions.

high court imposed strict conditions requiring approval by the German parliament before any extension of the country's total exposure to the ESM. ${ }^{49}$ This judgement was re-affirmed on March 18, 2014 when the high court ruled that constitutional challenges to the ESM were without merits. ${ }^{50}$ The legality of the ESM was also affirmed by the European Court of Justice in the Pringle Case, on November 27, $2012 .{ }^{51}$ From our point of view, the important observation is that the political process contains a certain amount of uncertainty, since it is not known ex-ante how the legal authorities will rule on these matters and whether future developments will re-open legal challenges.

In the rest of the paper, we capture both the political uncertainty and the attempt to achieve some form of ex-ante commitment with an exogenous parameter $0 \leq \pi \leq 1$, denoting the probability that ex-post transfers will not be implemented, even when they are ex-post in the best interest of both parties. By varying $\pi$, we nest the polar cases of full commitment $(\pi=1)$ and full discretion $(\pi=0)$.

It follows that a default occurs either if $\epsilon<\underline{\epsilon}$ or when $\underline{\epsilon}<\epsilon_{1}^{i} \leq \bar{\epsilon}$ and ex-post transfers are ruled to be illegal. The ex-ante probability of default is then given by:

$$
\pi_{d}=G(\underline{\epsilon})+\pi(G(\bar{\epsilon})-G(\underline{\epsilon}))
$$

Fig. 1 summarizes the default and bailout decisions for the general case $0 \leq \pi \leq 1$.

\section{Debt Rollover Problem at $t=0$}

We now turn to the optimal debt issuance problem $b_{1}^{i}$ at time $t=0$, taking the initial transfer $\tau_{0}$ and initial debt level $b_{0}^{i}$ as given.

\footnotetext{
${ }^{49}$ See https://www.bundesverfassungsgericht.de/SharedDocs/Pressemitteilungen/EN/2012/bvg12-067.html.

${ }^{50}$ See https://www.bundesverfassungsgericht.de/SharedDocs/Pressemitteilungen/EN/2014/bvg14-023.html.

${ }^{51}$ See http://curia.europa.eu/juris/liste.jsf?num=C-370/12\#.
} 


\subsection{The Debt Laffer Curve.}

If debt with notional value $b_{1}^{i}$ has been issued at $t=0$, the expected repayment $\mathcal{P} b_{1}^{i}$ is given by:

$$
\mathcal{P} b_{1}^{i}=\left(1-\pi_{d}\right) b_{1}^{i}+\rho \bar{y}_{1}^{i}\left(\int_{\epsilon_{\min }}^{\underline{\epsilon}} \epsilon d G(\epsilon)+\pi \int_{\underline{\epsilon}}^{\bar{\epsilon}} \epsilon d G(\epsilon)\right) .
$$

This expression has three terms. First, if country $i$ does not default (with probability $1-\pi_{d}$ ), it repays the face value. If default occurs, investors recover instead $\rho y_{1}^{i}$. This can happen either because default is ex-post optimal (when $\epsilon_{1}^{i}<\underline{\epsilon}$ ) or when a transfer is needed (when $\underline{\epsilon} \leq \epsilon_{1}^{i}<\bar{\epsilon}$ ) but fails to materialize (with probability $\pi$ ).

Substituting this expression into Eq. (15), we obtain an expression for the fiscal revenues $\mathcal{D}\left(b_{1}^{i}\right) \equiv$ $b_{1}^{i} / R^{i}$ raised by the government of country $i$ in period $t=0$ :

$$
\begin{aligned}
\mathcal{D}\left(b_{1}^{i}\right) & =\beta \mathcal{P} b_{1}^{i}+\bar{\lambda}^{i} \\
& =\beta b_{1}^{i}\left(1-\pi_{d}\right)+\beta \rho \bar{y}_{1}^{i}\left(\int_{\epsilon_{\min }}^{\underline{\epsilon}} \epsilon d G(\epsilon)+\pi \int_{\underline{\epsilon}}^{\bar{\epsilon}} \epsilon d G(\epsilon)\right)+\bar{\lambda}^{i}
\end{aligned}
$$

The function $\mathcal{D}(b)$ defines a Laffer curve that plays an important role in the analysis of the optimal choice of debt issuance. Fig. 2 illustrates the shape of this Laffer curve in the bondless limit and shows how it varies with the no-bailout probability $\pi .{ }^{52}$ Heuristically, we can consider the following cases: $:^{53}$

- When $0 \leq b_{1}^{i} \leq \underline{b} \equiv y_{\min }^{i}\left(\Phi /\left(1-\alpha^{i, i}\right)+\rho\right)$, the debt level is so low that $i$ will always prefer to repay, without bailout and regardless of the realization of the output shock. The debt is safe, there is no default risk and $\mathcal{D}(b)=b / R^{*}=\beta b+\bar{\lambda}^{i}$. This corresponds to the left part of the graph, labelled 'Safe Debt'.

- When $\underline{b}<b_{1}^{i} \leq \bar{b} \equiv\left(\left(\Phi+\rho \alpha^{i, u}\right) y_{\min }^{i}+\kappa y_{1}^{g}\right) / \alpha^{i, u}$, the level of debt is sufficiently low that it is optimal for $g$ to bailout $i$ when output is too low. Default might occur if bailouts are not allowed, i.e. with probability $\pi>0$. In that region, the Laffer curve with discretionary bailout $(\pi=0$, in blue on the figure) is linear and lies strictly above the Laffer curve under no bailout ( $\pi=1$, in red on the figure): this is a consequence of the soft budget constraint that is induced by the transfers. Under the assumptions specified in Appendix B, the Laffer curve is increasing (at a decreasing rate) over that range. This corresponds to the middle part of the graph, labelled 'Risky if no bailout.'

\footnotetext{
${ }^{52}$ This figure is drawn under the assumption that the shocks are uniformly distributed.

${ }^{53}$ Appendix B provides a full analysis of the Laffer curve.
} 


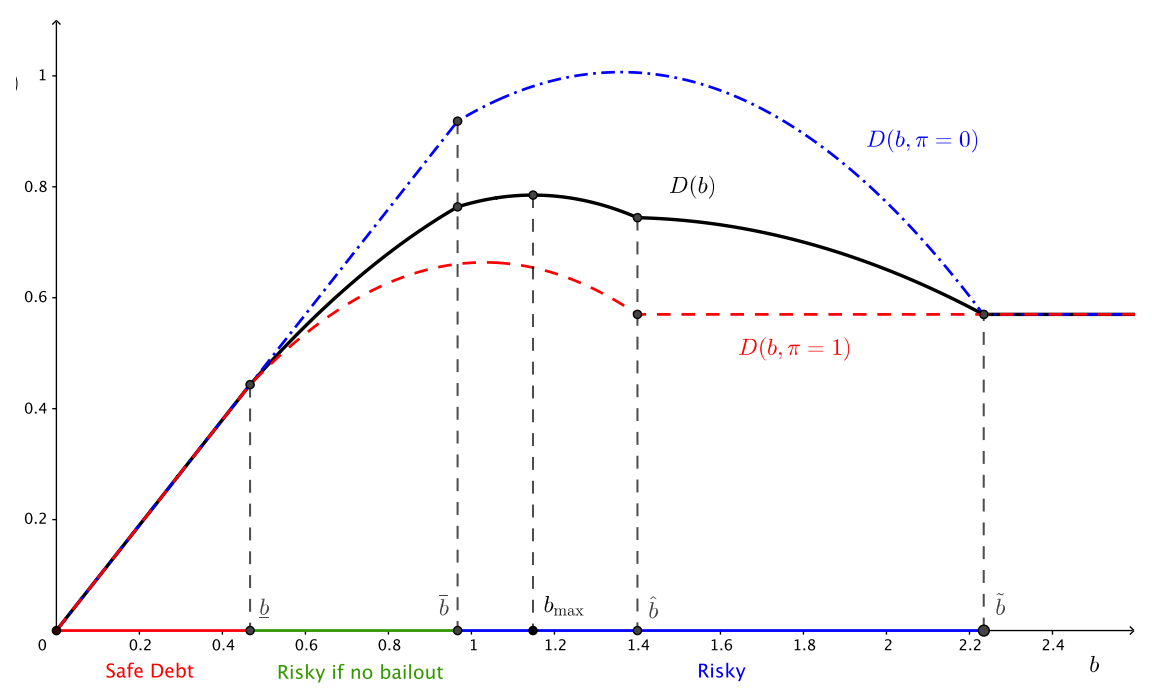

$\mathcal{D}(b)$ for $\pi=0$ (discretion), $\pi=0.5$ and $\pi=1$ (no bailout).

[The figure is drawn in the bondless limit under the assumption that $\epsilon_{1}^{i}$ is distributed uniformly with $\rho=0.6, \Phi=0.2$, $\kappa=0.05, \epsilon_{\min }=0.5, \epsilon_{\max }=1.5, \beta=0.95, \bar{y}_{1}^{i}=1, y_{1}^{g}=2, \alpha^{i, i}=0.4, \alpha^{i, g}=\alpha^{i, u}=0.3 . \underline{b}=0.47, \bar{b}=0.97$ and $\left.\hat{b}=1.4\right]$

Figure 2: The Debt-Laffer Curve for various values of the no-bailout probability $\pi$.

- Since default can occur when $b>\bar{b}$, the region $b>\bar{b}$ is labelled 'Risky' on Fig. 2. It consists of three sub-regions

- When $\bar{b}<b_{1}^{i} \leq \hat{b} \equiv y_{\max }^{i}\left(\Phi /\left(1-\alpha^{i, i}\right)+\rho\right)$, it becomes optimal for $g$ to let $i$ default when $y_{1}^{i}$ is sufficiently low, even if bailouts are allowed. This increases default risk and the yield on $i$ 's debt. Under the assumptions specified in Appendix $\mathrm{B}$, the Laffer curve is convex in this region and reaches its peak at $b=b_{\max }$ strictly below $\hat{b}$.

- When $\hat{b}<b \leq \tilde{b} \equiv\left(\left(\Phi+\rho \alpha^{i, u}\right) y_{\max }^{i}+\kappa y_{1}^{g}\right) / \alpha^{i, u}$, we enter a region where default would occur with certainty in the absence of transfers. With transfers, it is possible for default to be avoided, if output is sufficiently high. Under the assumptions in the appendix, the Laffer curve is decreasing over that region.

- Finally, for $b>\tilde{b}, i$ always defaults regardless of the realization of output and bailouts are never optimal. There are no transfers and investors expect a repayment $\rho \bar{y}_{1}^{i}$.

Appendix B provides a full characterization of these debt cut-offs and a set of necessary conditions to ensure that the Laffer curve $\mathcal{D}(b)$ is convex over the relevant range, $[0, \hat{b})$. The fact that country $i$ can choose its repayment level $b_{1}^{i}$ implies that it will never choose to locate itself on the 'wrong side' of the Laffer curve. It follows that we only need to consider levels of debt level such that $b \leq b_{\max }$. This eliminates Calvo (1988)-like rollover crises and multiple equilibria. Over the relevant range, the Laffer curve is convex, continuous and exhibits two non-differentiable points, $\underline{b}$ and $\bar{b}$, where it admits 


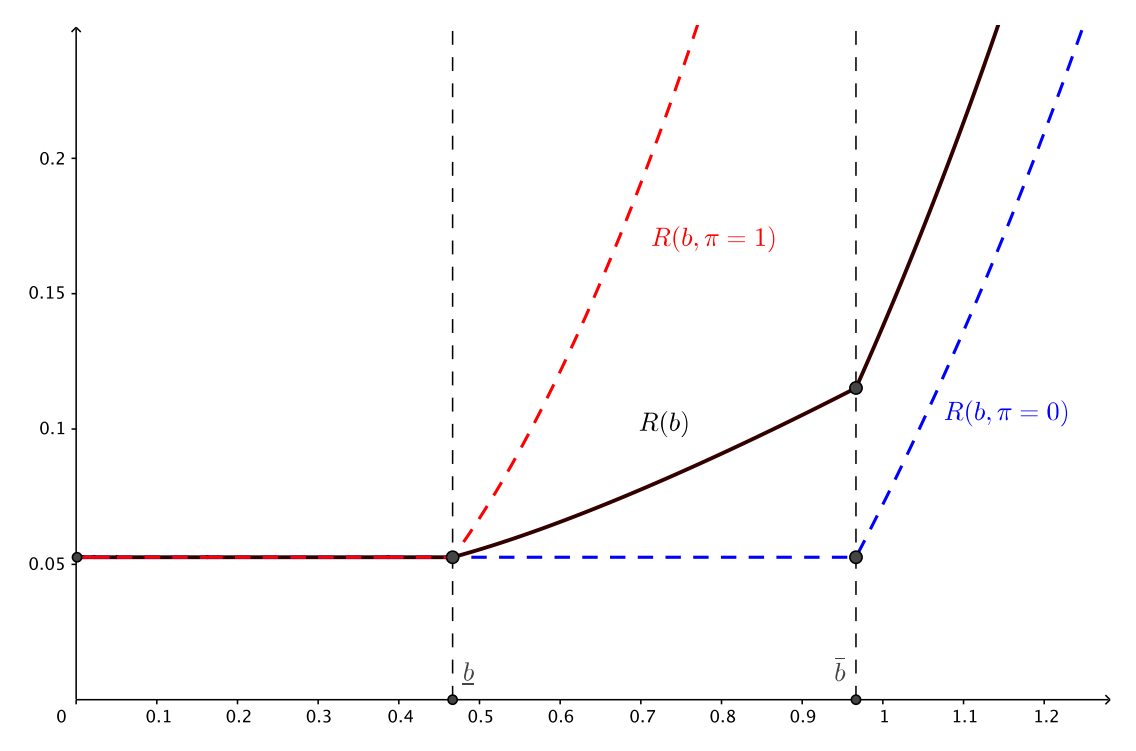

$R(b)=(\beta \mathcal{P}(b))^{-1}$ for $\pi=0, \pi=1$ and $\pi=0.2$.

[The figure is drawn in the bondless limit under the assumption that $\epsilon_{1}^{i}$ is distributed uniformly with $\rho=0.6, \Phi=0.2$, $\kappa=0.05, \epsilon_{\min }=0.5, \epsilon_{\max }=1.5, \beta=0.95, \bar{y}_{1}^{i}=1, y_{1}^{g}=2, \alpha^{i, i}=0.4, \alpha^{i, g}=\alpha^{i, u}=0.3 . \underline{b}=0.47$ and $\left.\bar{b}=0.97\right]$

Figure 3: Contractual Yields for various values of the no-bailout probability $\pi$

left and right differentials, which we denote $\mathcal{D}_{-}^{\prime}(b)$ and $\mathcal{D}_{+}^{\prime}(b)$ respectively. ${ }^{54}$

Fig. 3 illustrates how the contractual yield $R^{i}$ varies with $i$ 's debt levels and with the probability of enforcement of no-bailout clause $\pi$. The interesting range is for $\underline{b}<b \leq \bar{b}$ where the yield remains equal to $R^{*}$ if bailouts are allowed, since the debt remains safe with bailouts, but increases very rapidly -together with the ex-post probability of default- when bailouts are prohibited. This figure illustrates one possible channel for the rapid surge in yields when the crisis erupted: the perception that implicit bailout guarantees were removed (i.e. a switch from $\pi=0$ to $\pi>0$ ). Similarly, one can interpret the decline in yields following President Draghi's famous pronouncement that the ECB would do 'whatever it takes' to preserve the Euro, as a sign that bailout guarantees would be reinstated, i.e. a switch from $\pi>0$ to $\pi=0 .{ }^{55}$

We summarize these results in the following proposition.

Proposition 3 (Debt Laffer Curve). Under the regularity conditions stated in Appendix B, the Laffer curve $\mathcal{D}(b)$ has the following characteristics:

1. For low levels of debt, $b \leq \underline{b}$, the debt is safe there is no transfer, hence $\mathcal{D}(b)=b / R^{*}=\beta b+\bar{\lambda}^{i}$.

\footnotetext{
${ }^{54}$ Since $\mathcal{D}(b)$ is convex, $\mathcal{D}_{-}^{\prime}(b) \geq \mathcal{D}_{+}^{\prime}(b)$ with equality, denoted $\mathcal{D}^{\prime}(b)$, whenever $\mathcal{D}(b)$ is differentiable.

${ }^{55}$ 'Within our mandate, the ECB is ready to do whatever it takes to preserve the euro. And believe me, it will be enough.' July 26, 2012. See https://www.ecb.europa.eu/press/key/date/2012/html/sp120726.en.html.
} 
2. For intermediate levels of debt $\underline{b}<b \leq \bar{b}$, the debt is risky and a default occurs only if there is no ex-post transfer $(\pi>0)$.

3. For high levels of debt, $b>\bar{b}$, the debt is risky even when ex-post transfers are possible.

4. The Laffer curve is convex over the range $[0, \hat{b})$ where $\hat{b}>\bar{b}$ denotes the level of debt such that an ex-post default becomes unavoidable in the absence of transfers.

5. The Laffer curve reaches a maximum $\bar{b} \leq b_{\max }<\hat{b}$

6. Country $i$ always chooses a debt level on the 'correct' side of the Laffer curve, i.e. $0 \leq b \leq b_{\max }$.

Proof. See appendix B and text.

\subsection{Optimal Debt Issuance}

We now consider the optimal choice of debt $b_{1}^{i}$ in the bondless limit. This allows us to ignore the direct impact of the debt level on the utility of the agents via liquidity services. Recall that bond portfolios remain pinned down and invariant to the level of debt so we can take the portfolio shares $\alpha^{j, k}$ as given.

Consolidating the budget constraints of country $i$ 's representative household Eqs. (3) and (4) and government Eqs. (7) and (8), and substituting the optimal transfer $\tau_{1}$ from Proposition 2, we can express country $i$ 's aggregate consumption in both periods as a function of the face value of the debt issued in period $0 b_{1}^{i}$ :

$$
c_{0}^{i}\left(b_{1}^{i}\right)=\left(y_{0}^{i}+\tau_{0}-\left(1-\alpha^{i, i}\right) b_{0}^{i}+\alpha^{s, i} b_{0}^{s}\right)+\left(1-\alpha^{i, i}\right) \mathcal{D}\left(b_{1}^{i}\right)-\alpha^{s, i} b_{1}^{s} / R^{*}
$$

while

$$
\left\{\begin{array}{lr}
c_{1}^{i}\left(b_{1}^{i}\right)=y_{1}^{i}-b_{1}^{i}\left(1-\alpha^{i, i}\right)+\alpha^{s, i} b_{1}^{s} & \text { if } \epsilon_{1}^{i} \geq \bar{\epsilon}(i \text { repays, no transfer }) \\
c_{1}^{i}\left(b_{1}^{i}\right)=y_{1}^{i}(1-\Phi)-\rho y_{1}^{i}\left(1-\alpha^{i, i}\right)+\alpha^{i, s} b_{1}^{s} & \text { if } \epsilon_{1}^{i}<\bar{\epsilon}(i \text { defaults or receives a transfer }) .
\end{array}\right.
$$

The optimal debt issuance solves the following program: ${ }^{56}$

$$
\begin{array}{ll}
\max _{b_{1}^{i}} & U\left(b_{1}^{i}\right)=c_{0}^{i}\left(b_{1}^{i}\right)+\beta\left(\int_{\epsilon_{\min }}^{\bar{\epsilon}} c_{1}^{i}\left(b_{1}^{i}\right) d G(\epsilon)+\int_{\bar{\epsilon}}^{\epsilon_{\max }} c_{1}^{i}\left(b_{1}^{i}\right) d G(\epsilon)\right) \\
\text { s.t. } & c_{0}^{i}\left(b_{1}^{i}\right) \geq 0, \\
& 0 \leq b_{1}^{i} \leq b_{\max }, \\
& c_{0}^{1}\left(b_{1}^{i}\right) \text { and } c_{1}^{i}\left(b_{1}^{i}\right) \text { defined above. }
\end{array}
$$

\footnotetext{
${ }^{56}$ We do not need to impose the constraint that $c_{1}^{i} \geq 0$ : it is always satisfied under the assumption that $\Phi+\phi \leq 1$.
} 
Denoting $\nu_{0}$ the multiplier on period 0 consumption and $\mu_{1}$ the multiplier on $b_{1}^{i} \geq 0$, the first-order condition and complementary slackness conditions are:

$$
\begin{aligned}
0 \in & \mu_{1}+\left(1-\alpha^{i, i}\right) \partial \mathcal{D}\left(b_{1}^{i}\right)\left(1+\nu_{0}\right)-\beta(1-G(\bar{\epsilon}))\left(1-\alpha^{i, i}\right) \\
& \nu_{0} c_{0}^{i}\left(b_{1}^{i}\right)=0 \\
& \mu_{1} b_{1}^{i}=0
\end{aligned}
$$

where $\partial \mathcal{D}(b)$ denotes the sub-differential of $\mathcal{D}(b) .{ }^{57}$ Consider first an interior solution $\left(c_{0}^{i}>0\right.$ and $\left.b_{1}^{i}>0\right)$ where the revenue curve is differentiable. The first-order condition becomes:

$$
\mathcal{D}^{\prime}\left(b_{1}^{i}\right)=\beta(1-G(\bar{\epsilon})) .
$$

This condition equates the marginal gain from one additional unit of debt (at face value), $\mathcal{D}^{\prime}\left(b_{1}^{i}\right)$, with its marginal cost. Eq. (28) establishes that this marginal cost is equal to the probability of repayment without transfer $1-G(\bar{\epsilon})$, discounted back at the risk free rate $1 / R^{*}=\beta$. In other words, country $i$ only considers as relevant the states of the world where it is repaying the debt without default or bailout. In case of default, the repayment is proportional to output, and therefore independent of the debt level. In case of a bailout, the debt is -at the margin- repaid by country $g .{ }^{58}$

Substituting the general expression for $\mathcal{D}^{\prime}\left(b_{1}^{i}\right)$ from Eq. (27) into Eq. (28) we can rewrite the optimality condition as:

$$
(G(\bar{\epsilon})-G(\underline{\epsilon}))(1-\pi)=\left(b_{1}^{i}-\rho \bar{y}_{1}^{i} \underline{\epsilon}\right)(1-\pi) g(\underline{\epsilon}) \frac{d \underline{\epsilon}}{d b}+\left(b_{1}^{i}-\rho \bar{y}_{1}^{i} \bar{\epsilon}\right) \pi g(\bar{\epsilon}) \frac{d \bar{\epsilon}}{d b} .
$$

The left hand side of this equation has a very natural interpretation. It represents the likelihood of a bailout, i.e. the likelihood that an extra unit of debt borrowed today is not repaid by $i$ while avoiding default. This is a direct benefit to $i$. The right hand side represents the cost of issuing more debt via an increase in the contractual yield $R^{i}$. It has two components. The first term captures the cost of an increase in debt due to a change in $\underline{\epsilon}$. Recall that $i$ defaults below $\underline{\epsilon}$, and receives no bailout. An increase in $b_{1}^{i}$ increases $\underline{\epsilon}$, making outright default more likely. If $\epsilon=\underline{\epsilon}$, lenders lose $b_{1}^{i}$ and receive instead $\rho y_{1}^{i} \underline{\underline{\epsilon}}$, with probability $g(\underline{\epsilon})(1-\pi)$. They correspondingly ask for a higher contractual yield as compensation. The second term captures the cost of an increase in debt due to a change in $\bar{\epsilon}$. Recall that, above $\bar{\epsilon}, i$ repays its debts and default does not occur while below $\bar{\epsilon}$, a default can occur when bailouts are not allowed. An increase in debt increases $\bar{\epsilon}$, again making default more likely. At $\epsilon=\bar{\epsilon}$, lenders are now at

\footnotetext{
${ }^{57}$ The sub-differential is the derivative $\mathcal{D}^{\prime}(b)$ where that derivative exists. It is the convex set $\left[\mathcal{D}_{+}^{\prime}(b), \mathcal{D}_{-}^{\prime}(b)\right]$ where that derivative does not exist, at $\underline{b}$ and $\bar{b}$. See Rockafellar (1972). The constraint $b \leq b_{\max }$ does not need to be imposed.

${ }^{58}$ From Proposition 2, the thresholds $\bar{\epsilon}$ and $\underline{\epsilon}$ are also affected by the optimal debt level. However, since these thresholds are themselves optimally chosen, the envelope theorem ensures that $i$ does not need to consider their variation.
} 
risk of losing $b_{1}^{i}$ and receiving instead $\rho y_{1}^{i} \bar{\epsilon}$, in case a bailout does not materialize, i.e. with probability $g(\bar{\epsilon}) \pi$. Eq. (29) highlights that $i$ trades off the increased riskiness of debt -and therefore higher yieldsagainst the likelihood of a bailout, i.e. non-repayment.

Under a no-bailout clause $(\pi=1)$ the left hand side of Eq. (29) is identically equal to zero. The only interior solution is $\bar{\epsilon} \leq \epsilon_{\min }$, so that $g(\bar{\epsilon})=g(\underline{\epsilon})=0$ : country $i$ has no incentives to issue risky debt. By contrast, once $\pi>0$, country $i$ may choose to issue risky debt (i.e. $\bar{\epsilon}>\epsilon_{\min }$ ) in order to maximize the chance of a bailout in period 1. Eq. (29) makes clear that the possibility of a bailout in period 1 induces country $i$ to choose excessively elevated debt levels in period 0 . This risk shifting result is a common feature of moral hazard models. Ex-post bailouts partially shield borrowers from the fiscal consequences of excessive borrowing. Not surprisingly, this provides an incentive to borrow excessively. We call this the Northern view of the crisis.

Note also that a lower collateral cost of default for $g$, i.e. a lower $\kappa$, increases $\underline{\epsilon}$. This reduces the probability $i$ will receive a transfer from $g$ (the left hand side of Eq. (29)) and therefore the incentive to issue debt. Hence, reducing $\kappa$ has a direct positive impact on $g$ but also serves to discipline $i$. This resonates with proposals to introduce orderly restructuring in case of a default in a monetary union. These proposals can be interpreted in the context of our model as lower collateral costs of default that shield the rest of the monetary union, but also reduce risk-shifting (see Bénassy-Quéré et al. (2018)).

Appendix C provides a full description of the optimal level of debt issued in period 0. In particular, we show that, under some mild regularity conditions, the optimal choice of debt is either $b \leq \underline{b}$, i.e. a safe level of debt, or $b_{\text {opt }} \leq b \leq b_{\max }$, where $b_{\text {opt }}$ denotes the unique optimal level of risky debt that obtains when the funding needs are smaller than $\mathcal{D}\left(b_{\text {opt }}\right)$. The following proposition summarizes the optimal debt level, as a function of the funding needs of country $i$ in period 0 , defined as $x_{0}^{i} \equiv$ $\left(b_{0}^{i}\left(1-\alpha^{i, i}\right)+\alpha^{s, i} b_{1}^{s} / R^{*}-y_{0}^{i}-\tau_{0}-b_{0}^{s, i}\right) /\left(1-\alpha^{i, i}\right)$.

Proposition 4 (Optimal Debt Issuance in period 0). Under the regularity conditions specified in Appendix $C$, the optimal choice of debt as a function of the initial funding needs $x_{0}^{i}$ satisfies:

- For $x_{0}^{i}>\mathcal{D}\left(b_{\max }\right)$, country $i$ is insolvent in period 0 and must default. No level of debt can ensure solvency.

- For $\mathcal{D}\left(b_{\max }\right) \geq x_{0}^{i}>\mathcal{D}\left(b_{\text {opt }}\right)$, country $i$ issues $b \in\left[b_{\max }, b_{\text {opt }}\right)$ such that $\mathcal{D}(b)=x_{0}^{i}$ and there is no consumption in period 0 . There is no risk shifting in the sense that debt issuance is fully constrained by country $i$ 's funding needs in period 0 .

- For $\mathcal{D}\left(b_{o p t}\right) \geq x_{0}^{i}>\beta \underline{b}, i$ chooses to issue $b_{o p t}$. In that range, the possibility of a bailout leads $i$ to risk shiting in the sense that $\mathcal{D}\left(b_{o p t}\right)>x_{0}^{i}$. The probability of default is higher than necessary to cover $i$ 's funding needs. 


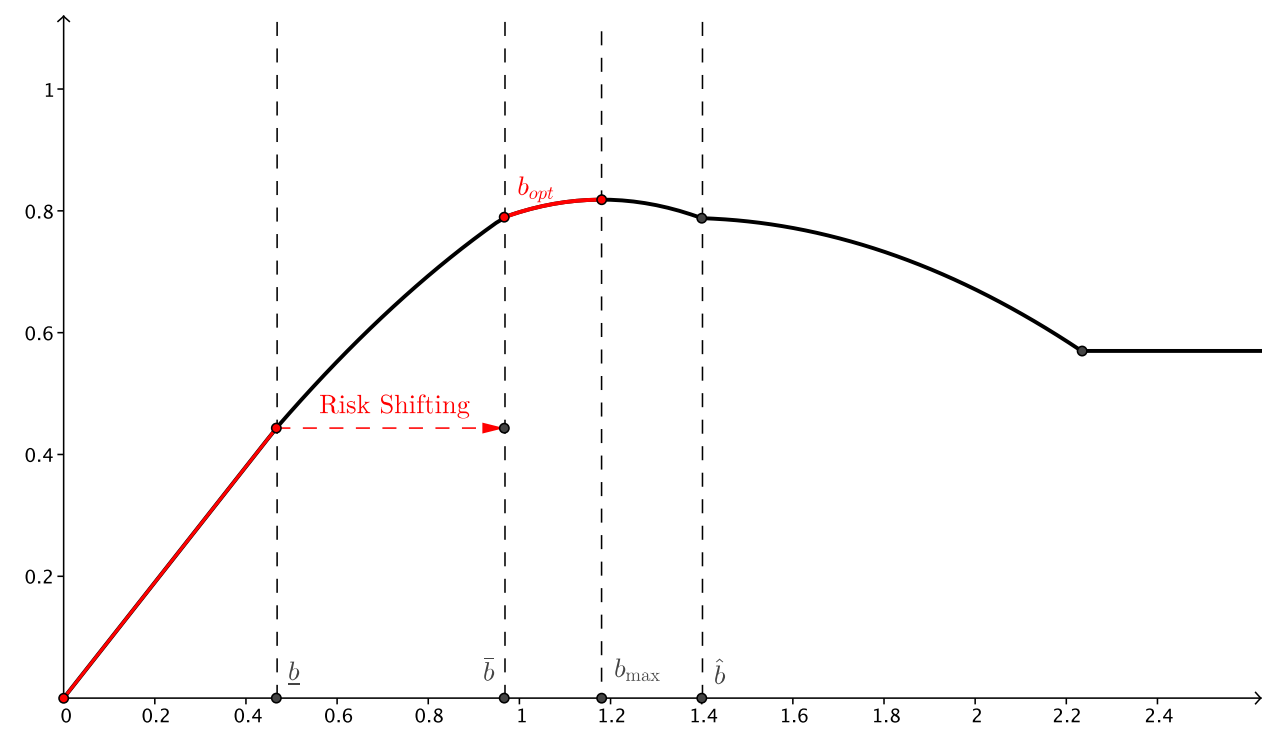

Optimal Debt Issuance for $\pi=0.5$.

Uniform distribution with $\rho=0.6, \Phi=0.2, \kappa=0.05, \epsilon_{\min }=0.5, \beta=0.95, \bar{y}_{1}^{i}=1, y_{1}^{g}=2, \alpha^{i, i}=0.4$, $\alpha^{i, g}=\alpha^{i, u}=0.3 . \underline{b}=0.47, \bar{b}=0.97$ and $\hat{b}=1.4$

Figure 4: Optimal Debt Issuance: Risk Shifting

- For $x_{0}^{i}<\beta \underline{b}$, country $i$ can choose to issue either a safe amount of debt $x_{0}^{i} / \beta<\underline{b}$ or the risky amount

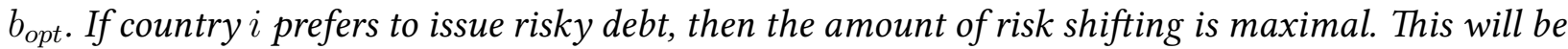
the case if $i$ achieves a higher level of utility at $b_{\text {opt }}$ then by keeping the debt safe, i.e. if:

$$
\begin{aligned}
U\left(b_{\text {opt }}\right)-U\left(x_{0}^{i} / \beta\right)= & \left(1-\alpha^{i, i}\right) \beta(1-\pi)(G(\bar{\epsilon})-G(\underline{\epsilon}))\left(b_{o p t}-\rho \bar{y}_{1}^{i} E[\epsilon \mid \epsilon \leq \epsilon \leq \bar{\epsilon}]\right) \\
& -\beta \Phi G(\bar{\epsilon}) \bar{y}_{1}^{i} E[\epsilon \mid \epsilon<\bar{\epsilon}]>0
\end{aligned}
$$

Proof. See Appendix C.

The first term of Eq. (30) represents the expected net gain from the bailout. Since $b_{\text {opt }}>\rho \bar{y}_{1}^{i} \bar{\epsilon}$, it follows that $b_{o p t}>\rho \bar{y}_{1}^{i} E[\epsilon \mid \underline{\epsilon}<\epsilon<\bar{\epsilon}]$. The second term represents the expected discounted cost of default for $i$. This cost is borne by $i$ as soon as $\epsilon<\bar{\epsilon}$ since the bailout does not affect $i$ 's utility. It is immediate that there is no risk shifting when $\pi=1$ or when $i$ holds most of its own debt $\left(\alpha^{i, i} \approx 1\right)$. Risk shifting is more likely the higher is the optimal debt output ratio $b_{\text {opt }} / \bar{y}_{1}^{i}$ and the lower the cost of default $\Phi$. Fig. 4 reports the Laffer curve and the optimal debt levels. It illustrates the extent of risk shifting that occurs when $i$ chooses to issue at $b_{\text {opt }}$ instead of a safe level $b<\underline{b}$ for low levels of funding needs. 


\subsection{Making $i$ 's Debt Safe or Gambling for Resurrection?}

The previous analysis makes clear that the extent of risk shifting depends on the likelihood of a bailout, $1-\pi$. When bailouts are very likely $(\pi \approx 0)$, and under the regularity conditions described in Appendices $\mathrm{B}$ and $\mathrm{C}, b_{\text {opt }}$ is larger than $\bar{b}$. In other words, $i$ chooses a level of risky debt sufficiently high so that there might be a possibility of default, even when ex-posts bailouts are almost guaranteed. In that case, the extent of risk shifting is maximal.

As $\pi$ increases, so that bailouts become less certain, the optimal level of risky debt decreases until it reaches $\bar{b}$. Appendix $C$ shows that there is a critical level of $\pi$, denoted $\pi_{c}$ such that for $\pi>\pi_{c}$, the optimal level of debt falls discontinuously from $\bar{b}$ to $b \leq \underline{b}$ and debt becomes safe. This indicates that it is not necessary for $g$ to enforce a strict no-bailout policy $(\pi=1)$ to eliminate risk shifting in period 0 . Any level $\pi$ superior to $\pi_{c}$ will result either in a safe debt level, or the minimum level of debt necessary to cover funding needs, i.e. $\mathcal{D}\left(b_{1}^{i}\right)=x_{0}^{i}$.

Suppose $g$ can choose a commitment technology $\pi$ in period 0 . A higher $\pi$ reduces the amount of risk shifting and for $\pi>\pi_{c}$ risk shifting is eliminated entirely. However, this also reduces resources available to country $i$ in $t=1$ and therefore makes a default more likely. It also makes country $i$ less solvent in $t=0$, by shifting down the Laffer curve. If the initial fundings needs $x_{0}^{i}$ are sufficiently high, it could force country $i$ to default in period 0 , with direct and indirect costs for $g$. We now establish formally that it can be in the interest of $g$ to choose $\pi<\pi_{c}$, i.e. to allow the possibility of a bailout in period 1 , even if it leads to risk shifting in period 0 . The reason is that $g$ prefers to gamble for resurrection: under certain conditions, a possible default tomorrow is preferable to a certain default today.

In the bondless limit, $g$ 's utility can be expressed as a function of the optimal debt $b(\pi)$ issued by $i$ under no-bailout policy $\pi$ :

$$
\begin{aligned}
U_{g}(b(\pi), \pi) & \equiv c_{0}^{g}+\beta E\left[c_{1}^{g}\right] \\
& =y_{0}^{g}-b_{0}^{g}+b_{0}^{i, g}+b_{0}^{s, g}+\beta y_{1}^{g}+\Psi(b(\pi) ; \pi) .
\end{aligned}
$$

where $\Psi(b ; \pi)$ denotes the net utility gain to $g$ from $i$ 's sovereign default decision and is defined as:

$$
\begin{aligned}
\Psi(b, \pi)= & -\beta \kappa y_{1}^{g} G(\bar{\epsilon}) \\
& -(1-\pi) \alpha^{i g} \beta b(G(\bar{\epsilon})-G(\underline{\epsilon})) \\
& +(1-\pi) \beta \int_{\underline{\epsilon}}^{\bar{\epsilon}}\left(y_{1}^{i}\left(\Phi+\rho\left(1-\alpha^{i i}\right)\right)-\alpha^{i u} b\right) d G(\epsilon) \\
& +(1-\pi) \beta \kappa y_{1}^{g}(G(\bar{\epsilon})-G(\underline{\epsilon})) .
\end{aligned}
$$


The term on the first line represents the expected utility loss to $g$ due to collateral damage when $i$ defaults and there is no bailout $(\pi=1)$. Notice that this loss is not baked into the borrowing rate $R^{i}$ since it is not a private loss for $g$ investors. The next three lines represent the gains/losses when $\pi$ is different from 1, i.e. in the presence of bailouts. The second line represents the cost of $g$ 's transfer to $i$. The third line represents the fact that $g$ captures the efficiency gains from avoiding a default and the last line captures the gain from avoiding collateral damage. It is immediate to check that if $i$ 's debt is safe, then $\Psi(b ; \pi)=0$.

The optimal choice of commitment technology maximizes $g$ 's utility and satisfies:

$$
\frac{d \Psi(b(\pi) ; \pi)}{d \pi}=\frac{\partial \Psi(b(\pi) ; \pi)}{\partial \pi}+\frac{\partial \Psi(b(\pi) ; \pi)}{\partial b} \frac{d b}{d \pi}=0
$$

The appendix provides a full discussion of the optimal choice of commitment technology and establishes that $g$ always prefers to choose a level of commitment that rules out risk shifting, i.e. $\pi \geq \pi_{c}$. The intuition is simple: when $\pi \geq \pi_{c}$, the optimal debt level does not depend on $\pi: d b / d \pi=0$. It follows that the optimal choice of $\pi$ over that range is controlled by the sign of $\partial \Psi / \partial \pi$. But since $i$ 's debt is safe $\Psi=0$ then therefore $g$ is indifferent. For lower levels of commitment, if a default with transfer is possible, it must lower the utility of $g$. Hence it is strictly preferable to eliminate risk shifting, to the extent possible.

This analysis is only valid as long as $i$ remains solvent. Denote $\mathcal{D}_{\max }(\pi)$ the maximum of the Laffer curve under commitment level $\pi$. It is immediate that $d \mathcal{D}_{\max }(\pi) / d \pi \leq 0$. If $\mathcal{D}_{\max }\left(\pi_{c}\right)<x_{0}^{i}$, country $i$ cannot honor its debts and is forced to default in the initial period if $g$ insists ruling out risk shifting. This has a direct cost for $g, \kappa y_{0}^{g}$, and an indirect cost, $\alpha^{i, g}\left(b_{0}^{i}-\rho y_{0}^{i}\right)$. Assume further that, in the event of a default in the initial period, $i$ is unable to borrow, so $b_{1}^{i}=0$. It follows that $g$ will choose either the maximum level of commitment $\pi$ consistent with avoiding a default in the current period, i.e. such that $\mathcal{D}_{\max }(\pi)=x_{0}^{i}$, or it will choose $\pi>\pi_{c}$ and let $i$ default in the initial period. It will prefer the former if the following condition is satisfied:

$$
\kappa y_{0}^{g}+\alpha_{0}^{i, g}\left(b_{0}^{i}-\rho y_{0}^{i}\right)+\Psi\left(b_{\max }, \pi\right) \geq 0
$$

Eq. (31) states that it can be optimal ex-ante for $g$ to allow ex-post bailouts if these allow $i$ to avoid an immediate default. The logic is quite intuitive: by allowing the possibility of a future bailout, $g$ gambles for resurrection: in the event that $i$ 's output is sufficiently hight in period 1 , debts will be repaid and a default will be avoided in both periods. Even if a bailout is required, the cost to $g$ as of period 0 is less than one for one. This condition is more easily satisfied the higher is $g$ 's output, and the higher its exposure to $i$ 's debt. We summarize these results with the following proposition.

Proposition 5 (Insulation and Gambling for Resurrection). Suppose g can choose a commitment policy 
$\pi$ in period 0. Then:

- If $x_{0}^{i} \leq \mathcal{D}_{\max }\left(\pi_{c}\right)$, country $i$ 's initial funding needs are sufficiently low so country $g$ optimally adopts a firm commitment policy: $\pi=\pi_{c}$. This rules out risk-shifting and makes $i^{\prime} s$ debt safe if $x_{0}^{i}<\underline{b} / \beta$.

- If $x_{0}^{i}>\mathcal{D}_{\max }\left(\pi_{c}\right)$, country $g$ prefers to gamble for resurrection if Eq. (31) is satisfied. In that case, it chooses $\pi$ such that $\mathcal{D}_{\max }(\pi)=x_{0}^{i}$, i.e. it provides just enough resources in expectation to cover $i$ 's funding needs. While this eliminates risk shifting, $i$ 's debt remains risky and $i$ may receive a bailout in $t=1$.

This discussion highlights that $g$ is more likely to adopt an ex-ante lenient position on future bailouts (i.e. a low $\pi$ ) when $i$ has initially a high debt level or a low output level. The proposition also highlights that $g$ can always eliminate risk shifting, even if it does not adhere to a strict no-bailout policy. This proposition provides an interesting interpretation of the early years following the creation of the Eurozone. Countries were allowed to join the Eurozone with vastly different levels of initial public debt. The strict imposition of a no-bailout guarantee could have pushed these countries towards an immediate default and debt restructuring. Instead, it may well have been optimal to allow countries to rollover their debt on the conditional belief that a bailout might occur in the future. The fiscal cost to $g$ of an immediate default may have exceeded the expected costs from possible future bailouts.

We now summarize the main points of the baseline model:

- When $\pi$ is sufficiently high, the probability of a bailout $(1-\pi)$ is small and there is no riskshifting. When rollover needs are low, country $i$ issues safe debt. When rollover needs are high, country $i$ issues exactly the amount necessary to roll over the debt (i.e. $c_{0}^{i}=0$ ).

- When $\pi$ is sufficiently small, and funding needs are not too high, country $i$ chooses a unique level of debt $b_{\text {opt }}$ regardless of its funding needs. This optimal level of debt satisfies $\bar{b} \leq b_{\text {opt }}<b_{\max }$, i.e. it is sufficiently elevated that default might occur in the second period.

\section{Extensions}

In the baseline model, we excluded the possibility that (i) the countries could bargain over the surplus; (ii) a country could default but still remain a member of the eurozone and that (iii) a third institution, for instance the European Central Bank, could intervene to alter the real value of public debt. We now analyze these three possibilities separately. 


\subsection{Bargaining over the surplus}

In the main model, we assumed that all the bargaining power was in the hands of the creditor country. Even though it is plausible that the creditor country has a larger bargaining weight, our assumption of a 'take it or leave it' offer may be too strong. Hence, in this section we relax it and assume that the bargaining weight of $i$ is $0<\gamma<1$, and that of country $g$ is $1-\gamma$. The baseline case corresponds to $\gamma=0$. This changes the size of the transfer that $i$ receives as it can obtain a share $\gamma$ of the total surplus generated by avoiding the default. The transfer to $i$ is now:

$$
\underline{\tau}_{1}(\gamma)=b_{1}^{i}\left(1-\alpha^{i, i}\right)-y_{1}^{i}\left[\Phi+\rho\left(1-\alpha^{i, i}\right)\right]+\gamma\left(\Phi y_{1}^{i}+\kappa y_{1}^{g}-\alpha^{i, u}\left(b_{1}^{i}-\rho y_{1}^{i}\right)\right) .
$$

The first two terms on the right hand side corresponds to the previous expression for the transfer, i.e. when $i$ has no bargaining power. The last term represents the share of the total surplus $\Phi y_{1}^{i}+\kappa y_{1}^{g}-$ $\left(b_{1}^{i}-\rho \alpha^{i, u}\right)$ that goes to country $i$. It increases with the collateral damage $\kappa$ inflicted on $g$ in case of default. While the transfer increases with $\gamma$, the threshold levels $\underline{\epsilon}$ and $\bar{\epsilon}$ remain unchanged. At $\underline{\epsilon}$ the surplus is zero, hence there is no transfer and default becomes optimal. At $\bar{\epsilon}$, country $i$ unilaterally prefers not to default even without transfers. As long as income realizations are observable, no transfer is needed. This implies a downward discontinuity in consumption for $i$ at $\epsilon=\bar{\epsilon}$ : a slight increase in income makes default non-credible and therefore eliminates the transfer.

The expectation that $i$ has some strictly positive bargaining weight in period 1 also modifies the incentive to issue debt in period 0 . Because the thresholds are unchanged, the probability of default is unaffected. Hence the Laffer curve is unchanged. However, the level of debt issued, $b_{1}^{i}$, affects the expected transfer along two margins. In comparison to Eq. (29), the first-order condition for optimal debt has two addtional terms :

$$
\begin{aligned}
& \left\{(G(\bar{\epsilon})-G(\underline{\epsilon}))+\frac{\gamma}{\left(1-\alpha^{i, i}\right)}\left[\Phi y_{1}^{i}(\bar{\epsilon})+\kappa y_{1}^{g}-\alpha^{i, u}\left(b_{1}^{i}-\rho y_{1}^{i}(\bar{\epsilon})\right)\right] g(\bar{\epsilon}) \frac{d \bar{\epsilon}}{d b}\right\}(1-\pi) \\
= & \left(b_{1}^{i}-\rho \bar{y}_{1}^{i} \underline{\epsilon}\right)(1-\pi) g(\underline{\epsilon}) \frac{d \underline{\epsilon}}{d b}+\left(b_{1}^{i}-\rho \bar{y}_{1}^{i} \bar{\epsilon}\right) \pi g(\bar{\epsilon}) \frac{d \bar{\epsilon}}{d b}+\frac{\gamma}{\left(1-\alpha^{i, i}\right)} \alpha^{i, u}[G(\bar{\epsilon})-G(\underline{\epsilon})](1-\pi) .
\end{aligned}
$$

On the left hand side (marginal gain of issuing debt), in addition to the expectation that marginal debt is paid by the transfer, an additional term (the second one in the bracket) is related to the discontinuity in consumption at $\bar{\epsilon}$ : increasing the level of debt raises $\bar{\epsilon}$ and therefore makes it more likely that a transfer will be needed. A share $\gamma$ of the surplus is now captured by $i$ and this additional marginal gain of debt increases risk shifting. There is however also an additional term on the right hand side (marginal cost of issuing debt). In addition to the cost of increasing debt due to higher thresholds $(\bar{\epsilon}$ and $\epsilon$ ) and therefore borrowing costs, the last term on the right hand side reduces the incentive to issue 
debt. This is because higher debt reduces the total surplus from not defaulting on the rest of the world (as measured by the share of debt held outside the eurozone $\alpha^{i, u}$ ). Country $i$ captures a share $\gamma$ of that surplus, hence this reduces the incentive to issue debt. The net effect on debt issuance is ambiguous.

Relaxing the assumption that all the bargaining power is in the hand of the creditor country leaves the thresholds for default or bailout unchanged compared to our baseline case. Instead, it shares the benefits of the bailout with the debtor country, and has an ambiguous effect on the incentive to issue debt.

\subsection{Default vs. Exit}

In July 2012, Greece restructured its debt, implementing one of the largest sovereign haircuts in modern history. Yet, the country remained in the eurozone, and agreed to the terms of a bailout that was described in Section 2. In our baseline model, in the event that the borrower defaults, it should not receive any bailout. To make this point explicitly, Fig. 5 reports the timeline of NPV transfers to Greece, estimated between 2010 and 2018 using the methodology of Section 2 and using the planned sequence of disbursements and repayments at each point in time. The figure indicates that the transfers to Greece were minimal between 2010 and 2012 and jumped to $20 \%$ of GDP in 2012, precisely at the time at which Greece defaulted on its sovereign debt. Through the lens of the model, Greece should have received a transfer in 2010-11 and no transfer post-default. We now extend the model to account for the pattern we see in the data. To do so, we consider an extension of the model were a country can decide to default and/or exit the monetary union altogether. In this extension, members of a monetary union may now find it in their interest to support financially one of their neighbors, so as to avoid a default, an exit from the currency union, or both. In particular, we characterize the conditions under which it is optimal to let a country default, yet provide a transfer so as to avoid an exit from the currency union. We provide a characterization of the optimal transfers and discuss the implications of the model in the context of the recent Eurozone crisis. A direct implication of our analysis is that any transfer from European institutions to Greece post 2012 must have served to prevent an implosion of the Eurozone. However, as in the baseline model, our model still implies that the surplus from these ex-post transfers are mostly captured by the rest of the monetary union.

The extended model differentiates between the direct cost of a default for country $i$, denoted $\Phi_{d}$, and that of an exit, denoted $\Phi_{e}$. Similarly, we differentiate between the collateral cost for country $g$ in the event of a default, denoted $\kappa_{d}$, and that in the event of an exit, denoted $\kappa_{e}$. As in the baseline model, these costs represent the net economic disruption associated with a default, and an exit respectively on $i$ and $g$. We also assume that a decision to simultaneously default and exit the currency union imposes additive costs $\Phi_{d}+\Phi_{e}$ on $i$ and $\kappa_{d}+\kappa_{e}$ on $g .{ }^{59}$ The decision to exit the currency union brings in additional

\footnotetext{
${ }^{59}$ This assumption is made mostly for simplicity. An alternative assumption which we do not explore in this paper is that
} 


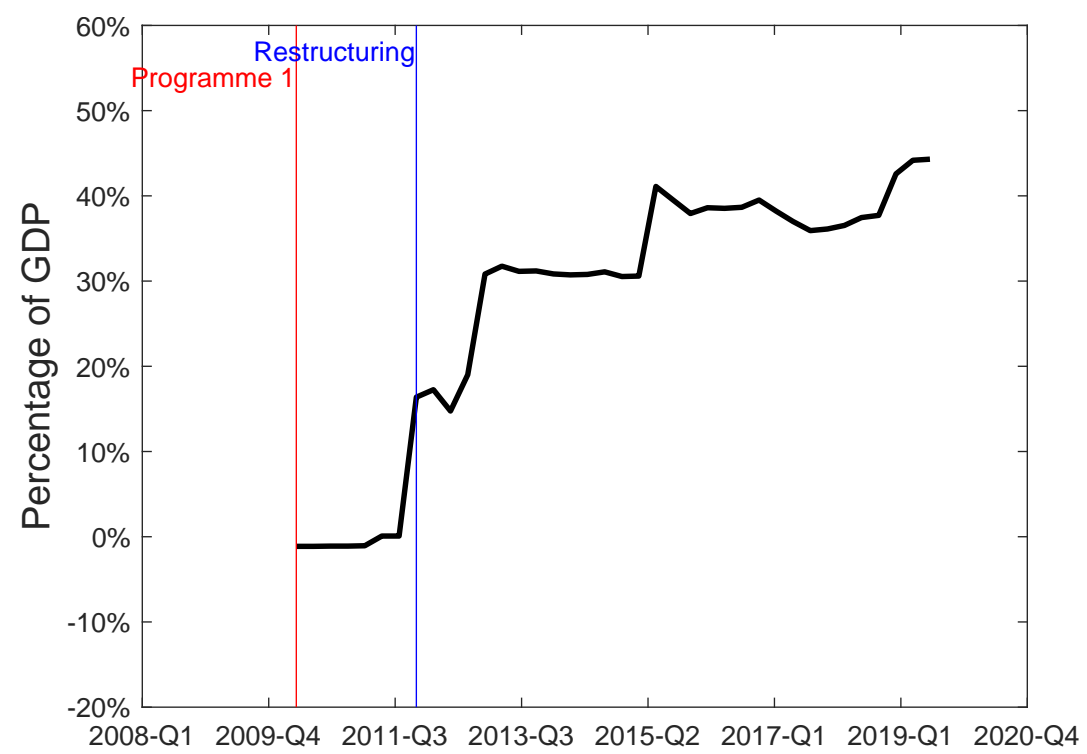

The figure reports the timeline of combined transfers in present value from the GLF, the EFSF, the ESM and the IFM to Greece, between 2010 and 2018, were the NPV at each point in time depend on the planned sequence of disbursements and repayments in place at that time. Fraction of 2010 Greek GDP. Source: Authors calculations from ESM, IFM data. See online appendix for details.

Figure 5: The Time Line of Greek Transfers. Percent of 2010 Greek GDP

benefits to $i$. Most importantly, it allows $i$ to regain some monetary autonomy, and debase the value of local currency debt held externally. ${ }^{60}$ We assume that this additional benefit is proportional to the outstanding stock of debt held abroad and express it as $\Delta b_{1}^{i}\left(1-\alpha_{1}^{i i}\right)$ where $\Delta>0$, with a corresponding loss for $g$ of $\Delta b_{1}^{i} \alpha^{i, g}{ }^{61}$ Nevertheless, we restrict the parameters so that $i$ always prefers to default before exiting the currency union. This is summarized in the following assumption. ${ }^{62}$

Assumption 1. : Country $i$ always prefers to default before exiting.

the cost function is superadditive in default and exit.

$$
\frac{\Delta}{\Phi_{e}}<\frac{1}{\Phi_{d}+\rho} .
$$

${ }^{60}$ While the debt is initially issued in the common currency, part of it may be re-denominated in local currency in the event of an exit.

${ }^{61}$ Monetary autonomy may also confer benefits to $i$ that are proportional to its output, but these are already subsumed in $\Phi_{e}$. Although an exiting country would be responsible for indemnifying the ECB for any net claims on Target2 imbalances that remained at the time of separation, one can imagine that exit could also lead to default on Target2 balances. This can be treated as additional default conditional on exit. In addition, one could imagine that exiting the currency union would also confer some flexibility to $g$. However, we consider in what follows that the gains from this increased autonomy are negligible from $g$ 's perspective, possibly because $g$ has more control over the currency union's policies, including monetary policy.

${ }^{62}$ The alternative assumptions, that $i$ would either default and exit jointly or always prefer to exit before defaulting, strike us as counterfactual. After all, Greece defaulted in 2012, yet remained in the Eurozone. 
This condition is satisfied if the cost of exit per unit of output $\Phi_{e}$ is large, and or the benefits per unit of debt held abroad $\Delta$ are small.

In period 1, country $i$ decides whether to repay or default and whether to stay or exit the currency union. Country $g$ can then decide to make a unilateral transfer conditional on $i$ 's decision and the realization of $i$ 's output. We further assume that $g$ cannot commit to a no-bailout clause, so $i$ and $g$ will always achieve ex-post efficiency. ${ }^{63}$ We begin by characterizing the decision choices of country $i$ in the absence of transfers. This is summarized in the following proposition.

Proposition 6 (Optimal Default and Exit Decisions without Bailouts). Under Assumption 1, and in the absence of transfers, country $i$ 's default and exit decisions in period $t=1$ are characterized by a default threshold $\bar{\epsilon}^{d}$ and an exit threshold $\bar{\epsilon}^{e}$ such that $\bar{\epsilon}^{d}>\bar{\epsilon}^{e}$ and:

1. $i$ repays and stays in the currency union if and only if:

$$
\epsilon_{1}^{i} \geq \bar{\epsilon}^{d} \equiv \frac{\left(1-\alpha^{i, i}\right) b_{1}^{i} / \bar{y}_{1}^{i}}{\Phi_{d}+\rho\left(1-\alpha^{i, i}\right)}
$$

2. $i$ defaults but remains in the currency union if and only if:

$$
\bar{\epsilon}^{d}>\epsilon_{1}^{i} \geq \bar{\epsilon}^{e} \equiv \frac{\Delta\left(1-\alpha^{i, i}\right) b_{1}^{i} / \bar{y}_{1}^{i}}{\Phi_{e}}
$$

3. $i$ defaults and exits the currency union if and only if:

$$
\bar{\epsilon}^{e}>\epsilon_{1}^{i}
$$

Proof. See the Appendix.

The intuition for the result is as follows. First, because the gains and costs of default and exit are additive, it is easy to check that default is preferred whenever $\bar{\epsilon}^{d}>\epsilon_{1}^{i}$, independently of the decision to exit, while exit is preferred whenever $\bar{\epsilon}^{e}>\epsilon_{1}^{i}$, regardless of the decision to repay. Second, Assumption 1 ensures that $\bar{\epsilon}^{d}>\bar{\epsilon}^{e}$ so that the country always prefers to default first, for a given initial debt level, as domestic economic conditions deteriorate.

Fig. 6 provides a graphical illustration of $i$ 's decision to default and/or exit, as a function of the ratio of debt to potential output, $b_{1}^{i} / \bar{y}_{1}^{i}$, on the horizontal axis, and the output gap $\epsilon_{1}^{i}$ on the vertical axis. The cut-offs $\bar{\epsilon}^{d}$ and $\bar{\epsilon}^{e}$ represent rays through the origin that partition the state space into the three regions described in the proposition. Higher realizations of output and lower initial debt levels make it more likely that debts will be repaid and that the country will remain in the currency union.

\footnotetext{
${ }^{63}$ In terms of the baseline model, we assume that $\pi=0$.
} 
Next, we consider the optimal transfers from $g$ to $i$. As before, we assume that $g$ makes the minimal transfer needed to avoid default and/or exit from $i$. Given the additivity assumption, we can consider three possible transfers: a transfer $\underline{\tau}_{1}^{d}$ to avoid a default, another transfer $\underline{\tau}_{1}^{e}$ to avoid an exit, and a transfer $\underline{\tau}_{1}^{d e}=\underline{\tau}_{1}^{d}+\underline{\tau}_{1}^{e}$, to avoid both default and exit.

Proposition 7 (Optimal Ex-post Transfers and Default/Exit Decisions). Under Assumption 1, country $g$ implements the following optimal ex-post bailout policy:

1. When $\epsilon_{1}^{i} \geq \bar{\epsilon}^{d}$, there is no bailout: $\tau_{1}=0$; Country $i$ repays and stays in the currency union;

2. When $\bar{\epsilon}^{d}>\epsilon_{1}^{i} \geq \underline{\epsilon}^{d}$, where

$$
\underline{\epsilon}^{d}=\frac{\alpha^{i, u} b_{1}^{i} / \bar{y}_{1}^{i}-\kappa_{d} y_{1}^{g} / \bar{y}_{1}^{i}}{\Phi_{d}+\rho \alpha^{i, u}}<\bar{\epsilon}^{d},
$$

country $g$ makes a transfer to avoid default and exit. Country $i$ repays and stays in the currency union;

3. When $\underline{\epsilon}^{d}>\epsilon_{1}^{i} \geq \underline{\epsilon}^{e}$, where

$$
\underline{\epsilon}^{e}=\frac{\Delta \alpha^{i, u} b_{1}^{i} / \bar{y}_{1}^{i}-\kappa_{e} y_{1}^{g} / \bar{y}_{1}^{i}}{\Phi_{e}},
$$

countryg makes a minimal transfer to avoid exit. Country $i$ defaults and stays in the currency union;

4. When $\underline{\epsilon}^{e}>\epsilon_{1}^{i}$, country $g$ does not make any transfer: $\tau_{1}=0$; Country $i$ defaults and exits.

Proof. See the Appendix.

The intuition for the result is as follows. First, when $\epsilon_{1}^{i} \geq \bar{\epsilon}^{d}$, country $i$ prefers to repay and stay in the currency union even in the absence of transfer. Therefore, $\tau_{1}=0$. When $\epsilon_{1}^{i}=\bar{\epsilon}^{d}$, country $i$ is indifferent between defaulting and repaying, but prefers to stay in the currency union. Yet, because a default inflicts collateral damage on $g$, the latter is willing to make a minimal transfer $\tau_{1}^{d}$ as long as $\bar{\epsilon}^{d}>\epsilon_{1}^{i} \geq \underline{\epsilon}^{d}$. The intuition is the same as in the baseline model: $g$ prefers to make an ex-post transfer as long as the joint surplus from not-defaulting remains positive. There is one difference with the previous case. When $\bar{\epsilon}^{d}>\epsilon_{1}^{i} \geq \bar{\epsilon}^{e}$, it is sufficient to transfer $\underline{\tau}_{1}^{d}$ since $i$ prefers not to exit. However, when $\bar{\epsilon}^{e}>\epsilon_{1}^{i}>\underline{\epsilon}^{d}, g$ must transfer $\underline{\tau}_{1}^{d}+\underline{\tau}_{1}^{e}$. Finally, when $\underline{\epsilon}^{d}>\epsilon_{1}^{i}, g$ is not willing to make a transfer to avoid repayment. However, as long as $\epsilon_{1}^{i}>\underline{\epsilon}^{e}$, it will make a transfer $\underline{\tau}_{1}^{e}$ to avoid exit.

Proposition 7 illustrates an important result: it is possible for $g$ to make transfers to avoid a default, or an exit, or both. Fig. 6 illustrates the optimal choice of default and exit in the presence of the optimal transfers. The transfers are also not monotonic in output. For moderate levels of debt, it is optimal to make transfers so that $i$ never defaults or exits. However, the transfers vary non-monotonically with the level of output. As output decreases, $i$ 's preference for a joint default and exit forces $g$ to increase 


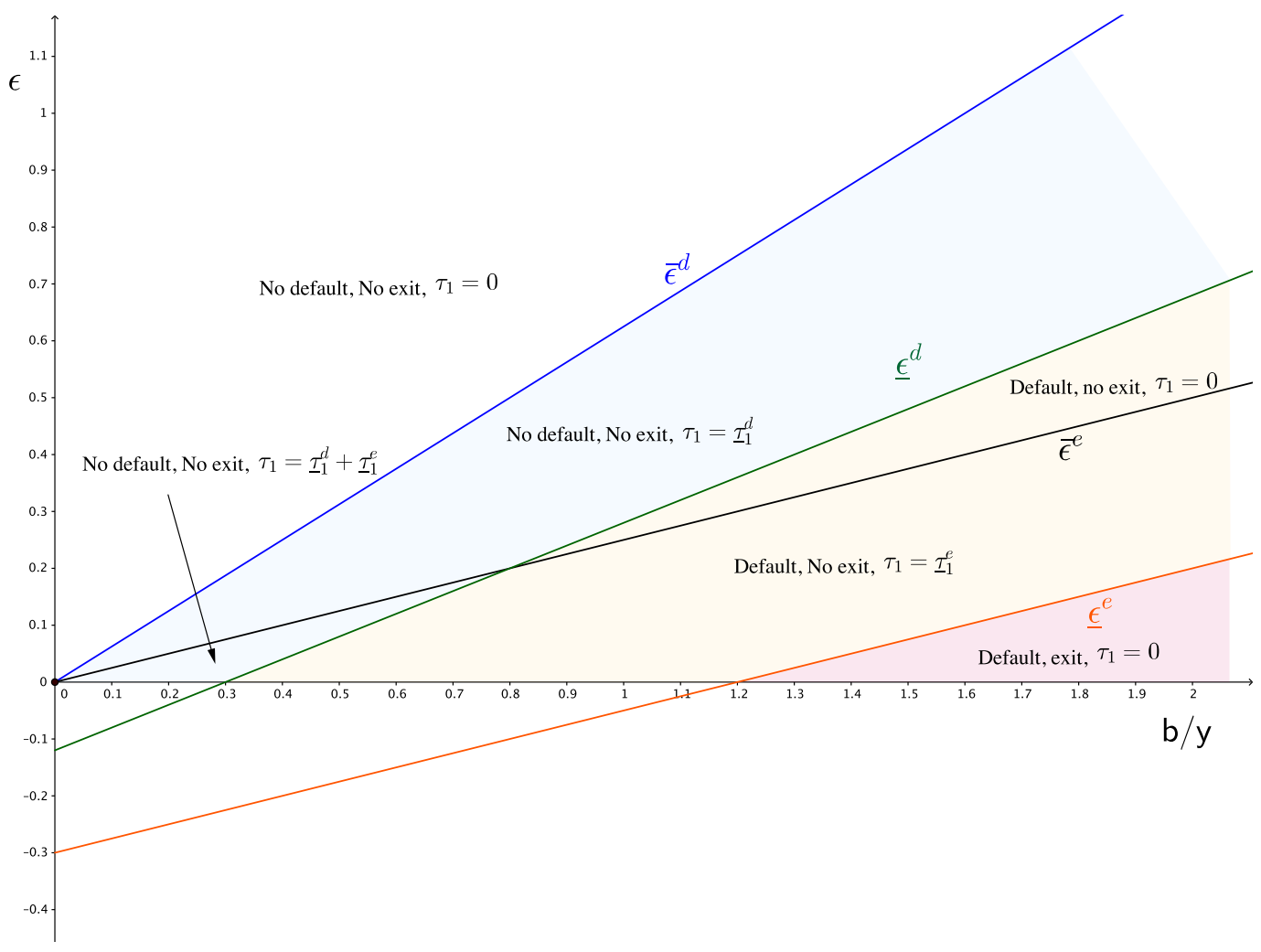

Figure 6: Optimal Ex-Post Bailout and Default vs. Exit Decisions

discretely its transfer from $\underline{\tau}_{1}^{d}$ to $\underline{\tau}_{1}^{d}+\underline{\tau}_{1}^{e}{ }^{64}$ For higher levels of debt, transfers go through two phases as a function of output. A first transfer $\tau_{1}^{d}$ is implemented when output is moderately high, to avoid a default. For moderate levels of output, it becomes optimal to let $i$ default and remain in the union. However, as output decreases, $g$ then initiates transfers $\underline{\tau}_{1}^{e}$ to avoid an exit from the currency union. Finally, if output becomes really low, it is optimal to let $i$ default and exit.

This extension allows us to think about the determinants of ex-post bailouts both prior to a default episode, or, in the case of Greece after 2012, post default, but before an exit.

\subsection{Debt monetization}

Debt monetization is an alternative to default which we have excluded so far. Even though article 123 of the Treaty of the European Union forbids ECB direct purchase of public debt, debt monetization can still take place through inflation and euro depreciation. In this section, we analyze in a very simplified framework how the interaction of transfers and debt monetization affects the probability of default and how the ECB may be overburdened when transfers are excluded. To facilitate the analysis of this

\footnotetext{
${ }^{64}$ This discontinuity is a consequence of the fact that output is perfectly observed by $g$.
} 
extension we simplify the model by assuming a zero recovery rate $(\rho=0)$ and by focusing on two polar cases where transfers are always possible $(\pi=0)$ and where transfers are excluded $(\pi=1)$.

There are now three players: $i, g$ and the $E C B$. In addition to $g$ 's decision on the transfer, $i$ 's decision on default, the ECB decides how much and whether to monetize the debt. We assume the ECB can choose the inflation rate for the monetary union as a whole. This would be the case for example with Quantitative Easing $(\mathrm{QE})$ which generates higher inflation and euro depreciation that both reduce the real value of public debt. Importantly, all public debts are inflated away at the same rate in the monetary union so that $g$ also stands to benefit from it. We follow Aguiar et al. (2015) and assume that the ECB trades off distortionary costs of inflation against the fiscal benefits of debt reduction ${ }^{65}$. If $z$ is the inflation rate, the distortion cost is $\delta z y_{1}^{h}$ for $h=i, g$. We also assume as in Aguiar et al. (2015) that the inflation rate is between 0 and a maximum rate $\bar{z}$ above which distortion costs are infinite.

The ECB can also implement targeted purchases of public debt. In this case, it would be possible to buy public debt of a specific country without any inflation cost for example if it was sterilized by sales of other eurozone countries debt. The Outright Monetary Transactions (OMT) program announced in September 2012 (but never put into place) is close to such a description. The Securities Markets Program (SMP) program was put into place in May 2010 by the ECB and terminated in September 2012 to be replaced by OMT. The aim was to purchase sovereign bonds on the secondary markets. At its peak, the program's volume totaled around 210 bn euros. In the case of Greece, the Eurogroup decided in 2018 to transfer (via the ESM) part of the profits made through SMP back to the country. Such a decision can therefore be interpreted in the context of our model as similar to transfers that we analyzed above. Debt monetization at the inflation rate $z$ is of a different nature and resembles a partial default, except that the total cost for the eurozone is $\delta \bar{z}\left(y_{1}^{i}+y_{1}^{g}\right)$ in case of inflation and $\Phi y_{1}^{i}+\kappa y_{1}^{g}$ in case of a standard default. We also reasonably assume that $\Phi$ and $\kappa$ are larger than $\delta \bar{z}$, so that,in proportion to output, the costs of default are both larger than the marginal distortionary cost of inflation.

\subsubsection{The case with transfers}

We first analyze the case where transfers by $g$ are possible and not subject to political risk i.e. $\pi=0$. Remember that in presence of transfers by $g$ to $i, g$ captures the entire surplus of $i$ not defaulting: $g$ 's transfers are ex-post efficient from the joint perspective of $g$ and $i$. This implies that the objective of the ECB and $g$ are perfectly aligned if, as we assume, the ECB maximizes the whole EMU welfare. The $\mathrm{ECB}$ will choose either zero or maximum inflation rate $\bar{z}$ depending whether the marginal benefit of inflating the eurozone debt held in the rest of the world is below or above its marginal distortion cost. Without default, the ECB will choose not to inflate the debt if the gain from inflating debt held outside

\footnotetext{
${ }^{65}$ An alternative is de Ferra and Romei (2019) who analyze the interaction between sovereign default risk and monetary policy in a monetary union where debt is denominated in real terms. In their model, a looser stance of monetary policy increases debtors' incentive to repay debt.
} 
the eurozone is lower than the distortion costs of inflation. The ECB chooses a zero inflation rate if $i$ 's output realization is high enough such that:

$$
\epsilon_{1}^{i}>\frac{b_{1}^{i} \alpha^{i, u}+b_{1}^{g} \alpha^{g, u}}{\delta \bar{y}_{1}^{i}}-\frac{y_{1}^{g}}{\bar{y}_{1}^{i}} \equiv \overline{\bar{\epsilon}}
$$

We exclude situations such that the ECB inflates even in case of default of $i$ (which we call fiscal dominance) which apply when $g$ debts are very high and situations where the ECB never inflates (which we call monetary dominance) which apply when distortion costs $\delta$ are very high. This latter case is identical to the main model. The conditions on parameters are detailed in Appendix E. Hence, we concentrate on the interesting case where the ECB may inflate the debt for low levels of $i$ output (below $\overline{\bar{\epsilon}}$ ) which we call "weak fiscal dominance". When the ECB decides not to monetize the debt, $\bar{\epsilon}^{\prime}=\frac{b_{1}^{i}\left(1-\alpha^{i, i}\right)}{\Phi \bar{y}_{1}^{i}}$ defines the threshold level of shock above which $i$ does not require any transfer and does not default. In the case of monetization, the transfer necessary to make $i$ indifferent between default and no default becomes:

$$
\tau_{1}=b_{1}^{i}\left(1-\alpha_{1}^{i, i}\right)(1-\bar{z})-y_{1}^{i}[\Phi-\delta \bar{z}]+\bar{z} b_{1}^{g} \alpha^{g, i}
$$

We can compare the transfer with and without monetization $(\bar{z}=0)$. The first element on the right hand side reduces the required transfer because debt monetization weakens the incentive of $i$ to default on debt held outside of $i$. The inflation distortion in the second term, proportional to output, $y_{1}^{i}$ must be compensated by a higher transfer given that in default there is no such inflation distortion. The last term is the inflation tax on the $g$ debt held by $i$ which also must be compensated by a higher transfer. Hence, debt monetization allows to reduce the transfer for low levels of $g$ debt and high levels of $i$ debt which is the case we concentrate on.

The threshold level of $i$ output below which $g$ prefers a default is also affected by the possibility of ECB monetization:

$$
\epsilon_{1}^{i}<\frac{\alpha^{i u} b_{1}^{i}(1-\bar{z})-\alpha^{g u} b_{1}^{g} \bar{z}-y_{1}^{g}(\kappa-\delta \bar{z})}{(\Phi-\delta \bar{z}) \bar{y}_{1}^{i}} \equiv \underline{\epsilon}^{\prime}
$$

It can be shown that ECB monetization, if it takes place, always reduces the likelihood of default in the sense that $\frac{\partial \epsilon^{\prime}}{\partial \bar{z}}<0$, i.e. the output realization below which $i$ defaults falls with debt monetization.

The intuition is that the net gain of inflating the debt for the eurozone is eliminated when default occurs. Hence, monetization, because it taxes agents from outside the eurozone, produces an additional incentive for $g$ not to let $i$ default. Another result is that the whole benefit of debt monetization (on the part of debt held outside the eurozone), if it occurs, is captured by $g$. The increase in consumption by $g$ due to debt monetization can be shown to be: $\bar{z}\left[b_{1}^{i} \alpha^{i, u}+b_{1}^{g} \alpha^{g, u}-\delta\left(y_{1}^{i}+y_{1}^{g}\right)\right]$ which represents the entire surplus of monetization of eurozone debt held by the rest of the world (net of distortion costs). The intuition is that any increase in net income (through debt monetization or through an increase in 


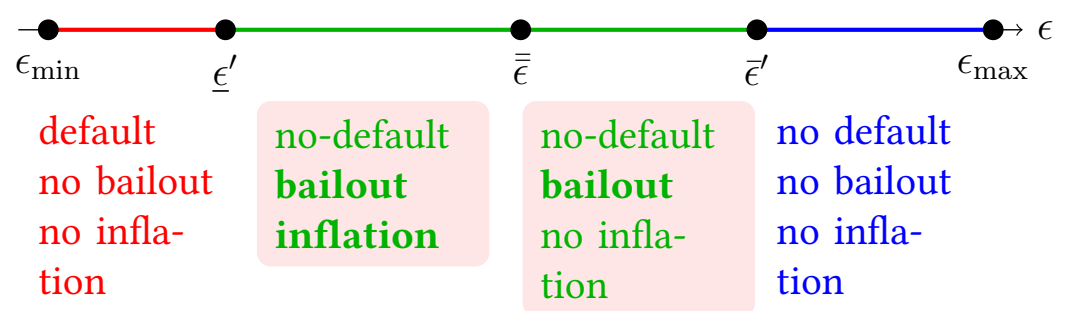

Figure 7: Bailout and Inflation under Weak Fiscal Dominance

$\left.\epsilon_{1}^{i}\right)$ of $i$ serves to lower the necessary transfer to avoid default.

Under reasonable parameters (see appendix) Fig. 7 depicts how the equilibrium changes with $i$ output realizations. As they deteriorate, the equilibrium moves from a situation with 1) no default, no transfer, no inflation, ; 2) no default, transfer, no inflation; 3) no default, inflation, transfer; 4) default, no inflation, no transfer. This case applies in particular for low levels of $g$ debt.

\subsubsection{When transfers are excluded: the overburdened ECB}

The situation we described is one where a fiscal union or a strong cooperative agreement exists such that fiscal transfers are possible with full discretion $(\pi=0)$. This meant that two instruments exist for two objectives: transfers to avoid default and inflation to monetize the debt held outside the eurozone. This is an efficient use of these two instruments.

These transfers may actually be hard to implement for political and legal reasons which we captured in the previous analysis with $\pi>0$. We analyze the simplest version of this situation with $\pi=1$. Because ex-post efficient transfers to avert a default are not possible, the ECB may now use monetary policy to avert a costly default. To make the analysis as simple and as stark as possible we assume that the ECB may choose positive inflation only because transfers are not possible and in order to avoid a default of $i$. In addition, we assume that $b_{1}^{g}=0$ as we concentrate on the incentive to avert a default of $i$. The minimum inflation rate necessary to avoid a default is the one that leaves $i$ indifferent between default and no default:

$$
\tilde{z}=\frac{b_{1}^{i}\left(1-\alpha^{i, i}\right)-\Phi y_{1}^{i}}{b_{1}^{i}\left(1-\alpha^{i, i}\right)-\delta y_{1}^{i}}
$$

Note that as long as $\Phi>\delta$ (which we assume), the inflation rate necessary to avert default increases as the output shock in $i$ deteriorates. This equation also defines a threshold level of shock $\bar{\epsilon}^{\prime}=\frac{b_{1}^{i}\left(1-\alpha^{i, i}\right)}{\Phi \bar{y}_{1}^{i}}$ above which $i$ does not require any monetization and does not default. It can be shown that for $\Phi>$ $\kappa>\delta$ the ECB is willing to accept such monetization at rate $\tilde{z}$ to avert a default but the constraint that it is below the maximum rate $\bar{z}$ defines a level of shock below which the ECB prefers to let the country 


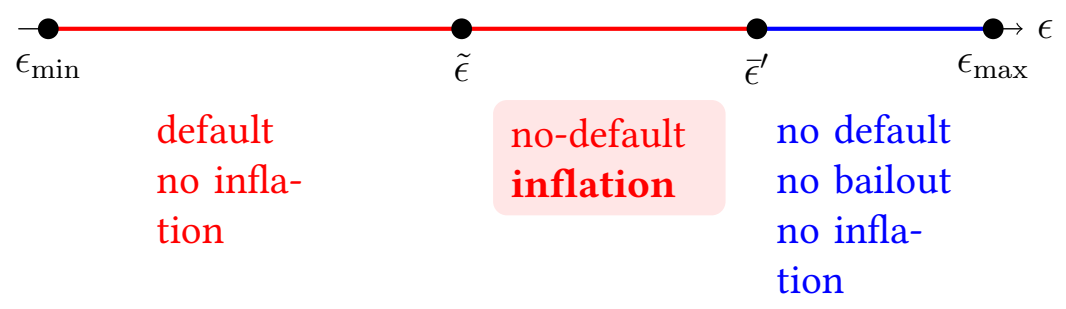

Figure 8: Bailout with Overburdened Central Bank

default rather than monetize it:

$$
\tilde{\epsilon} \equiv \frac{\left(1-\alpha^{i, i}\right) b_{1}^{i}(1-\bar{z})}{(\Phi-\delta \bar{z}) \bar{y}_{1}^{i}}
$$

Fig. 8 shows that when transfers are impossible, the ECB inflates the debt for intermediate levels of output realizations to avoid default. The inflation rate is maximum just above the threshold $\tilde{\epsilon}$. Contrary to transfers, inflation generates distortion costs. Hence, using inflation rather than transfers to avoid default, a situation where the ECB is "overburdened", is inefficient.

\section{Conclusion and policy debates}

Our paper proposes a view that reconciles the "Northern" and "Southern" narratives of the crisis. The former focuses on the collateral damage of default in the EMU that reduces the credibility of the nobailout commitment and induces excessive borrowing by fiscally fragile countries. The later stresses that the efficiency benefits of transfers and debt monetization that prevent a default are entirely captured by the creditor country. There is no "solidarity" in the transfers offered to prevent a default. We show that these two views are two sides of the same coin and are necessary to understand the dynamics of the crisis at play. Our paper can also shed light on some discussions on eurozone reforms and why these reforms need to carefully balance these two sides by improving both market discipline and risk sharing. Proposals (see Bénassy-Quéré et al. (2018)) to introduce orderly restructuring in case of default in the eurozone can be interpreted as lowering the collateral cost of default and also decreasing the probability of a bailout. In our model, these should reduce risk shifting, excessive borrowing and should be welcome by creditor countries. However, these proposals have been criticised (see Tabellini (2018)) as potentially destabilizing for high debt countries. This concern is indeed validated in our model because a strengthening of the no bailout commitment or any policy that increases the probability of a future default may precipitate an immediate default due to the spike in the cost of debt rollover. "kicking the can down the road" may have some merit after all and improving market discipline should be done very carefully and gradually especially for high debt countries. The controversy on the possible

introduction a parallel currency in Italy (the so-called mini-BOTs) can also be interpreted in the light of 
our model. Such an introduction should reduce the cost of a potential exit with several consequences: the size of the necessary transfer to avoid exit increases but this is also the case for the probability of exit and the cost of borrowing. Such a move has therefore an ambiguous impact for a fiscally fragile country.

Our model can also speak to the debate on the creation of a fiscal capacity with macroeconomic stabilization objectives (see Kenen (1969) for the first proposal and Farhi and Werning (2017) and BénassyQuéré et al. (2018) more recent ones) as well as in response to large asymmetric shocks such as COVID19 (Bénassy-Quéré et al., 2020) . One criticism of such a eurozone budget is that it would generate transfers to fiscally fragile countries with insufficient fiscal space to use national fiscal policy during a downturn. Our model shows that these transfers are indeed ex-post efficient in case of a shock that threatens the repayment and integrity of the eurozone. One message of our paper is that these transfers can be substantial in a monetary union with collateral damage. 


\section{References}

Acharya, Viral V, and Sascha Steffen. 2015. "The "greatest" carry trade ever? Understanding eurozone bank risks." fournal of Financial Economics, 115(2): 215-236.

Aguiar, Mark, Manuel Amador, Emmanuel Farhi, and Gita Gopinath. 2015. "Coordination and Crisis in Monetary Unions." Quarterly fournal of Economics, 130(4): 1727-1779.

Bénassy-Quéré, Agnès, Giancarlo Corsetti, Antonio Fatás, Gabriel J Febelmayr, Marcel Fratzscher, Clemens Fuest, Francesco Giavazzi, Ramon Marimon, Philippe Martin, Jean Pisani-Ferry, et al. 2020. "COVID-19 economic crisis: Europe needs more than one instrument." CEPR Vox-EU.

Bénassy-Quéré, Agnès, Markus Brunnermeier, Henrik Enderlein, Emmanuel Farhi, Marcel Fratzscher, Clemens Fuest, Pierre-Olivier Gourinchas, Philippe Martin, Jean PisaniFerry, Hélène Rey, Isabel Schnabel, Nicolas Veron, Beatrice Weder di Mauro, and Jeromin Zettelmeyer. 2018. "Reconciling Risk Sharing With Market Discipline: A Constructive Approach to Euro Area Reform.” CEPR Policy Insights, , (91).

Bindseil, Ulrich, Marco Corsi, Benjamin Sahel, and Ad Visser. 2017. "The Eurosystem Collateral Framework Explained." European Central Bank ECB Occasional Paper 189.

Blustein, Paul. 2015. "Laid low: The IMF, the euro zone and the first rescue of Greece." Centre for International Governance Innovation CIGI Paper Series 61.

Broner, Fernando, Aitor Erce, Alberto Martin, and Jaume Ventura. 2014. "Sovereign Debt Markets in Turbulent Times: Creditor Discrimination and Crowding-out Effects.” fournal of Monetary Economics, 61: 143-147.

Buiter, Willem H, and Anne Sibert. 2005. "How the Eurosystem's Treatment of Collateral in its Open Market Operations Weakens Fiscal Discipline in the Eurozone (and what to do about it)." CEPR Discussion Paper 5387.

Bulow, Jeremy, and Kenneth Rogoff. 1989a. "A Constant Recontracting Model of Sovereign Debt." Journal of Political Economy, 97(1): 155-178.

Bulow, Jeremy, and Kenneth Rogoff. 1989b. “Sovereign Debt: Is to Forgive to Forget?" American Economic Review, 79(1): 43-50.

Bulow, Jeremy, and Kenneth Rogoff. 2015. "Why Sovereigns Repay Debts to External Creditors and Why It Matters." CEPR Vox-EU. 
Calvo, Guillermo. 1988. "Servicing the Public Debt: The Role of Expectations." American Economic Review, 78(4): 647-661.

Chodorow-Reich, Gabriel, Loukas Karabarbounis, and Rohan Kekre. 2019. "The macroeconomics of the Greek Depression.” NBER Working Paper 25900.

Cohen, Daniel, and Jeffrey Sachs. 1986. "Growth and External Debt under Risk of Debt Repudiation.” European Economic Review, 30: 529-60.

Cole, Harold, and Timothy Kehoe. 2000. "Self-Fulfilling Debt Crises." The Review of Economic Studies,, 67(1): $91-11 \S$.

Constâncio, Vítor. 2012. "Contagion and the European debt crisis." Financial Stability Review, 16: 109121.

Corsetti, Giancarlo, Aitor Erce, and Timothy Uy. 2017. “Official Sector Lending Strategies During the Euro Area Crisis." Centre for Macroeconomics (CFM) Discussion Papers 1720.

Corsetti, Giancarlo, Aitor Erce, and Timothy Uy. 2018. "Debt Sustainability and the Terms of Official Support.” CEPR Discussion Paper 13292.

Corsetti, Giancarlo, and Luca Dedola. 2016. "The mystery of the printing press: Monetary policy and self-fulfilling debt crises." Journal of the European Economic Association, 14(6): 1329-1371.

de Ferra, Sergio, and Federica Romei. 2019. "Sovereign Default in a Monetary Union." CEPR Discussion Paper 12976.

de Grauwe, Paul. 2012. “The governance of a fragile Eurozone.” Australian Economic Review, 45(3): 255268.

Dellas, Harris, and Dirk Niepelt. 2016. "Sovereign debt with heterogeneous creditors." Journal of International Economics, 99: S16-S26.

Dovis, Alessandro, and Rishabh Kirpalani. 2020. "Fiscal rules, bailouts, and reputation in federal governments." American Economic Review, 110(3): 860-88.

Du, Wenxin, Joanne Im, and Jesse Schreger. 2018. “The U.S. Treasury Premium.” Fournal of International Economics, 112(C): 167-181.

Eaton, Jonathan, and Mark Gersovitz. 1981. "Debt with Potential Repudiation: Theoretical and Empirical Analysis." The Review of Economic Studies, 48(2): 289-309. 
EC. 2010. "The Economic Adjustment Programme for Greece - First Review." European Commission Occasional Papers 68.

EC. 2012a. "The Financial Sector Adjustment Programme for Spain." European Commission Occasional Papers 118.

EC. 2012b. "The Second Economic Adjustment Programme for Greece." European Commission Occasional Papers 94.

EC. 2012c. "The Second Economic Adjustment Programme for Greece - First Review." European Commission Occasional Papers 123.

EC. 2014. "The Second Economic Adjustment Programme for Greece - Fourth Review." European Commission Occasional Papers 192.

EC. 2016. "Ex Post Evaluation of the Economic Adjustment Programme - Portugal 2011-2014." European Commission Institutional Papers 40.

EFSF. 2010. "Financial Assistance Facility Agreement between European Stability Mechanism and The Republic of Cyprus as the Beneficiary Member State and Central Bank of Cyprus as Central Bank.” European Financial Stability Facility.

EFSF. 2012a. "Master Financial Assistance Facility Agreement between European Financial Stability Facility and Central Bank of Ireland." European Financial Stability Facility.

EFSF. 2012b. "Master Financial Assistance Facility Agreement between European Financial Stability Facility, The Portuguese Republic as Beneficiary Member State, and Banco De Portugal.” European Financial Stability Facility.

EFSF. 2013a. "Amend Agreement Relating to the Loan Facility Agreement, Financial Assistance Facility Agreement, and Master Financial Assistance Facility Agreement.” European Financial Stability Facility.

EFSF. 2013b. "Amendment Agreement Relating to the Loan Facility Agreement, First Financial Assistance Facility Agreement, Second Financial Assitance Facility agreement, and Master Financial Assistance Facility Agreement.” European Financial Stability Facility.

EFSF. 2014. “Second Amendment Agreement.” European Financial Stability Fund.

EFSF. 2015. “Third Amendment Agreement.” European Financial Stability Fund.

ESM. 2014. “Annual Report European Stability Mechanism 2013.” European Stability Mechanism. 
ESM. 2015. “Annual Report European Stability Mechanism 2014.” European Stability Mechanism.

ESM. 2017. “Short-Term Debt Measures for Greece, Explainer.” European Stability Mechanism.

ESM. 2019a. "EFSF approves reimbursement and reduction of step-up interest margin for Greece." European Stability Mechanism.

ESM. 2019b. "Lending Rates." https://www.esm.europa.eu/lending-rates, European Stability Mechanism, Accessed: 2019-07-29.

EU. 2011a. “Council regulation (EU) no 323/2013.” Council of European Union.

EU. 2011b. "Council regulation (EU) no 344/2011." Council of European Union.

EU. 2011c. "Council regulation (EU) no 682/2011." Council of European Union.

EU. 2011d. "Council regulation (EU) no 683/2011." Council of European Union.

EU. 2011e. "Council regulation (EU) no 77/2011." Council of European Union.

EU. 2012a. "Treaty on the European Stability Mechanism." European Union, European Union.

EU. 2012b. "Treaty on the Functioning of the European Union." European Union, European Union.

EU. 2013. "Council regulation (EU) no 313/2013." Council of European Union.

European Commission. 2012. "Parliamentary questions - Answer given by Mr Rehn on behalf of the Commission.” 29 June 2012.

Farhi, Emmanuel, and Ivan Werning. 2017. "Fiscal Unions." American Economic Review, 12(107): $3788-3834$.

Farhi, Emmanuel, and Jean Tirole. 2018. "Deadly embrace: Sovereign and financial balance sheets doom loops." The Review of Economic Studies, 85(3): 1781-1823.

Fernandez, Raquel, and Robert Rosenthal. 1990. "Strategic Models of Sovereign-Debt Renegotiations." The Review of Economic Studies, 57(3): 331-349.

Giannone, Domenico, Michele Lenza, Huw Pill, and Lucrezia Reichlin. 2012. "The ECB and the Interbank Market.” Economic fournal, 122(564): 467-486.

Gourinchas, Pierre-Olivier, Thomas Philippon, and Dimitri Vayanos. 2017. "The Analytics of the Greek Crisis.” NBER Macroeconomics Annual. 
IMF. 2013. "Twelfth Review under the Extended Arrangement and Proposal for Post-Program Monitoring.” International Monetary Fund.

IMF. 2014. "Fifth Review under the Extended Arrangement under the Extended Fund Facility, and Request for Waiver of Nonobservance of Performance Criterion and Rephasing of Access." International Monetary Fund.

IMF. 2016a. “Conditionality Factsheet.” International Monetary Fund.

IMF. 2016b. “IMF Stand-By Arrangement.” International Monetary Fund.

IMF. 2017. “The IMF’s Extended Fund Facility.” International Monetary Fund.

IMF. 2018a. "IMF Financial Operations." International Monetary Fund.

IMF. 2018b. “Second Post-Program Monitoring Discussions.” International Monetary Fund.

Joshi, Priyadarshani, and Jeromin Zettelmeyer. 2005. "Implicit Transfers in IMF Lending, 19732003.” IMF Working Paper 05/8.

Kaplan, Greg, and Giovanni L Violante. 2018. "Microeconomic heterogeneity and macroeconomic shocks." Journal of Economic Perspectives, 32(3): 167-94.

Kenen, Peter. 1969. "Monetary Problems of the International Economy." , ed. R.A. Mundell and A.K. Swoboda, Chapter he Theory of Optimum Currency Areas: An Eclectic View. University of Chicago Press.

Krishnamurthy, Arvind, and Annette Vissing-Jorgensen. 2012. "The aggregate demand for treasury debt." Journal of Political Economy, 120(2): 233-267.

Mengus, Eric. 2014. "International Bailouts: Why Did Banks' Collective Bet Lead Europe to Rescue Greece?” Banque de France Working Paper 502.

Niepmann, Friederike, and Tim Schmidt-Eisenlohr. 2013. "Bank Bailouts, International Linkages, and Cooperation." American Economic fournal: Economic Policy, 5(4): 270-305.

Reuters. 2009. "EU's Almunia:no chance Greece default, euro zone exit." https://uk.reuters.com/article/davos-almunia/davos-eus-almuniano-chance-greece-default-euro-zoneexit-idUSLAE00004520100129, (Last Accessed: Nov. 11 2019).

Reuters. 2010. "EU visit starts in Greece, Stark says no bailout.” https://www.reuters.com/article/us-ecbstark/eu-visit-starts-in-greece-stark-says-no-bailout-idUSTRE60519Q20100106, (Last Accessed: Nov. 11 2019). 
Reuters. 2013. "Bailout loans to Cyprus to have maximum average maturity of 15 years: ESM." https://www.reuters.com/article/us-cyprus-loans-maturity/bailout-loans-to-cyprus-to-have-maximumaverage-maturity-of-15-years-esm-idUSBRE9390Q220130410, Last Accessed: June 12, 2018.

Rockafellar, Ralph Tyrell. 1972. Convex analysis. Princeton university press.

Rose, Andrew K. 2005. "One Reason Countries Pay their Debts: Renegotiation and International Trade." Journal of Development Economics, 77(1): 189-206.

Schumacher, Julian, and Beatrice Weder di Mauro. 2015. "Greek Debt Sustainability and Official Crisis Lending." Brookings Papers on Economic Activity, 46(2 (Fall)): 279-305.

Shambaugh, Jay C. 2012. “The Euro's Three Crises.” Brookings Papers on Economic Activity, 43(1 (Spring): 157-231.

Tabellini, Guido. 2018. "Risk Sharing and Market Discipline: Finding the Right Mix." CEPR Vox-EU.

Tenreyro, Silvana. 2019. "Monetary policy and open questions in international macroeconomics." Speech John Flemming Memorial Lecture.

The Financial Times. 2009. "Germany ready to help eurozone members." https://www.ft.com/content/825af89a-fe02-11dd-932e-000077b07658, (Last Accessed: Nov. 11 2019).

Tirole, Jean. 2015. “Country Solidarity in Sovereign Crises.” American Economic Review, 105(8): 233363.

Uhlig, Harald. 2014. "Sovereign default risk and banks in a monetary union." German Economic Review, 15(1): 23-41.

Woodford, Michael. 1998. "Doing without money: controlling inflation in a post-monetary world." Review of Economic Dynamics, 1(1): 173-219.

Zettelmeyer, Jeromin, Christoph Trebesch, and Mitu Gulati. 2013. "The Greek debt restructuring: an autopsy." Economic Policy, 28(75): 513-563. 


\section{Appendices}

\section{A Construction of the Dataset}

A detailed description of the data construction is available on a not-for-publication online appendix to the paper.

- IMF Data for Cyprus, Greece, Ireland, and Portugal comes from the IMF website (https://www.imf.org/), which reports actual and projected disbursements, repayments of principal, and interest payments. Spain did not receive IMF assistance.

- EFSF and ESM Disbursements and Repayment schedules for Cyprus, Greece, Ireland, Portugal, and are available from the ESM website (https://www.esm.europa.eu/). For interest payments, we apply the blended rate for December 2019 to the series of outstanding debt over the lifetime of the lending cycle. We are grateful to Corsetti, Erce and Uy (2017) for initially sharing this data, which we have extended via the ESM website.

- EFSM data for Ireland come from the Irish Treasury website. EFSM data for Portugal come from the European Commission website (https://ec.europa.eu/info/). Realized interest payments are calculated by applying lending rates from European Commission (2012). For future interest payments, we include a term premium calculated using euribor OIS rates relative to the last observed euribor 3-month rate. We use the Bloomberg Tickers as in Du, Im and Schreger (2018).

- Data for the Greek Lending Facility (GLF) for Greece comes from the European Commission website and various reports therein. To calculate interest rates, we add the reported margins to the end of period 3-month Euribor rate. To forecast 3-month Euribor rates, we again use the euribor OIS rates from Du, Im and Schreger (2018) to calculate a term premium.

- Although we do not calculate the transfer, our information on bilateral loan data to Ireland come from the United Kingdom Treasury and the Sweden, and Denmark Ministry of Finances:

- https://www.gov.uk/government/organisations/hm-treasury

- https://www.government.se/government-of-sweden/ministry-of-finance/

- https://m.fm.dk/ministryoffinance/home

\section{B Characterizing the Laffer Curve}

This appendix provides a full characterization of the Laffer curve in the basic model.

The Laffer curve satisfies :

$$
D(b)=\beta b\left(1-\pi_{d}(b)\right)+\beta \rho \bar{y}_{1}^{i}\left(\pi \int_{\underline{\epsilon}(b)}^{\bar{\epsilon}(b)} \epsilon d G(\epsilon)+\int_{\epsilon_{\min }}^{\underline{\epsilon}(b)} \epsilon d G(\epsilon)\right)+\bar{\lambda}^{i}
$$

where the cut-offs are defined as:

$$
\bar{\epsilon}(b)=\frac{\left(1-\alpha^{i, i}\right) b / \bar{y}_{1}^{i}}{\Phi+\rho\left(1-\alpha^{i, i}\right)}
$$




\begin{tabular}{llr}
\hline \hline Borrower & Lender & Start Date \\
\hline Cyprus & ESM & May, 2013 \\
Cyprus & IMF & May, 2013 \\
Greece & EC & May, 2010 \\
Greece & EFS & March, 2012 \\
Greece & ESM & August, 2015 \\
Greece & IMF & May, 2010 \\
Hungary & BoP & December, 2008 \\
Hungary & IMF & November, 2008 \\
Ireland & EFS & February, 2011 \\
Ireland & EFSM & January, 2011 \\
Ireland & IMF & January, 2011 \\
Latvia & BoP & February, 2009 \\
Latvia & IMF & December, 2008 \\
Portugal & EFSF & June, 2011 \\
Portugal & EFSM & May, 2011 \\
Portugal & IMF & May, 2011 \\
Romania & BoP & July, 2009 \\
Romania & IMF & May, 2009 \\
Spain & ESM & December, 2012 \\
\hline \hline
\end{tabular}

Table A.1: Starting Date by Programme.

Note that in the case of Greece, we treat both IMF Programs as one lending cycle. Programme 2 officially begins in May 2012.

\begin{tabular}{lrr}
\hline \hline Borrower & Quota & Share of Quota \\
\hline Cyprus & 140 & $567 \%$ \\
Greece & 823 & $3,374 \%$ \\
Hungary & 1,038 & $735 \%$ \\
Ireland & 838 & $2,322 \%$ \\
Latvia, Republic of & 127 & $775 \%$ \\
Portugal & 867 & $2,645 \%$ \\
Romania & 1,030 & $1,026 \%$ \\
\hline \hline
\end{tabular}

Table A.2: IMF Quotas (in thousands of SDR) and Share of Quotas.

Note: Share of Quotas defined as Total IMF disbursements divided by total quota as of January 2010. Source: IMF. 


$$
\underline{\epsilon}(b)=\frac{\alpha^{i, u} b / \bar{y}_{1}^{i}-\kappa y_{1}^{g} / \bar{y}_{1}^{i}}{\Phi+\rho \alpha^{i, u}}
$$

and the probability of default is:

$$
\pi_{d}(b)=G(\underline{\epsilon}(b))+\pi(G(\bar{\epsilon}(b))-G(\underline{\epsilon}(b)))
$$

There are a number of cases to consider:

- When $b \leq \underline{b} \equiv y_{\min }^{i}\left(\Phi /\left(1-\alpha^{i, i}\right)+\rho\right)$. In that case $\bar{\epsilon} \leq \epsilon_{\min }$ and $i$ 's output is always sufficiently high that $i$ prefers to repay even without any transfer from $g$. This makes $i$ 's debt riskless and

$$
D(b)=\beta b+\bar{\lambda}^{i}
$$

- If $\bar{b} \equiv\left(\left(\Phi+\rho \alpha^{i, u}\right) y_{\min }^{i}+\kappa y_{1}^{g}\right) / \alpha^{i, u} \leq \hat{b} \equiv y_{\max }^{i}\left(\Phi /\left(1-\alpha^{i, i}\right)+\rho\right)$. This is a condition on the parameters. It can be rewritten as:

$$
\kappa y_{1}^{g} / \bar{y}_{1}^{i} \leq \alpha^{i, u} \rho\left(\epsilon_{\max }-\epsilon_{\min }\right)+\Phi /\left(1-\alpha^{i, i}\right)\left(\alpha^{i, u} \epsilon_{\max }-\epsilon_{\min }\left(\alpha^{i, u}+\alpha^{i, g}\right)\right)
$$

- When $\underline{b}<b \leq \bar{b}<\hat{b}$. In that case, we have $\underline{\epsilon} \leq \epsilon_{\min }<\bar{\epsilon}<\epsilon_{\max }$. When $b=\bar{b}, \underline{\epsilon}=\epsilon_{\min }<\bar{\epsilon}<\epsilon_{\max }$. Default can occur if $\epsilon_{1}^{i} \leq \bar{\epsilon}$ and ex-post transfers are forbidden. It follows that

$$
D\left(b_{1}\right)=\beta\left[b_{1}(1-\pi G(\bar{\epsilon}))+\rho \bar{y}_{1}^{i} \pi \int_{\epsilon_{\min }}^{\bar{\epsilon}} \epsilon d G(\epsilon)\right]+\bar{\lambda}^{i}
$$

and the slope of the Laffer curve is given by

$$
D^{\prime}\left(b_{1}\right)=\beta\left[1-\pi G(\bar{\epsilon})-\frac{\pi \bar{\epsilon} g(\bar{\epsilon}) \Phi}{\Phi+\rho\left(1-\alpha^{i, i}\right)}\right]
$$

For these intermediate debt levels, default is a direct consequence of the commitment not to bail-out country $i$ in period $t=1$. The derivative of the Laffer curve is discontinuous at $b=\underline{b}$ if the distribution of shocks is such that $g\left(\epsilon_{\min }\right)>0$ and the can write the discontinuity as:

$$
\begin{aligned}
D^{\prime}\left(\underline{b}^{+}\right)-D^{\prime}\left(\underline{b}^{-}\right) & =\left.\beta\left(-\underline{b}+\rho y_{\min }^{i}\right) \pi g\left(\epsilon_{\min }\right) \frac{d \bar{\epsilon}}{d b}\right|_{b=\underline{b}} \\
& =-\beta \frac{\pi \epsilon_{\min } g\left(\epsilon_{\min }\right) \Phi}{\Phi+\rho\left(1-\alpha^{i, i}\right)} \leq 0
\end{aligned}
$$

The intuition for the discontinuity is that at $b=\underline{b}$, a small increase in debt increases the threshold $\bar{\epsilon}$ beyond $\epsilon_{\min }$, so a default is now possible. This happens with probability $\pi g\left(\epsilon_{\min }\right) d \bar{\epsilon}$. In that case, investors' discounted net loss is $\beta\left(-\underline{b}+\rho y_{\min }^{i}\right)$.

It is possible for the Laffer curve to decrease to the right of $\underline{b}$ if $\pi \epsilon_{\min } g\left(\epsilon_{\min }\right) \Phi /\left(\Phi+\rho\left(1-\alpha^{i, i}\right)\right)>1$. In that case the increase in default risk is so rapid that the interest rate rises rapidly and $i$ 's revenues $D(b)$ decline as soon as $b>\underline{b}$. Given that $i$ can always choose to be on the left side of the Laffer curve by choosing a lower $b_{1}^{i}$, there would never be any default or bailout. We view this case as largely uninteresting. 
This case can be ruled out my making the following assumption sufficient to ensure $D^{\prime}\left(\underline{b}^{+}\right)>0$ :

Assumption 2. We assume the following restriction on the pdf of the shocks and the probability of bailout

$$
\pi \epsilon_{\min } g\left(\epsilon_{\min }\right)<1
$$

[Note: (a) this condition cannot be satisfied with a power law and $\pi=1$ (i.e. no transfers); (b) this condition is satisfied for a uniform distribution if $\pi<\epsilon_{\max } / \epsilon_{\min }-1$. A sufficient condition for this is $\epsilon_{\min }<2 / 3$. $\left.^{66}\right]$

The second derivative of the Laffer curve is:

$$
D^{\prime \prime}(b)=-\beta \pi \frac{d \bar{\epsilon}}{d b}\left[g(\bar{\epsilon})+\frac{\Phi}{\Phi+\left(1-\alpha^{i, i}\right) \rho}\left(g(\bar{\epsilon})+\bar{\epsilon} g^{\prime}(\bar{\epsilon})\right)\right]
$$

If we want to ensure that $D^{\prime \prime}(b)<0$ a sufficient condition is:

Assumption 3. We assume that $g$ satisfies

$$
\frac{\epsilon g^{\prime}(\epsilon)}{g(\epsilon)}>-2
$$

[Note: we can replace this condition by a condition on the slope of the monotone ratio: $\pi g(\epsilon) /(1-\pi G(\epsilon))$.] [Note: (a) that sufficient condition is not satisfied for $\rho=0$ and a power law; (b) it is always satisfied for a uniform distribution since $g^{\prime}(\epsilon)=0$. ]

The value of $D^{\prime}\left(\bar{b}^{-}\right)$is:

$$
D^{\prime}\left(\bar{b}^{-}\right)=\beta\left[1-\pi G(\bar{\epsilon}(\bar{b}))-\frac{\pi \Phi \bar{\epsilon}(\bar{b}) g(\bar{\epsilon}(\bar{b}))}{\Phi+\rho\left(1-\alpha^{i, i}\right)}\right]
$$

We can ensure that this is positive (so that the peak of the Laffer curve has not been reached) by assuming that:

$$
1 / \pi>G(\bar{\epsilon}(\bar{b}))+\frac{\Phi \bar{\epsilon}(\bar{b}) g(\bar{\epsilon}(\bar{b}))}{\Phi+\rho\left(1-\alpha^{i, i}\right)}
$$

This condition is always satisfied when there is no default $(\pi=0)$. Otherwise, a sufficient condition is:

Assumption 4. We assume that the distribution of shocks satisfies:

$$
1>G(\bar{\epsilon}(\bar{b}))+\bar{\epsilon}(\bar{b}) g(\bar{\epsilon}(\bar{b}))
$$

[Note: with a uniform distribution, the condition above becomes $\bar{\epsilon}(\bar{b})<\epsilon_{\max } / 2$. Substituting for $\bar{\epsilon}(\bar{b})$, this can be ensured by choosing $\epsilon_{\min }$ such that

$$
\frac{1-\alpha^{i, i}}{\Phi+\left(1-\alpha^{i, i}\right) \rho} \frac{\left(\Phi+\rho \alpha^{i, u}\right) \epsilon_{\min }+\kappa y_{1}^{g} / \bar{y}_{1}^{i}}{\Phi+\rho \alpha^{i, u}}<1-\frac{\epsilon_{\min }}{2}
$$

This can be ensured with $\epsilon_{\min }$ sufficiently small, provided $\left.\left(\Phi+\left(1-\alpha^{i, i}\right) \rho\right) \alpha^{i, u}>\left(\Phi+\rho \alpha^{i, u}\right)\left(1-\alpha^{i, i}\right) \kappa y_{1}^{g} / \bar{y}_{1}^{i} \cdot\right]$

\footnotetext{
${ }^{66}$ To see this, observe that since $E[\epsilon]=1$ we can solve for $\epsilon_{\min }<2 /(2+\pi)$.
} 
Under assumptions $2-4$, the Laffer curve is upward sloping, decreasing in $b$, discontinuous at $\underline{b}$ and has not yet reached its maximum at $\bar{b}$.

- When $\bar{b}<b \leq \hat{b}$ then we have $\epsilon_{\min }<\underline{\epsilon}<\bar{\epsilon} \leq \epsilon_{\max }$. It's now possible to default even with optimal transfers and the Laffer curve satisfies

$$
D\left(b_{1}\right)=\beta\left[b_{1}(1-G(\underline{\epsilon})-\pi(G(\bar{\epsilon})-G(\underline{\epsilon})))+\rho \bar{y}_{1}^{i}\left(\pi \int_{\underline{\epsilon}}^{\bar{\epsilon}} \epsilon d G(\epsilon)+\int_{\epsilon_{\min }}^{\underline{\epsilon}} \epsilon d G(\epsilon)\right)\right]+\bar{\lambda}^{i}
$$

with slope:

$$
D^{\prime}\left(b_{1}\right)=\beta\left[1-\pi_{d}-\frac{\pi g(\bar{\epsilon}) \bar{\epsilon} \Phi}{\Phi+\rho\left(1-\alpha^{i, i}\right)}-(1-\pi) g(\underline{\epsilon}) \frac{\Phi \underline{\epsilon}+\kappa y_{1}^{g} / \bar{y}_{1}^{i}}{\Phi+\rho \alpha^{i, u}}\right]
$$

One can check immediately that the slope of the Laffer curve is discontinuous at $b=\bar{b}$ as well, if $\pi<1$ and $g\left(\epsilon_{\min }\right)>0$, with:

$$
\begin{aligned}
D^{\prime}\left(\bar{b}^{+}\right)-D^{\prime}\left(\bar{b}^{-}\right) & =\left.\beta\left(-\bar{b}+\rho y_{\min }^{i}\right)(1-\pi) g\left(\epsilon_{\min }\right) \frac{d \underline{\epsilon}}{d b}\right|_{b=\bar{b}} \\
& =-\beta(1-\pi) g\left(\epsilon_{\min }\right) \frac{\Phi \epsilon_{\min }+\kappa y_{1}^{g} / \bar{y}_{1}^{i}}{\Phi+\rho \alpha^{i, u}} \leq 0
\end{aligned}
$$

The interpretation is the following: when $b=\bar{b}$, a small increase in debt makes default unavoidable, i.e. default probabilities increase from $\pi$ to 1 , since the debt level is too high for transfers to be optimal. The probability of default jumps up by $(1-\pi) g\left(\epsilon_{\min }\right) d \underline{\epsilon}$. The discounted investor's loss in case of default is $\beta\left(-\bar{b}+\rho y_{\min }^{i}\right)$.

The second derivative of the Laffer curve is:

$$
\begin{aligned}
D^{\prime \prime}(b)= & -\beta \pi \frac{d \bar{\epsilon}}{d b}\left[g(\bar{\epsilon})+\frac{\Phi}{\Phi+\left(1-\alpha^{i, i}\right) \rho}\left(g(\bar{\epsilon})+\bar{\epsilon} g^{\prime}(\bar{\epsilon})\right)\right] \\
& -\beta(1-\pi) \frac{d \underline{\epsilon}}{d b}\left[g(\underline{\epsilon})+\frac{\Phi}{\Phi+\rho \alpha^{i, u}} g(\underline{\epsilon})+g^{\prime}(\underline{\epsilon}) \frac{\Phi \underline{\epsilon}+\kappa y_{1}^{g} / \bar{y}_{1}^{i}}{\Phi+\rho \alpha^{i, u}}\right]
\end{aligned}
$$

The first term is negative under assumption 3. The second term is also negative under assumption 3, unless $g^{\prime}(\epsilon)$ becomes too negative.

Assumption 5. The parameters of the problem are such that $D^{\prime \prime}(b)<0$ for $b<\hat{b}$.

[Note: with a uniform distribution, this condition is satisfied since $g^{\prime}(\underline{\epsilon})=0$.]

We can check that:

$$
D^{\prime}\left(\hat{b}^{-}\right)=\beta\left[(1-\pi)(1-G(\underline{\epsilon}))-\frac{\pi g\left(\epsilon_{\max }\right) \epsilon_{\max } \Phi}{\Phi+\rho\left(1-\alpha^{i, i}\right)}-(1-\pi) g(\underline{\epsilon}) \frac{\Phi \underline{\epsilon}+\kappa y_{1}^{g} / \bar{y}_{1}^{i}}{\Phi+\rho \alpha^{i, u}}\right]
$$

- As $\hat{b}<b \leq \tilde{b}$ where $\tilde{b} \equiv\left(\left(\Phi+\rho \alpha^{i, u}\right) y_{\max }^{i}+\kappa y_{1}^{g}\right) / \alpha^{i, u}$, we have $\epsilon_{\min }<\underline{\epsilon} \leq \epsilon_{\max }<\bar{\epsilon}$ and now the only way 
for $i$ to repay its debts is with a transfer from $g$.

$$
D(b)=\beta\left(b(1-\pi)(1-G(\underline{\epsilon}))+\rho \bar{y}_{1}^{i}\left(\pi \int_{\underline{\epsilon}(b)}^{\epsilon_{\max }} \epsilon d G(\epsilon)+\int_{\epsilon_{\min }}^{\underline{\epsilon}(b)} \epsilon d G(\epsilon)\right)\right)+\bar{\lambda}^{i}
$$

The derivative satisfies:

$$
D^{\prime}(b)=\beta\left[(1-\pi)(1-G(\underline{\epsilon}))-(1-\pi) g(\underline{\epsilon}) \frac{\Phi \underline{\epsilon}+\kappa y_{1}^{g} / \bar{y}_{1}^{i}}{\Phi+\rho \alpha^{i, u}}\right]
$$

Evaluating this expression at $b=\hat{b}^{+}$, there is an upwards discontinuity in the Laffer curve:

$$
\begin{aligned}
D^{\prime}\left(\hat{b}^{+}\right)-D^{\prime}(\hat{b}-) & =\left.\beta\left(\hat{b}-\rho y_{\max }^{i}\right) \pi g\left(\epsilon_{\max }\right) \frac{d \bar{\epsilon}}{d b}\right|_{b=\hat{b}} \\
& =\beta \pi \frac{\Phi g\left(\epsilon_{\max }\right) \epsilon_{\max }}{\Phi+\rho\left(1-\alpha^{i, i}\right)} \geq 0
\end{aligned}
$$

This upwards discontinuity arises because, at $b=\hat{b}$, an infinitesimal increase in debt pushes $\bar{\epsilon}$ above $\epsilon_{\max }$. The increase in the threshold becomes inframarginal and does not affect the value of the debt anymore (since the realizations where $\epsilon>\bar{\epsilon}$ cannot be achieved anymore).

At $b=\tilde{b}$, the derivative of the Laffer curve satisfies:

$$
D^{\prime}\left(\tilde{b}^{-}\right)=-\beta(1-\pi) g\left(\epsilon_{\max }\right) \frac{\Phi \epsilon_{\max }+\kappa y_{1}^{g} / \bar{y}_{1}^{i}}{\Phi+\rho \alpha^{i, u}} \leq 0
$$

so the peak of the Laffer curve occurs necessarily at or before $\tilde{b}$.

The second derivative satisfies:

$$
D^{\prime \prime}(b)=-\beta(1-\pi) \frac{d \underline{\epsilon}}{d b}\left[g(\underline{\epsilon})+\frac{\Phi}{\Phi+\rho \alpha^{i, u}} g(\underline{\epsilon})+g^{\prime}(\underline{\epsilon}) \frac{\Phi \underline{\epsilon}+\kappa y_{1}^{g} / \bar{y}_{1}^{i}}{\Phi+\rho \alpha^{i, u}}\right]
$$

which is still negative under assumption 5 .

The discontinuity at $\hat{b}$ could be problematic for our optimization problem. Consequently, we make assumptions to ensure that the peak of the Laffer curve occurs at or before $\hat{b}$. A sufficient assumption is that $D^{\prime}\left(\hat{b}^{+}\right)<0$.

Assumption 6. We assume that the parameters of the problem are such that

$$
D^{\prime}\left(\hat{b}^{+}\right)=\beta(1-\pi)\left[1-G(\underline{\epsilon})-g(\underline{\epsilon}) \frac{\Phi \underline{\epsilon}+\kappa y_{1}^{g} / \bar{y}_{1}^{i}}{\Phi+\rho \alpha^{i, u}}\right]<0
$$

Under this assumption, the Laffer curve reaches its maximum at $0<b_{\max }<\hat{b}$ such that $0 \in \partial D\left(b_{\max }\right)$, where $\partial D(b)$ is the sub-differential of the Laffer curve at $b$. The peak of the Laffer curve cannot be reached at $\hat{b}$ or beyond since $D^{\prime}\left(\hat{b}^{-}\right)<D^{\prime}\left(\hat{b}^{+}\right)<0$, so $0 \notin \partial D(\hat{b})$ and $D^{\prime \prime}(b)<0$ for $b<\tilde{b}$. It follows immediately that $b_{\max }<\hat{b}$.

The economic interpretation of this assumption is that we restrict the problem so that the maximum revenues that $i$ can generate by issuing debt in period 0 do not correspond to levels of debt so elevated that no realization 
of $\epsilon$ would allow $i$ to repay on its own. In other words, the implicit transfer and the recovery value of debt are limited.

- As $b>\tilde{b}$ we have $\epsilon_{\max }<\underline{\epsilon}$ so that default is inevitable, even with transfers and the Laffer curve becomes:

$$
D(b)=\beta \rho \bar{y}_{1}^{i}+\bar{\lambda}^{i}
$$

which does not depend on the debt level. Note that there is an upwards discontinuity at $\tilde{b}$ since $D^{\prime}(b)=0$ for $b>\tilde{b}$.

To summarize, under assumptions 2-6, the Laffer curve reaches its peak at $b_{\max }$ with $\bar{b} \leq b_{\max }<\hat{b}$. The Laffer curve is continuous, convex and exhibits two (downward) discontinuities of $D^{\prime}(b)$ on the interval $\left[0, b_{\text {max }}\right]$. Since $i$ will never locate itself on the 'wrong side' of the Laffer curve $\left(b>b_{\max }\right)$, we can safely ignore the non-convexity associated with the upward discontinuities of the $D^{\prime}(b)$ at $\hat{b}$ and $\tilde{b}$.

- For the sake of completeness, the remaining discussion describes what happens if $\bar{b}>\hat{b}$ (the reverse condition on the parameters). In that case, as $b$ increases, the country stops being able to repay on its own first. This leads to a somewhat implausible case where the only reason debts are repaid is because of the transfer. We would argue that this is not a very interesting or realistic case.

- When $\underline{b}<b \leq \hat{b}<\bar{b}$. In that case, we have $\underline{\epsilon}<\epsilon_{\min } \leq \bar{\epsilon}<\epsilon_{\max }$. When $b=\hat{b}, \underline{\epsilon}<\epsilon_{\min }<\bar{\epsilon}=\epsilon_{\max }$. Default can occur if $\epsilon_{1}^{i} \leq \bar{\epsilon}$ and ex-post transfers are forbidden. It follows that

$$
D\left(b_{1}\right)=\beta\left[b_{1}(1-\pi G(\bar{\epsilon}))+\rho \bar{y}_{1}^{i} \pi \int_{\epsilon_{\min }}^{\bar{\epsilon}} \epsilon d G(\epsilon)\right]+\bar{\lambda}^{i}
$$

and the slope of the Laffer curve is given by

$$
D^{\prime}(b)=\beta\left[1-\pi G(\bar{\epsilon})-\frac{\pi \bar{\epsilon} g(\bar{\epsilon}) \Phi}{\Phi+\rho\left(1-\alpha^{i, i}\right)}\right]
$$

As before, default is a direct consequence of the commitment not to bail-out country $i$ in period $t=1$. The derivative of the Laffer curve is discontinuous at $b=\underline{b}$ if the distribution of shocks is such that $g\left(\epsilon_{\min }\right)>0$ and $\pi>0 .{ }^{67}$

Under the same assumptions as before, the Laffer curve slopes up at $b=\underline{b}$.

The second derivative of the Laffer curve is:

$$
D^{\prime \prime}(b)=-\beta \pi \frac{d \bar{\epsilon}}{d b}\left[g(\bar{\epsilon})+\frac{\Phi}{\Phi+\left(1-\alpha^{i, i}\right) \rho}\left(g(\bar{\epsilon})+\bar{\epsilon} g^{\prime}(\bar{\epsilon})\right)\right]
$$

and we can to ensure that $D^{\prime \prime}(b)<0$ with:

$$
\frac{\epsilon g^{\prime}(\epsilon)}{g(\epsilon)}>-2
$$

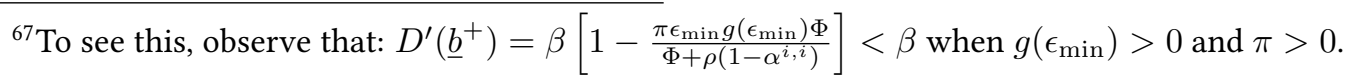


- When $\hat{b}<b<\bar{b}$, we have $\underline{\epsilon} \leq \epsilon_{\min }<\epsilon_{\max }<\bar{\epsilon}$. It follows that

$$
D(b)=\beta b(1-\pi)+\beta \pi \rho \bar{y}_{1}^{i}+\bar{\lambda}^{i}
$$

which has a constant positive slope $\beta(1-\pi)$. At $b=\hat{b}$ the slope is discontinuous, with

$$
D^{\prime}\left(\hat{b}^{-}\right)=\beta\left[1-\pi-\frac{\pi \epsilon_{\max } g\left(\epsilon_{\max }\right) \Phi}{\Phi+\rho\left(1-\alpha^{i, i}\right)}\right]
$$

so there is an upwards discontinuity in the slope at $b=\hat{b}$.

- for $\bar{b}<\tilde{b}$ we have $\epsilon_{\min }<\underline{\epsilon}<\epsilon_{\max }<\bar{\epsilon}$ and it is now possible to default even with optimal transfers. The Laffer curve satisfies

$$
D\left(b_{1}\right)=\beta\left[b_{1}\left((1-\pi)(1-G(\underline{\epsilon}))+\rho \bar{y}_{1}^{i}\left(\pi \int_{\underline{\epsilon}}^{\epsilon_{\max }} \epsilon d G(\epsilon)+\int_{\epsilon_{\min }}^{\underline{\epsilon}} \epsilon d G(\epsilon)\right)\right]+\bar{\lambda}^{i}\right.
$$

with slope:

$$
D^{\prime}\left(b_{1}\right)=\beta(1-\pi)\left[\left(1-G(\underline{\epsilon})-g(\underline{\epsilon}) \frac{\Phi \underline{\epsilon}+\kappa y_{1}^{g} / \bar{y}_{1}^{i}}{\Phi+\rho \alpha^{i, u}}\right]\right.
$$

One can check that the slope of the Laffer curve is discontinuous also at $b=\bar{b}$ as long as $\pi<1$ and $g\left(\epsilon_{\min }\right)>0$ with:

$$
D^{\prime}\left(\bar{b}^{+}\right)-D^{\prime}\left(\bar{b}^{-}\right)=-\beta(1-\pi) g\left(\epsilon_{\min }\right) \frac{\Phi \epsilon_{\min }+\kappa y_{1}^{g} / \bar{y}_{1}^{i}}{\Phi+\rho \alpha^{i, u}}<0
$$

At $b=\tilde{b}$, the derivative satisfies:

$$
D^{\prime}\left(\tilde{b}^{-}\right)=-\beta(1-\pi) g\left(\epsilon_{\max }\right) \frac{\Phi \epsilon_{\max }+\kappa y_{1}^{g} / \bar{y}_{1}^{i}}{\Phi+\rho \alpha^{i, u}}<0
$$

so the peak of the Laffer curve needs to occur before $\tilde{b}$.

The second derivative satisfies:

$$
D^{\prime \prime}(b)=-\beta(1-\pi) \frac{d \underline{\epsilon}}{d b}\left[g(\underline{\epsilon})+\frac{\Phi}{\Phi+\rho \alpha^{i, u}} g(\underline{\epsilon})+g^{\prime}(\underline{\epsilon}) \frac{\Phi \underline{\epsilon}+\kappa y_{1}^{g} / \bar{y}_{1}^{i}}{\Phi+\rho \alpha^{i, u}}\right]
$$

which is still negative as long as $g^{\prime}(\underline{\epsilon})$ is not too negative.

- As $b>\tilde{b}$ we have $\epsilon_{\max }<\underline{\epsilon}$ so that default is inevitable, even with transfers and the Laffer curve becomes:

$$
D(b)=\beta \rho \bar{y}_{1}^{i}+\bar{\lambda}^{i}
$$

which does not depend on the debt level. 


\section{Optimal Debt}

Let's consider the rollover problem of country $i$. The first order condition is

$$
\begin{aligned}
0 \in & \mu_{1}+\left(1-\alpha^{i, i}\right) \partial D\left(b_{1}^{i}\right)\left(1+\nu_{0}\right)-\beta(1-G(\bar{\epsilon}))\left(1-\alpha^{i, i}\right) \\
& \nu_{0} c_{0}^{i}=0 \\
& \mu_{1} b_{1}^{i}=0
\end{aligned}
$$

We consider first an interior solution and ignore the non-continuity of $D^{\prime}(b)$ at $\underline{b}$ and $\bar{b}$. The first-order condition becomes:

$$
D^{\prime}\left(b_{1}^{i}\right)=\beta(1-G(\bar{\epsilon}))
$$

Both sides of this equation are decreasing in $b$.

- Consider first the region $0 \leq b_{1}^{i}<\underline{b}$. Over that range, debt is safe: $D^{\prime}(b)=\beta$ and $G(\bar{\epsilon})=0$. The first order condition is trivially satisfied: since debt is safe, risk neutral agents price the debt at $\beta$ and $i$ is indifferent as to the amount of debt it issues as long as it can ensure positive consumption.

- Consider now the interval $\underline{b}<b_{1}^{i}<\bar{b}$. We need to consider two cases.

- when $\pi=0, g$ always bails out $i$ and $i$ 's debt is safe. This implies $D^{\prime}\left(b_{1}^{i}\right)=\beta$ and

$$
D^{\prime}(b)-\beta(1-G(\bar{\epsilon}))=\beta G(\bar{\epsilon})>0
$$

so there is no solution in that interval: $i$ would always want to issue more debt.

- when $\pi=1, i$ defaults when $b>\underline{b}$. Going back to the definition of $D^{\prime}\left(b_{1}^{i}\right)$ and $\bar{\epsilon}$ we can check that

$$
D^{\prime}(b)-\beta(1-G(\bar{\epsilon}))=-\beta \frac{\Phi}{\Phi+\rho\left(1-\alpha^{i, i}\right)} g(\bar{\epsilon}) \bar{\epsilon}<0
$$

from which it follows that there is no solution in that interval: $i$ would always want to issue less debt to remain safe.

- In the intermediate case where $0<\pi<1$, it is possible to find a solution to the first-order condition. However, under reasonable conditions the second-order condition of the optimization problem will not be satisfied. This will be the case if $D^{\prime}(b)-\beta(1-G(\bar{\epsilon})$ is increasing. A sufficient condition is that $g / G$ is monotonously decreasing. To see this, observe that for $\underline{b}<b \leq \bar{b}$, we have $\underline{\epsilon}<\epsilon_{\min }$ and therefore we can write:

$$
D^{\prime}(b)-\beta(1-G(\bar{\epsilon}))=\beta(1-\pi) G(\bar{\epsilon})\left[1-\frac{\pi}{1-\pi}\left(b-\rho \bar{y}_{1}^{i} \bar{\epsilon}\right) \frac{g(\bar{\epsilon})}{G(\bar{\epsilon})} \frac{d \bar{\epsilon}}{d b}\right]
$$

The term in brackets is increasing in $\bar{\epsilon}$ when $g / G$ is decreasing. If this condition is satisfied, then there is no solution in the interval $(\underline{b}, \bar{b})$. [Note: this condition is satisfied for a uniform distribution.]

- Consider next the interval $\bar{b} \leq b<\hat{b}$. We already know under the assumptions laid out in section B that we only need to consider the subinterval $\left(\bar{b}, b_{\max }\right)$ where $b_{\max }$ is the value of the debt that maximizes period 1 revenues. Let's consider the various values of $\pi$ again: 
- for $\pi=0$, we have $D^{\prime}\left(\bar{b}^{-}\right)=\beta$ and $D^{\prime}\left(b_{\max }\right)=0$. Since $D^{\prime}(b)-\beta(1-G(\bar{\epsilon}))$ is continuous over that interval, then there is at least one solution to the first-order condition, possibly at $b=\bar{b}$. This solution is unique if $D^{\prime}(b)-\beta(1-G(\bar{\epsilon}))$ is strictly decreasing over that interval. Recall that over that interval we have:

$$
\begin{aligned}
D^{\prime}(b)-\beta(1-G(\bar{\epsilon})) & =\beta\left[G(\bar{\epsilon})-G(\underline{\epsilon})-g(\underline{\epsilon})\left(b-\rho \bar{y}_{1}^{i} \underline{\epsilon}\right) \frac{d \underline{\epsilon}}{d b}\right] \\
& =\beta\left[G(\bar{\epsilon})-G(\underline{\epsilon})-g(\underline{\epsilon}) \frac{\Phi \underline{\epsilon}+\kappa y_{1}^{g} / \bar{y}_{1}^{i}}{\Phi+\rho \alpha^{i}, u}\right]
\end{aligned}
$$

The condition that $D^{\prime}(b)-\beta(1-G(\bar{\epsilon}))$ is decreasing over this range is satisfied for a uniform distribution if $\alpha^{i, g}$ is not too high.

Let's denote the unique solution $b_{\text {opt }}$. If $D^{\prime}\left(\bar{b}^{+}\right)<\beta(1-G(\bar{\epsilon}))$ then the solution is $b_{o p t}=\bar{b}$.

- for $\pi=1$ (no bailout), we can check that in that interval we can write

$$
D^{\prime}(b)-\beta(1-G(\bar{\epsilon}))=-\beta g(\bar{\epsilon})\left(b-\rho \bar{y}_{1}^{i} \bar{\epsilon}\right) \frac{d \bar{\epsilon}}{d b}<0
$$

Since $D^{\prime}\left(\bar{\epsilon}^{+}\right)<\beta(1-G(\bar{\epsilon}))$, it follows that there is no solution over that interval.

- For intermediate values of $\pi$, as long as $\pi$ is not too high, we will have a unique solution $b_{\text {opt }}$ as before. $b_{\text {opt }}$ is decreasing in $\pi$ for $\pi<\pi_{c}$. Above this critical value, this equilibrium disappears and the only remaining solutions are for $b \leq \underline{b} . \pi_{c}$ is characterized by the condition that $D^{\prime}\left(\bar{b}^{-}\right)=\beta(1-G(\bar{\epsilon}))$. Substituting, we obtain:

$$
\pi_{c}=\frac{G(\bar{\epsilon})}{G(\bar{\epsilon})+\frac{\Phi g(\bar{\epsilon}) \bar{\epsilon}}{\Phi+\rho\left(1-\alpha^{i, i}\right)}}
$$

In the case where there is no recovery, the formula for $\pi_{c}$ simplifies to

$$
\pi_{c}=\frac{1}{1+g(\bar{\epsilon}) \bar{\epsilon} / G(\bar{\epsilon})}
$$

These results are summarized in Fig. 9. The figure reports, for the case of a uniform distribution the function $\beta(1-G(\bar{\epsilon}(b)))$ (in black) and the function $D^{\prime}(b)$ (in blue). There are two discontinuities of the function $D^{\prime}(b)$ at $b=\underline{b}$ and $b=\bar{b}$. In red, the figure reports the possible optimal equilibrium debt levels. For $b \leq \underline{b}$ the debt is safe and any level -if sufficient to rollover the debt- provides equivalent level of utility; $b_{\text {opt }} \geq \bar{b}$ is the optimal level of risky debt when the rollover constraint $\left(c_{0}^{i} \geq 0\right)$ does not bind. Finally, $b_{o p t}<b \leq b_{\max }$ obtains when the rollover constraint binds (i.e. $c_{0}^{i}=0$ and $D(b)=x_{0}^{i}{ }^{68}$

\footnotetext{
${ }^{68}$ As can be seen on the figure, there is another solution to the first order condition between $\underline{b}$ and $\bar{b}$. However, this solution does not satisfy the second-order conditions.
} 


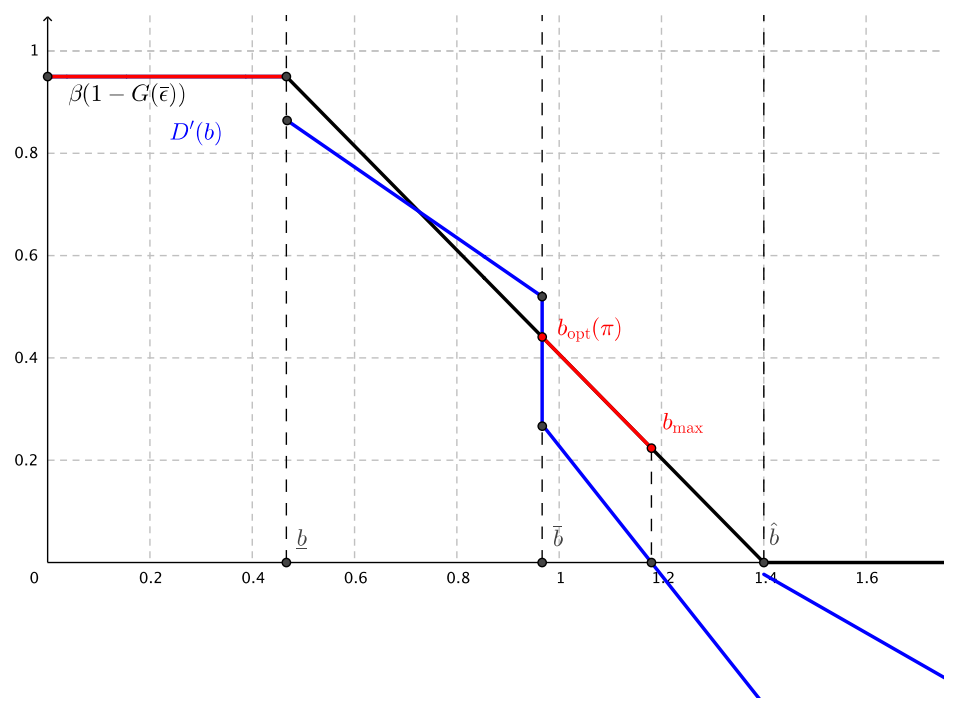

$D^{\prime}(b)$ and $\beta(1-G(\bar{\epsilon}))$ for $\pi=0.5$.

[Uniform distribution with $\rho=0.6, \Phi=0.2, \kappa=0.05, \epsilon_{\min }=0.5, \beta=0.95, \bar{y}_{1}^{i}=1, y_{1}^{g}=2, \alpha^{i, i}=0.4$, $\alpha^{i, g}=\alpha^{i, u}=0.3 . \underline{b}=0.47, \bar{b}=0.97$ and $\left.\hat{b}=1.4\right]$

Figure 9: Optimal Debt Issuance

\section{Exit and Default}

\section{D.1 Proof of Proposition 6.}

Proof. Denote D/ND the decision to default/repay and E/NE the decision to exit/stay in the currency union. Denote $\hat{b}$ the amount of debt held abroad, scaled by potential output: $\hat{b}=\left(1-\alpha^{i, i}\right) b_{1}^{i} / \bar{y}_{1}^{i}$. Denote also $\hat{\rho}=\rho\left(1-\alpha^{i, i}\right)$ the foreign debt holder's recovery rate per unit of output. $i$ prefers ND/NE to D/NE whenever:

$$
-\Phi_{d} \epsilon_{1}^{i}+\hat{b}-\hat{\rho} \epsilon_{1}^{i} \leq 0 \Longleftrightarrow \epsilon_{1}^{i} \geq \bar{\epsilon}=\frac{\hat{b}}{\Phi_{d}+\hat{\rho}}
$$

Similarly, $i$ prefers ND/E to D/E whenever

$$
-\Phi_{e} \epsilon_{1}^{i}+\Delta \hat{b} \geq-\left(\Phi_{d}+\Phi_{e}\right)+(1+\Delta) \hat{b}-\hat{\rho} \Longleftrightarrow \epsilon_{1}^{i} \geq \bar{\epsilon}^{d}
$$

It follows that $\bar{\epsilon}^{d}$ represents the cut-off for default decisions, regardless of exit decisions.

Now, by a similar reasoning, we can show that $i$ chooses to stay in the currency union whenever $\epsilon_{1}^{i} \geq \bar{\epsilon}^{e}$, regardless of the decision to default.

Under the assumption $\Delta / \Phi_{e}>1 /\left(\Phi_{d}+\rho\right)$, we have $\bar{\epsilon}^{d}>\bar{\epsilon}^{e}$ for all $\hat{b}$ and the proposition follows. 


\section{D.2 Proof of Proposition 7}

Proof. Let's define the minimal transfer to avoid a default $\underline{\tau}_{1}^{d}$ and the minimal transfer to avoid an exit $\underline{\tau}_{1}^{e}$. They satisfy:

$$
\begin{aligned}
\underline{\tau}_{1}^{d} & =\left(b_{1}^{i}-\rho y_{1}^{i}\right)\left(1-\alpha^{i, i}\right)-\Phi_{d} y_{1}^{i} \\
\underline{\tau}_{1}^{e} & =\Delta b_{1}^{i}\left(1-\alpha^{i, i}\right)-\Phi_{e} y_{1}^{i}
\end{aligned}
$$

Now, define $U_{g}\left(N D, N E, \tau_{1}\right)$ the utility of $g$ if there is no default (ND), no exit (NE) and transfer $\tau_{1}$. It satisfies:

$$
U_{g}\left(N D, N E, \tau_{1}\right)=x_{1}^{g}+b_{1}^{i} \alpha^{i, g}-\tau_{1}
$$

where $x_{1}^{g}=y_{1}^{g}+b_{1}^{s, g}-b_{1}^{g}$ is constant regardless of the transfers and $i$ 's decision. Similarly, we can define:

$$
\begin{aligned}
U_{g}\left(D, N E, \tau_{1}\right) & =x_{1}^{g}-\kappa_{d} y_{1}^{g}+\rho y_{1}^{i} \alpha^{i, g}-\tau_{1} \\
U_{g}\left(N D, E, \tau_{1}\right) & =x_{1}^{g}-\kappa_{e} y_{1}^{g}+b_{1}^{i} \alpha^{i, g}-\Delta b \alpha^{i, g}-\tau_{1} \\
U_{g}(D, E) & =x_{1}^{g}-\left(\kappa_{d}+\kappa_{e}\right) y_{1}^{g}+\rho y_{1}^{i} \alpha^{i, g}-\Delta b \alpha^{i, g}
\end{aligned}
$$

where we note that $g$ will never make a transfer if $i$ defaults and exits. Consider now the following cases:

- When $\epsilon_{1}^{i} \geq \bar{\epsilon}^{d}$. Since $i$ does not want to default or exit, no transfer is necessary: $\tau_{1}=0$.

- When $\bar{\epsilon}^{d}>\epsilon_{1}^{i} \geq \bar{\epsilon}^{e}, i$ prefers to default and exit. To prevent this, $g$ must make a transfer $\underline{\tau}_{1}^{d}$. This is optimal as long as $U_{g}\left(N D, N E, \underline{\tau}_{1}^{d}\right)>U_{g}(D, N E, 0)$. This condition takes the form:

$$
\Phi_{d} y_{1}^{i}+\kappa_{d} y_{1}^{g} \geq\left(b_{1}^{i}-\rho y_{1}^{i}\right) \alpha^{i, u}
$$

or equivalently:

$$
\epsilon_{1}^{i} \geq \underline{\epsilon}^{d} \equiv \frac{\alpha^{i, u} b_{1}^{i} / \bar{y}_{1}^{i}-\kappa_{d} y_{1}^{g} / \bar{y}_{1}^{g}}{\Phi_{d}+\rho \alpha^{i, u}}
$$

where $\underline{\epsilon}^{d}<\bar{\epsilon}^{d}$. It follows that:

- When $\bar{\epsilon}^{d}>\epsilon_{1}^{i} \geq \underline{\epsilon}^{d}, g$ makes the transfer $\underline{\tau}_{1}^{i}$ and there is no default

- When $\underline{\epsilon}^{d}>\epsilon_{1}^{i} \geq \bar{\epsilon}^{e}, g$ does not make a transfer $\left(\tau_{1}=0\right), i$ defaults, but without exiting.

- $\bar{\epsilon}^{e}>\epsilon_{1}^{i}, i$ prefers to default and exit without transfer. $g$ can consider two types of transfer: $\underline{\tau}_{1}^{e}$ to avoid the exit (but not the default) or $\underline{\tau}_{1}^{d}+\underline{\tau}_{1}^{e}$ to avoid both default and exit. Consider first a transfer to avoid exit. This is optimal as long as $U_{g}\left(D, N E, \underline{\tau}_{1}^{e}\right)>U_{g}(D, E)$. This condition takes the form:

$$
\Phi_{e} y_{1}^{i}+\kappa_{e} y_{1}^{g}>\Delta b \alpha^{i, u}
$$

or equivalently

$$
\epsilon_{1}^{i} \geq \underline{\epsilon}^{e} \equiv \frac{\Delta \alpha^{i, u} b_{1}^{i} / \bar{y}_{1}^{i}-\kappa_{e} y_{1}^{g} / \bar{y}_{1}^{i}}{\Phi_{e}}
$$


where $\underline{\epsilon}^{e}<\bar{\epsilon}^{e}$, and it yields the following utility for $g$ :

$$
U_{g}\left(D, N E, \underline{\tau}_{1}^{e}\right)=x_{1}^{g}-\kappa_{d} y_{1}^{g}+\rho y_{1}^{i} \alpha^{i, g}-\Delta b_{1}^{i}\left(1-\alpha^{i, i}\right)+\Phi_{e} y_{1}^{i}
$$

Now, within that region, $g$ prefers to make a transfer $\underline{\tau}_{1}^{d}+\underline{\tau}_{1}^{e}$, to avoid both default and exit as long as $U_{g}\left(N D, N E, \underline{\tau}_{1}^{d}+\right.$ $\left.\underline{\tau}_{1}^{e}\right) \geq U_{g}\left(D, N E, \underline{\tau}_{1}^{e}\right)$ which takes the form:

$$
\Phi_{d} y_{1}^{i}+\kappa_{d} y_{1}^{g} \geq\left(b_{1}^{i}-\rho y_{1}^{i}\right) \alpha^{i, u}
$$

or equivalently:

$$
\epsilon_{1}^{i} \geq \underline{\epsilon}^{d}
$$

It follows that:

- When $\bar{\epsilon}^{e}>\epsilon_{1}^{i}>\underline{\epsilon}^{e}$ and $\epsilon_{1}^{i} \geq \underline{\epsilon}^{d}, g$ prefers to make the transfer $\underline{\tau}_{1}^{d}+\underline{\tau}_{1}^{e}$ to avoid default and exit.

- When $\bar{\epsilon}^{e}>\epsilon_{1}^{i}>\underline{\epsilon}^{e}$ and $\epsilon_{1}^{i}<\underline{\epsilon}^{d}, g$ makes the transfer $\underline{\tau}_{1}^{e}, i$ defaults but stays in the currency union

- When $\underline{\epsilon}_{1}^{e}>\epsilon_{1}^{i}, g$ makes no transfer $\left(\tau_{1}=0\right), i$ defaults and exits.

\section{E Debt Monetization}

This appendix provides a full characterization of the different cases that arise with possible debt monetization within a monetary union. They depend on the output shock realization $\epsilon_{1}^{i}$ and on the ranking of the output thresholds. We first analyze the decision to default of $i$ for a given transfer and inflation/monetization rate. If $i$ repays the ECB chooses the rate $z$ and if $i$ defaults it chooses the rate $\hat{z}$. The budget constraint in period 1 of the $i$ households becomes:

$$
\begin{aligned}
& c_{1}^{i}=y_{1}^{i}-T_{1}^{i}+\left(b_{1}^{i, i}+b_{1}^{g, i}\right)(1-z)-\delta z y_{1}^{i}+b_{1}^{u, i} \quad \text { if } i \text { repays } \\
& c_{1}^{i}=y_{1}^{i}(1-\Phi)-T_{1}^{i}+b_{1}^{g, i}(1-\hat{z})-\delta \hat{z} y_{1}^{i}+b_{1}^{u, i} \quad \text { if } i \text { defaults }
\end{aligned}
$$

Government $i$ constraint in $t=1$ is:

$$
\begin{aligned}
T_{1}^{i}+\tau_{1} & =b_{1}^{i}(1-z) \quad \text { if } i \text { repays } \\
T_{1}^{i} & =0 \quad \text { if } i \text { defaults }
\end{aligned}
$$

Consolidating the private and public budget constraints, we again proceed by backward induction. At $t=1, i$ can decide to default after the shock $\epsilon_{1}^{i}$ has been revealed and the transfer $\tau_{1}$ announced. Taking $b_{1}^{i}$ and $\tau_{1}$ as given, $i$ repays if and only if:

$$
y_{1}^{i}[\Phi-\delta(z-\hat{z})] \geq b_{1}^{i}\left(1-\alpha^{i, i}\right)(1-z)+(z-\hat{z}) b_{1}^{g} \alpha^{g, i}-\tau_{1}
$$

For $g$, the budget constraint is:

$$
c_{1}^{g}=y_{1}^{g}-T_{1}^{g}+\left(b_{1}^{i, g}+b_{1}^{g, g}\right)(1-z)-\delta z y_{1}^{g}+b_{1}^{u, g} \quad \text { if } i \text { repays }
$$




$$
c_{1}^{g}=y_{1}^{g}(1-\kappa)-T_{1}^{g}+b_{1}^{g, g}(1-\hat{z})-\delta \hat{z} y_{1}^{g}+b_{1}^{u, g} \quad \text { if } i \text { defaults }
$$

and $g$ government constraint in $t=1$ is:

$$
\begin{aligned}
T_{1}^{g}-\tau_{1} & =b_{1}^{g}(1-z) & & \text { if } i \text { repays } \\
T_{1}^{g} & =b_{1}^{g}(1-\hat{z}) & & \text { if } i \text { defaults }
\end{aligned}
$$

We now detail the different relevant thresholds:

- No default, no monetization, no transfer. Comparison made when $z=0$ in no default and default. Necessary conditions on output shock:

$$
\begin{aligned}
& \epsilon_{1}^{i}>\frac{b_{1}^{i} \alpha^{i u}-\kappa y_{1}^{g}}{\Phi \bar{y}_{1}^{i}} \equiv \bar{\epsilon}^{\prime \prime} \quad \text { ECB and g prefer no default to default with } z=0 \text { in both cases } \\
& \epsilon_{1}^{i}>\frac{b_{1}^{i} \alpha^{i u}+b_{1}^{g} \alpha^{g u}}{\delta \bar{y}_{1}^{i}}-\frac{y_{1}^{g}}{\bar{y}_{1}^{i}} \equiv \overline{\bar{\epsilon}} \quad \text { ECB prefers } z=0 \text { in no default } \\
& \epsilon_{1}^{i}>\frac{\alpha^{g u} b_{1}^{g}-\delta y_{1}^{g}}{\delta \bar{y}_{1}^{i}} \equiv \hat{\epsilon} \quad \text { ECB chooses } z=0 \text { in case of default } \\
& \epsilon_{1}^{i}>\frac{b_{1}^{i}\left(1-\alpha^{i i}\right)}{\Phi \bar{y}_{1}^{i}} \equiv \bar{\epsilon}^{\prime} \quad i \text { repays with zero transfer and } z=0
\end{aligned}
$$

- No default, no monetization, positive transfer Necessary conditions on output shock:

$$
\begin{aligned}
& \epsilon_{1}^{i}>\bar{\epsilon}^{\prime \prime} \quad \text { ECB and g prefer no default to default with } z=0 \text { in both cases } \\
& \epsilon_{1}^{i}>\overline{\bar{\epsilon}} \quad \text { ECB prefers } z=0 \text { in case of no default } \\
& \epsilon_{1}^{i}<\bar{\epsilon}^{\prime} \quad i \text { repays only with transfer and } z=0
\end{aligned}
$$

- No default, monetization at maximum rate, no transfer Comparison made when $z=\bar{z}$ in no default and $z=0$ in case of default.

$$
\begin{aligned}
& \epsilon_{1}^{i}<\overline{\bar{\epsilon}} \quad \text { ECB prefers } z=\bar{z} \text { in no default } \\
& \epsilon_{1}^{i}>\frac{\left(1-\alpha^{i i}\right) b_{1}^{i}(1-\bar{z})+\alpha^{g i} b_{1}^{g} \bar{z}}{(\Phi-\delta \bar{z}) \bar{y}_{1}^{i}} \equiv \tilde{\epsilon} \quad i \text { repays with zero transfer with } z=\bar{z}
\end{aligned}
$$

- No default, monetization at maximum rate, positive transfer Comparison made when $z=\bar{z}$ in no default and $z=0$ in case of default.

$$
\begin{aligned}
& \epsilon_{1}^{i}<\overline{\bar{\epsilon}} \text { ECB prefers } z=\bar{z} \text { in no default } \\
& \epsilon_{1}^{i}>\frac{\alpha^{i u} b_{1}^{i}(1-\bar{z})-\alpha^{g u} b_{1}^{g} \bar{z}-y_{1}^{g}(\kappa-\delta \bar{z})}{(\Phi-\delta \bar{z}) \bar{y}_{1}^{i}} \equiv \underline{\epsilon}^{\prime} \quad g \text { prefers no default, transfer and } z=\bar{z}
\end{aligned}
$$




$$
\epsilon_{1}^{i}<\frac{\left(1-\alpha^{i, i}\right) b_{1}^{i}(1-\bar{z})+\alpha^{g i} b_{1}^{g} \bar{z}}{(\Phi-\delta \bar{z}) \bar{y}_{1}^{i}} \equiv \tilde{\epsilon} \quad i \text { repays only with transfer with } z=\bar{z}
$$

In this case, the transfer is the minimum that leaves $i$ indifferent between default and no default (see equation 34).

\section{- Default, no monetization, no transfer}

Comparison made when $z=\bar{z}$ in no default and $z=0$ in case of default.

$$
\begin{aligned}
\epsilon_{1}^{i} & <\overline{\bar{\epsilon}} \text { ECB prefers } z=\bar{z} \text { in no default } \\
\epsilon_{1}^{i} & <\frac{\alpha^{i u} b_{1}^{i}(1-\bar{z})-\alpha^{g u} b_{1}^{g} \bar{z}-y_{1}^{g}(\kappa-\delta \bar{z})}{(\Phi-\delta \bar{z}) \bar{y}_{1}^{i}} \equiv \underline{\epsilon}^{\prime} \quad g \text { prefers default, no transfer } \\
\epsilon_{1}^{i} & >\frac{\alpha^{g u} b_{1}^{g}-\delta y_{1}^{g}}{\delta \bar{y}_{1}^{i}} \equiv \hat{\epsilon} \quad \text { ECB chooses } z=0 \text { in default }
\end{aligned}
$$

\section{- Default, monetization, no transfer}

Comparison made with $z=\bar{z}$ in both cases:

$$
\begin{aligned}
\epsilon_{1}^{i} & <\frac{\alpha^{i u} b_{1}^{i}(1-\bar{z})-\kappa y_{1}^{g}}{\Phi \bar{y}_{1}^{i}} \equiv \underline{\epsilon}^{\prime \prime} \quad g \text { prefers default, no transfer and } z=\bar{z} \\
\epsilon_{1}^{i} & <\frac{\alpha^{g, u} b_{1}^{g}-\delta y_{1}^{g}}{\delta \bar{y}_{1}^{i}} \equiv \hat{\epsilon} \quad \text { ECB chooses } z=\bar{z} \text { in default }
\end{aligned}
$$

There are therefore 7 thresholds for output realizations: $\overline{\bar{\epsilon}} ; \bar{\epsilon}^{\prime} ; \bar{\epsilon}^{\prime \prime} ; \hat{\epsilon} ; \tilde{\epsilon} ; \underline{\epsilon}^{\prime} ; \underline{\epsilon}^{\prime \prime}$. In addition, we assume there is a minimum and maximum output realization $\epsilon^{\max }$ and $\epsilon^{\min }$.

We can rank some of them under the assumption that $\Phi>\kappa>\delta: \underline{\epsilon}^{\prime}<\bar{\epsilon}^{\prime} ; \underline{\epsilon}^{\prime \prime}<\bar{\epsilon}^{\prime \prime} ; \hat{\epsilon}<\bar{\epsilon}^{\prime} ; \underline{\epsilon}^{\prime \prime}<\underline{\epsilon}^{\prime} ; \tilde{\epsilon}>\underline{\epsilon}^{\prime}$

To simplify the analysis, we focus on parameter configurations that are most interesting and most plausible for the situation of the eurozone, we rank these thresholds based on the following general assumptions : $b_{1}^{g}$ is small relative $y_{1}^{g}$ and to $b_{1}^{i}$.

Assumptions on parameters: We can compare different cases with different degrees of fiscal dominance. Fiscal dominance would apply if the ECB inflates the eurozone debt even if $i$ defaults so that only $g$ debt remains. This is not a very interesting or plausible case so we ignore it and assume $\hat{\epsilon}<\epsilon^{\min }$ which means that we concentrate as before on relatively low levels of debt to GDP levels in $g$ and relatively high levels of the distortion costs $\delta$. Another polar case is one of monetary dominance. This is a situation with low levels of $g$ debt relative to GDP and high distortion costs $\delta$. A sufficient condition is: $\overline{\bar{\epsilon}}<\epsilon^{\text {min }}$. The ECB never inflates the debt in a situation where transfers are possible because transfers are sufficient and the ECB would never want to avert a default if it was not in $g$ interest which is also the interest of the Eurozone as whole. This case is identical to the one analyzed in section (4) where the role of the ECB was ignored.

- $\hat{\epsilon}<\epsilon^{\min }$ which insures that the ECB will choose a zero inflation rate in the case of default. This excludes the case of strong fiscal dominance.

$$
\frac{b_{1}^{g}}{y_{1}^{g}}<\frac{\delta}{\alpha^{g u}}\left(1+\frac{y_{1}^{i}}{y_{1}^{g}} \epsilon^{\min }\right)
$$

The condition on parameters is such that the debt to GDP ratio for $g$ is small enough. 


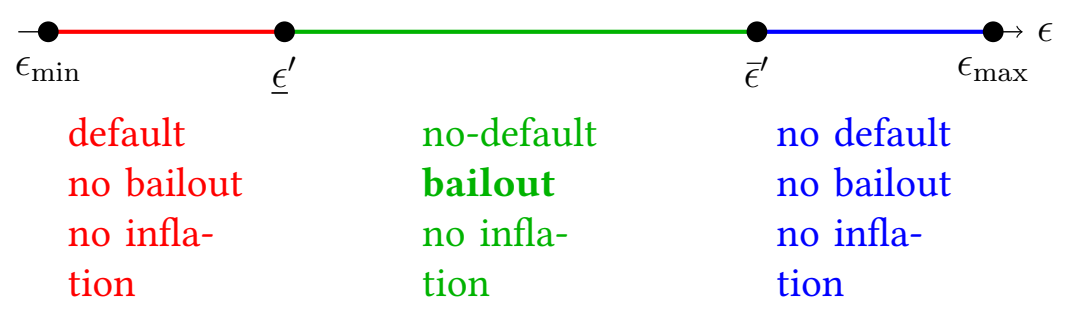

Figure 10: Bailout under Monetary Dominance

We then examine two cases: monetary dominance and weak fiscal dominance/.

- Monetary dominance: If $\overline{\bar{\epsilon}}<\underline{\epsilon}^{\prime}$, then when transfers are possible, the ECB never chooses positive inflation. This case is valid with high $y_{1}^{g}$ and $\delta$, and low $b_{1}^{g}$.

- Weak fiscal dominance: If $\bar{\epsilon}^{\prime}>\overline{\bar{\epsilon}}>\underline{\epsilon}^{\prime}$, then when transfers are possible, the ECB may choose positive inflation. This is the case with intermediate levels of $y_{1}^{g}$ and $\delta$, and low $b_{1}^{g}$.

Under monetary dominance, the possible equilibria are shown in figure 10. Only binding thresholds are indicated. Monetary policy does not affect transfers and the decision whether to default or not.

Under weak fiscal dominance, possible equilibria are shown in figure 7. In this case, when output realization in $i$ is sufficiently high $\left(\epsilon_{1}^{i}>\bar{\epsilon}^{\prime}\right)$, there is no default, no inflation and no transfer. If it is lower, $i$ requires a transfer in order not to default $\left(\bar{\epsilon}^{\prime}>\epsilon_{1}^{i}>\overline{\bar{\epsilon}}\right)$ but there is no inflation. For $\left.\overline{\bar{\epsilon}}>\epsilon_{1}^{i}>\underline{\epsilon}^{\prime}\right)$, the ECB partly inflates the debt, $g$ makes a transfer to avoid the default. For $\epsilon_{1}^{i}<\underline{\epsilon}^{\prime}$, the default is optimal and there is no more incentive to inflate the debt.

There are several conditions on output realizations and parameters for such a situation to exist:

$$
\begin{aligned}
\epsilon_{1}^{i} & <\overline{\bar{\epsilon}} \\
\epsilon_{1}^{i} & >\frac{\alpha_{1}^{i, u} b_{1}^{i}(1-\bar{z})-\alpha_{1}^{g u} b_{1}^{g} \bar{z}-y_{1}^{g}(\kappa-\delta \bar{z})}{(\Phi-\delta \bar{z}) \bar{y}_{1}^{i}} \equiv \underline{\epsilon}^{\prime} \\
\epsilon_{1}^{i} & <\frac{\left(1-\alpha_{1}^{i, i}\right) b_{1}^{i}(1-\bar{z})+\alpha_{1}^{g, i} b_{1}^{g} \bar{z}}{(\Phi-\delta \bar{z}) \bar{y}_{1}^{i}} \equiv \tilde{\epsilon} \\
\hat{\epsilon} & <\epsilon^{m i n}<\underline{\epsilon}^{\prime}<\overline{\bar{\epsilon}}<\tilde{\epsilon}
\end{aligned}
$$

The first condition says that the output realization is such that the ECB sets $z=\bar{z}$, the second that $g$ prefers no default and transfer and the third that indeed $i$ requires a transfer when $z=\bar{z}$. These conditions apply for intermediate levels of the output realization $i$. The last condition on the ranking of thresholds requires in particular intermediate levels of debt (see appendix for details).

Finally, when transfers are excluded (and $\overline{\bar{\epsilon}}<\underline{\epsilon}^{\prime}$ so that monetary dominance applies with zero inflation in presence of transfers) the possible equilibria are shown in figure 8. When output realization in $i$ is sufficiently high $\left(\epsilon_{1}^{i}>\bar{\epsilon}^{\prime}\right)$, there is no default and no inflation. If it is lower, $i$ requires a positive inflation rate in order not to default $\left(\bar{\epsilon}^{\prime}>\epsilon_{1}^{i}>\tilde{\epsilon}\right)$. For $\epsilon_{1}^{i}<\tilde{\epsilon}$, the default is optimal and there is no more incentive to inflate the debt. 


\section{ONLINE DATA APPENDIX. Not for Publication}

The outline of this appendix is as follows. Section $\mathrm{F}$ documents how the data was constructed. Section $\mathrm{G}$ presents a historical overview of the bailouts for Cyprus, Greece, Ireland, Portugal, and Spain. Section I presents details regarding the "rolling" estimate of the size of the transfer for Greece over time.

\section{F Construction of the Dataset}

Depending on the official lender (e.g., IMF, ESM, etc.), the level of detail regarding the timing of disbursements, the repayment projections, and the estimated interest payments varies. Here, we report broadly how we construct disbursements, repayments, and interest payments by lender, and relegate specific details to Section G.

IMF Data for Cyprus, Greece, Ireland, Portugal, Hungary, Latvia, and Romania comes from the IMF website, which reports actual disbursements, actual and projected repayments of principal, and actual and projected interest payments. We use the listed SDR amounts for disbursements, repayments, and interest payments and convert these amounts to Euros by using the average realized EUR/SDR exchange rate prevailing during the month of the disbursement. For forecasted payments, we use the last observed date for the SDR/EUR exchange rate of October $2018 .{ }^{69}$

Realized flows come from the "Flows" database. Disbursements are those listed as "GRA Purchases," repayments are those listed as "GRA Repurchases," and interest payments are those listed as "GRA Charges." These include both GRA Charges and GRA Burden Sharing Charges. ${ }^{70}$ Projections come from the "Projections" database. Projected repayments are those listed as "GRA Repurchase." Interest payments are those listed as "GRA Charges".

EFSF and ESM Data for Cyprus, Greece, Ireland, and Portugal are available from the ESM website (the EFSF data is kept updated on this website as well). Actual disbursements and actual and projected repayment schedules are typically reported. In our baseline specification, we use the actual numbers and projections as of December 2019 to calculate the size of the transfer. For interest payments, we apply the historical blended rates as of December 2019, one each for EFSF and ESM loans, to the outstanding level of debt. We go into more detail on this interest rate in the Historical Overview section.

EFSM Data for disbursements and repayments, both realized and projected, for Ireland and Portugal come from the European Commission website. ${ }^{72}$ For interest payments, we apply the average cost of funding as of 2012. Realized interest payments are calculated by applying lending rates from European Commission (2012). For future interest payments, we include a term premium calculated using euribor OIS rates relative to the last observed euribor 3-month rate. We use the Bloomberg Tickers as in Du, Im and Schreger (2018).

GLF Data for Greece comes from the European Commission website and various reports therein. Data on disbursements and repayment schedules are available. To calculate interest rates, we add the reported margins to the end of period 3-month Euribor rate. To forecast 3-month Euribor rates, we again use the euribor OIS rates used in Du, Im and Schreger

\footnotetext{
${ }^{69}$ Since around 2008, there has been a secular depreciation of the Euro. To the extent that the Euro continues to depreciate, this would increase the size of the transfer payments. We therefore view our estimates as a lower bound with respect to this source of bias.

${ }^{70}$ This also includes one GRA SCA-1 Charge, which is listed as -1 .

${ }^{71}$ This excludes "SDR Assessments," which are levied annually to reimburse the IMF SDR department, and "Net SDR Charges," which are charges if a member holds too few SDRs.

${ }^{72}$ Note that Greece also benefitted from a one-month bridge loan from the EFSM in August 2015. However, due to the short nature of the loan, we do not model its transfer component.
} 
(2018) to calculate the term premium.

GDP Data for all countries comes from the Eurostat annual national accounts.

Inflation Data for all countries comes from the World Bank

\section{G Historical Overview}

The European Sovereign Debt Crisis dates back to at least March 2010, when Greece formally requested assistance from the rest of Europe. However, financial assistance to countries within Europe occurred earlier, during the Global Financial Crisis, at least since 2008. In this section, we follow the main text and discuss the details of the the lenders and borrowers during this time period, with an emphasis on the construction of our dataset. We begin by documenting broadly how the major lenders structured financial assistance during the European debt crisis. We then give a broad overview of the lending programmes for the Eurozone borrowers (Cyprus, Greece, Ireland, Portugal, and Spain). ${ }^{73}$ Finally, we discuss the lending programmes for the Non-Eurozone borrowers.

\section{G.1 The Lenders}

Established in 1945, the IMF's primary purpose is to "ensure the stability of the international monetary system."74 The IMF's lending structure is discussed at length in Joshi and Zettelmeyer (2005). The countries involved in the Eurocrisis are not low-income countries, which means their lending came through non-concessional facilities. The shorter programme available was the Stand-By Arrangement (SBA) where repayment is typically due within 3-5 years. However, most borrowing eventually came through the Extended Fund Facility (EFF), which allows for repayment within 4.5-10 years. Both of these facilities come with conditionality on achieving structural improvements.(IMF, 2016a)

The maximum amount a country can borrow through either the SBA or the EFF is $145 \%$ of their quota annually or $435 \%$ over the lifetime of a programme. During the European debt crisis, countries typically went over this amount by being given "exceptional access". The interest rate on these loans is a floating rate based on the SDR interest rate. The base rate is the standard rate of charge, which is given by the weekly SDR rate plus a margin (currently 100bp). On top of this, there is a surcharge for equal to $200 \mathrm{bp}$ on amounts greater than $187.5 \%$ of quota, and a higher surcharge of $300 \mathrm{bp}$ if the amount above $187.5 \%$ of quota is outstanding for at least 51 months.(IMF, 2017)

In addition to this variable rate, there are also two important fees. First, there is a one-time service charge of 50bp when ever a disbursement is drawn. Additionally, there is an upfront commitment fee based on the size of the programme (15bp if less than $115 \%$ of quota, $30 \mathrm{bp}$ if at least $115 \%$ but less than $575 \%$, and $60 \mathrm{bp}$ if greater than $575 \%$ ). This commitment fee is refunded over the lifetime of the programme. (IMF, 2018a)

Other than the IMF, the European community as the largest source of financial aid to distressed countries during the European debt crisis. The European Commission provided direct aid to Greece through the Greek Loan Facility and to Latvia, Hungary,a nd Romania through the Balance of Payments financial assistance facility. By direct aid, we refer to aid given not through the special purpose vehicles of the EFSF or the ESM, which we consider as separate loans. We discuss the Greek Loan Facility at length in Section I.

These loans carried similar interest rate schemes across the difference loan facilities. Interest rates for EFSF and ESM loans are equal to the cost of funding plus a margin. The cost of funding is typically given as a weighted average of interest rates on outstanding borrowing from investors. As discussed in this appendix, the margin was gradually reduced over time

\footnotetext{
${ }^{73}$ For another treatment of this history, see Corsetti, Erce and Uy (2017).

${ }^{74}$ See the "IMF at a Glance" on the IMF website. Note that since 2012 its mandate was updated to expand beyond exchange rates and balance of payments and include all macroeconomic and financial sector issues that bear on global stability.
} 
until, in most cases, it was equal to 0 . Just like in the case of the IMF, there is also a commitment fee and an upfront service fee of $50 \mathrm{bp} .^{75}$

The Medium-term Balance of Payments financial assistance facility was established on February 18, 2002 by EC No. 332/2002, and subsequently updated by EC No. 431/2009. This facility is for states who have not adopted the Euro. This lending is concessionary, which means a memorandum of understanding listing the required structural reforms is a precondition for aid, as well as monitoring during and after the country receives funds. Post-programme surveillance is required until at least $70 \%$ of the loan is repaid. ${ }^{76}$ Lending through the balance of payments financial assistance facility can be one of two types. In our sample, we study almost exclusively loans, however precautionary loans were also available for countries like Romania.

\section{G.2 Eurozone Programmes}

\section{G.2.1 Greece}

Greece entered three different programmes. The first programme came in the form of a series of bilateral loans from other Europea countries via the newly created Greek Loan Facility (GLF) and the International Monetary Fund (IMF) between 2010-2011. A second round of bailouts (Programme 2) came from the European Financial Stability Fund (EFSF) and the IMF between 2012-2015. Finally, a third round of bailouts (Programme 3), came from the European Stability Mechanism (ESM) between 2015-2018. This last programme ended in August 2018. In this section, we outline the state of the three Greek programmes as of August 2018. In Section I, we go into detail about the evolution of the Greek programmes in order to calculate the change in the NPV of the transfer over time.

The buildup to programme 1 involved substantial debate regarding its form, size, and participation. Although Greek's economic position was in dire straights by the end of 2009, it was not until March 2010 that the EC and ECB included the IMF due to the EC's inability to provide the amount of funding and expertise necessary for Greece. Programme 1 therefore involved disbursements by the IMF and the GLF. Disbursements by the IMF totaled $€ 20.1$ Billion over six tranches. ${ }^{778}$ The European Member states committed a total of $€ 80$ bn to Programme 1, although not all was disbursed. (EC (2012b),Eurogroup (2010)) The first disbursement of Programme 1 was in May 2010, with the sixth and final disbursement of Programme 1 coming in December 2011. Programme 1 disbursements totaled $€ 52.9$ bn by the European Members, with Germany ( $€ 15.17$ Billion), France (€11.39 Billion), and Italy (€10.00 Billion) contributing the most. (EC (2012c)) Originally, Ireland and Portugal were slated to contribute to Programme 1. However, their own fiscal struggles caused them to eventually drop out. Of the remaining members, Slovakia was the only to never participate.

The original loan agreement between Greece and the European Commission stipulated the structure of principal repayment and interest. This original loan agreement was officially amended three times: in June 2011, February 2012, and December 2012. (EFSF (2014), EFSF (2015), ESM (2017)) The December 2012 agreement extended the maximum weighted average maturity to 30 years. The February 2012 agreement lowered the interest rate margin to only 50 basis points each

\footnotetext{
${ }^{75}$ There are also a number of other fees. For example, in the initial FFA for Greece, there exited a guarantee commission fee of $10 \mathrm{bp}$, that was later cancelled in the case of Greece. There was also an annual service fee of $0.5 \mathrm{bp}$

${ }^{76}$ The statistic varies according to the source. The $70 \%$ statistic is taken from EC $(2017 a)$. However, $75 \%$ can be seen in Article 15 of EU (2013a)

${ }^{77}$ The IMF lends in Special Drawing Rights (SDRs). Throughout, we convert the SDR value to Euros using the prevailing SDR/EUR exchange rate at the time of the disbursement. For realized interest payments, we use the prevailing SDR/EUR exchange rate. For forecasted interest payments, we use the last observed value of the exchange rate.

${ }^{78}$ Whenever possible, we use the net disbursement amount, which is the financial assistance amount less the sum of issuance costs, upfront service fees, and negative carry costs.The exact details are stipulated in the FFAs for each country. These are the amounts expressed on the official websites.
} 
year. ${ }^{79}$. In calculating interest rates, we follow the amendments closely by using the prevailing margin at the time of the interest payment. We use the 3-month annualized Euribor as the base rate and add a 50bp margin. Interest is calculated as a quarterly rate derived from the annualized rate and paid in March, June, September, and December until outstanding debt is equal to zero.

The IMF's lending structure is discussed at length in Joshi and Zettelmeyer (2005). The countries involved in the Eurocrisis are not low-income countries, which means their lending came through non-concessional facilities. Greece originally borrowed through a Stand-By Arrangement (SBA) where repayment is typically due within 3-5 years. However, eventually all of their borrowing came through the Extended Fund Facility (EFF), which allows for repayment within 4.5-10 years. Both of these facilities come with conditionality on achieving structural improvements. (IMF (2016a)) The maximum amount a country can borrow through the EFF is typically $145 \%$ of a their quota annually or $435 \%$ over the lifetime of a programme. Programme 1, with $€ 30$ bn committed, was around 3,200\% of Greece's total Quota. Greece was permitted to go over the quota limit due to the IMF's special circumstances. ${ }^{80}$ The lending rate on all non-concessional facilities is tied to the Basic Rate of Charge, which is the SDR rate plus a premium that depends on the size of the loan relative to a country's quota. The margin is 100bp for loans less than $187.5 \%$ of Quota, 200bp for credit above $187.5 \%$ of Quota, and 300bp for credit above $187.5 \%$ of Quota for more than 51 months. (IMF (2017))

Programme 2 still involved the IMF, however the Eurogroup operated through the newly created EFSF. The EFSF committed a total of $€ 144.7$ Billion to Programme 2 over 2012-2014. (EC (2012b)) A total of approximately $€ 141.8$ Billion was disbursed, although $€ 10.9$ Billion was returned, leaving a net outstanding as of June 2018 of $€ 130.9$ Billion. ${ }^{81}$ Details on lending rates and maturties are given in the Master Financial Facility Agreement (FFA). Lending rates were calculated as the EFSF cost of funding plus some margin, although currently all margins are eliminated. The weighted average maturity of the loans, which had fallen to approximately 28 years, was lengthened to "update" the weighted average maturity back to the maximum permitted 32.5 years. The agreement also reduced interest rate risk via bond exchanges, swap arrangements, and matched funding. In June 2018, this agreement was modified again. While the official repayment schemes have not yet been determined, the maximum weighted average maturity was extended to 42.5 years, and interest payments were deferred by twenty years. ${ }^{82}$

In calculating interest payments, we set interest payments to begin in 2033. All interest payments prior to this time period, with the exception of the PSI loans, are rolled forward into a new loan set to be disbursed at that time. We set the annualized interest rate to be equal to the last value available from the ESM in August 2018 of 135bp. This interest paid annually in March. Our assumption implies both that all loans amortize at the same rate and that interest rates will not rise over the lifetime of the loans. This latter assumption is most likely false, as the base rate is tied to the cost of funding by the EFSF plus a margin, where the cost of funding includes borrowing rates by the EFSF. However, given the current very low interest rate environment, it is probable that interest rates will rise, implying that our interest payments are an upper bound on the size of the transfer in this respect. In robustness checks, we use market expectations of future interest rates. Note that as part of two debt relief agreements, interest payments were deferred for 10 years each. Hence, interest payments will be accumulated through 2033, at which point they will be amortized. We therefore treat the twenty years

\footnotetext{
${ }^{79}$ Note that, because Portugal and Ireland were also receiving assistance, the interest rate was not lowered for their loans that had already been disbursed. However, due to the difficult nature of disentangling payments and because their contributions were relatively small, we simply lower all the margins on all loans to 50bp.

${ }^{80}$ The "No More Argentinas Rule" was put in place following the Argentinean defaulted, when the IMF attempted rescue of Argentina led to default a short time later. This rule stipulated that a country's debt would need to be sustainable in order to warrant a large loan. For a discussion of the IMF eventually overcame this rule, see Blustein (2015).

${ }^{81}$ The $€ 10.9$ Billion consisted of bonds that were to be used to recapitalize Greek banks through the Hellenic Financial Stability Fund.

${ }^{82}$ This includes ten years from the December 2012 agreement plus ten years in this agreement.
} 
of deferred interest as an additional disbursement in January 2033 that is to be repaid over constant amortisation over 20 years.

Disbursements by the IMF for the second programme totalled $€ 8.33$ Billion over four tranches, although they planned to contribute $€ 28$ Billion. The first loan was in 2010 and the last loan was in May 2010 from the SBA. The last loan listed from the IMF was on June 3, 2014 from the EFF. Greece received one bridge loan from the European Finacial Stability Mechanism (EFSM) when it missed a payment on its loans to the IMF in July 2015. This was a three-month loan for $€ 7.16$ Billion given to allow Greece time to transition to the third Programme and receive assistance from the ESM. This loan was repaid when ESM assistance was given. Because of the short-term nature of this loan, we do not model it.

Programme 3 began in August 2015 and ran through August 2018. This programme consisted of new loans by the ESM only (although debt relief on earlier loans by other officials has also occurred). The ESM committed €86 Billion to Greece but only disbursed $€ 61.9$ Billion. ${ }^{83}$

In calculating interest payments for the ESM, interest is paid annually in, we assume, March of each year. We calculate the outstanding level of debt for each year and multiply this value by the annualized interest rate equal to the last value available from the ESM in August 2018 of 163bp.

Figure 11 shows the realized and projected disbursements and realizations as of August 2018. We include our forecast of repayments under the June 2018 extension of the WAM. Recall that we treat the deferred interest payments as a new disbursement in the year following the end of the deferral.

\section{G.2.2 Ireland}

Ireland's bailout programme ran from 2010-2013, although disbursements did not begin until 2011. Total commitments were $€ 85$ Billion, comprised of $€ 17.7$ Billion from the EFSF, $€ 22.5$ Billion from the EFSM, $€ 22.5$ Billion from the IMF, and $€ 4.8$ Billion from Bilateral Loans (United Kingdom, Sweden, and Denmark) ${ }^{84}$ (EU (2011e)) Therefore, $€ 67.5$ Billion was committed externally. All of this was eventually disbursed.

IMF disbursements amounted to around 2,322\% of Ireland's quota. IMF assistance to Ireland was under the EFF. (IMF (2010b)) These loans were via the EFF, described above in the section on Greece.

EFSF disbursements occurred between February 2011 and December 2013, when the programme was concluded. EFSF lending rates were equal to the EFSF funding costs plus a margin. The original FFA had a margin of 247bp with a maximum weighted average maturity of 7.5 years. In July 2011, the maximum weighted average maturity of 15 years and margins were reduced to 0 . Finally, in June 2013, the maximum weighted average maturity was officially extended to 22 years.

The EFSM disbursed its first tranche of funding in January 2011, and their last tranche was disbursed in March 2014. Interest Rates for the EFSM loans were originally equal to cost of funding for the European Union plus 292.5bp. (EU (2011e)) In October 2011, all EFSM margins were set to 0 and the maximum weighted average maturities were extended to 12.5 years. (EU (2011c)) In June 2013, the maximum weighted average maturity was extended to 19.5 years. (EU (2013)) This last decision also extended the maturity of the initial disbursement by splitting this disbursement into three tranches and extending each one. We set the interest rate on the EFSM loans to Ireland equal to $3.10{ }^{85}$

Finally, there were also bilateral loans to Ireland. Sweden committed and disbursed $€ 600$ Million in four tranches in 2012 and 2013. The United Kingdom committed €3,830 Million (£3.23) in December 2010 and disbursed this amount between October 2011 and September 2013 in 8 disbursements of $£ 403,370,000$ each. Denmark offered a loan of $€ 400$ Million in four

\footnotetext{
${ }^{83}$ There was one cashless loan for bank recapitalization of $€ 5.4$ Billion. For this loan, originally there was supposed to be $\mathrm{a} € 2.2$ Billion has an interim maturity in 2018.

${ }^{84}$ Ireland also had to commit $€ 17.5$ Billion itself. This money was taken from, among other sources, their pension program.

${ }^{85}$ This number comes from a parliamentary question by the European Union to Olli Rehn in 2012, where he states that the average interest rate on Irish loans is $3.1 \%$.
} 


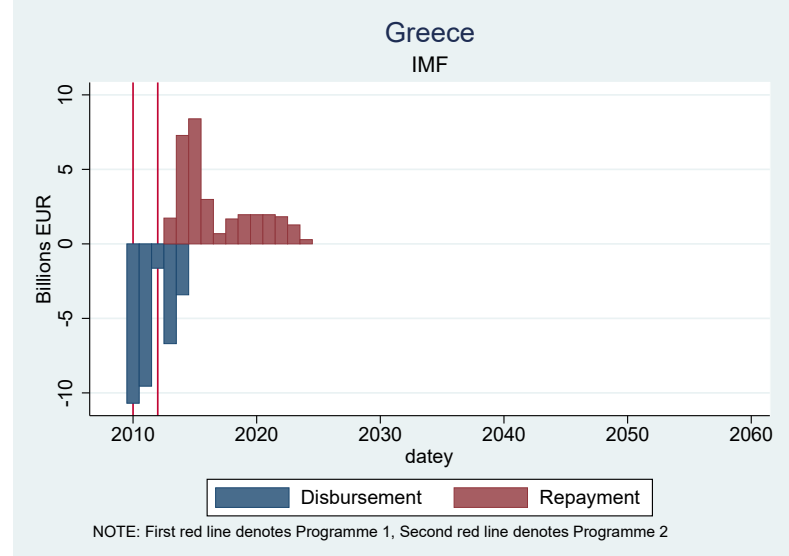

(a) IMF

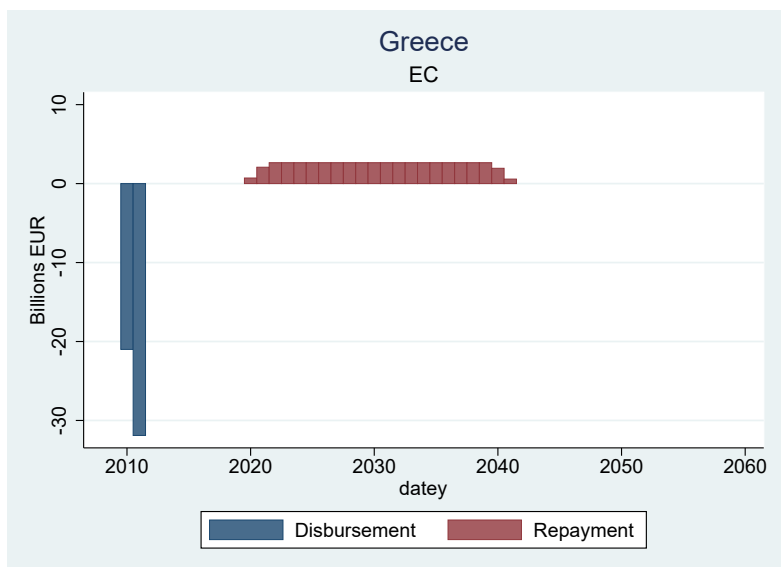

(b) EC

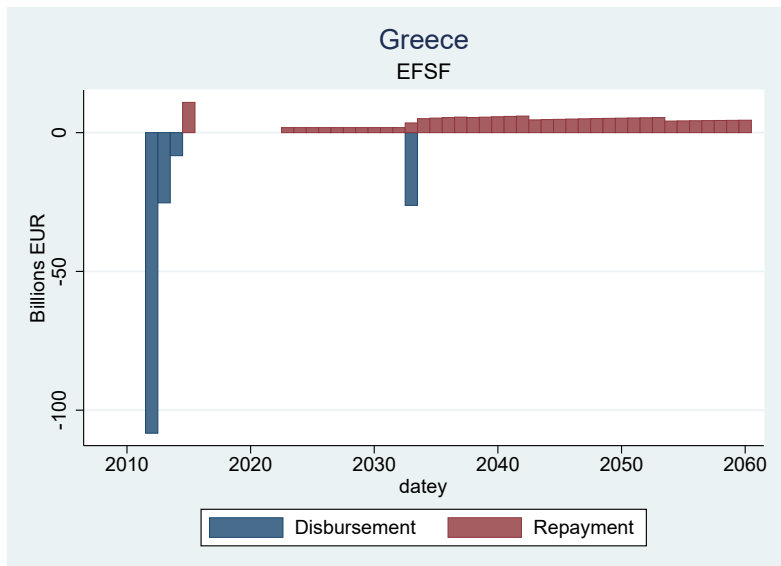

(d) EFSF

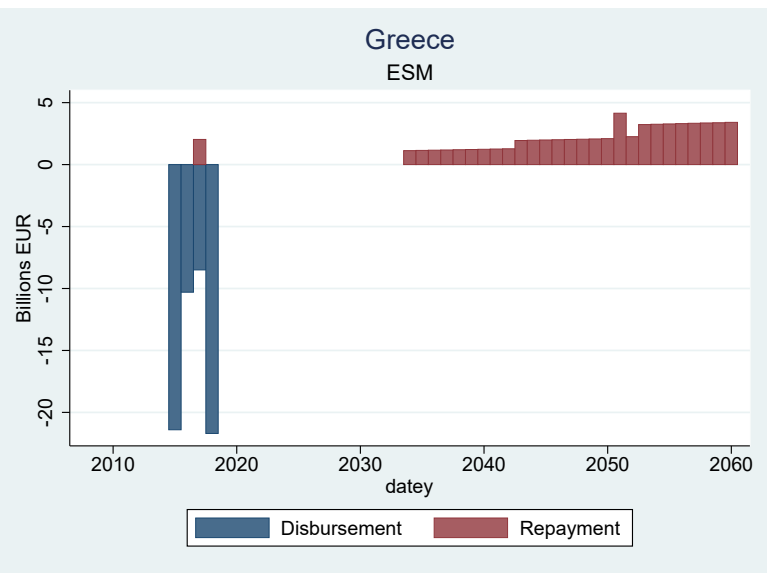

(c) ESM

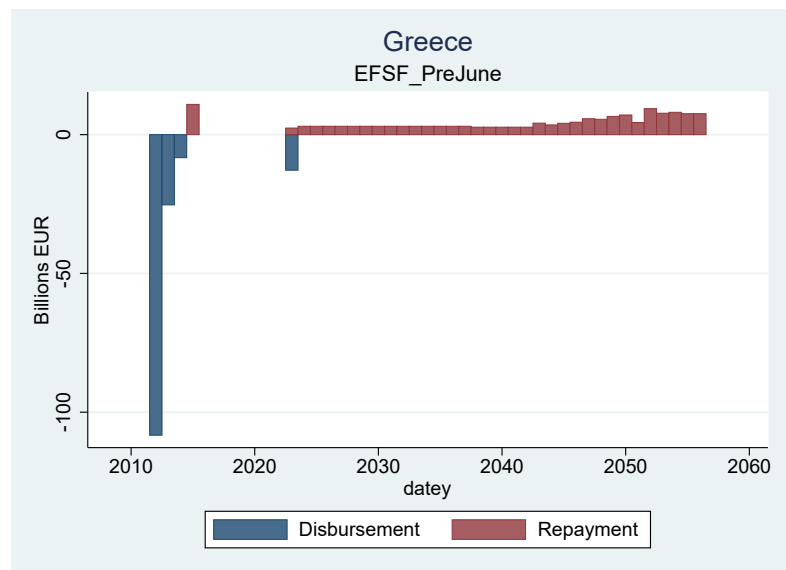

(e) EFSF (Pre June Agreement)

Figure 11: Greece Programmes 


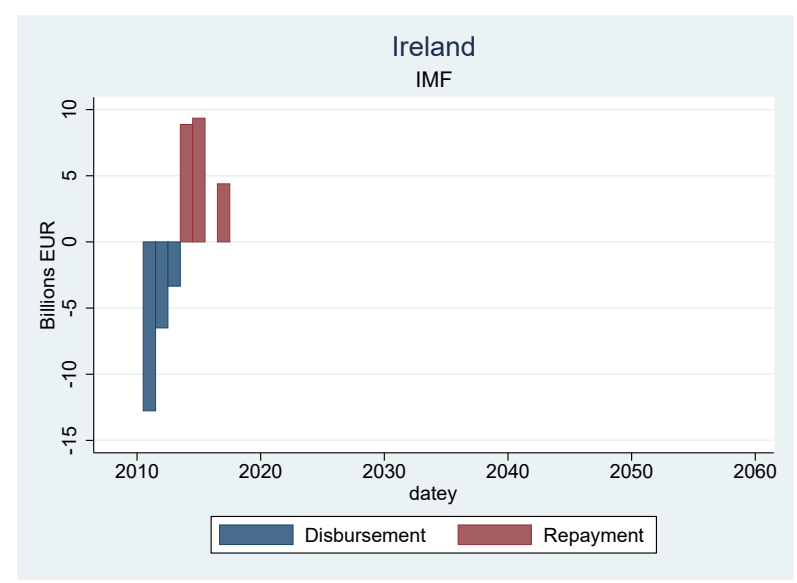

(a) IMF

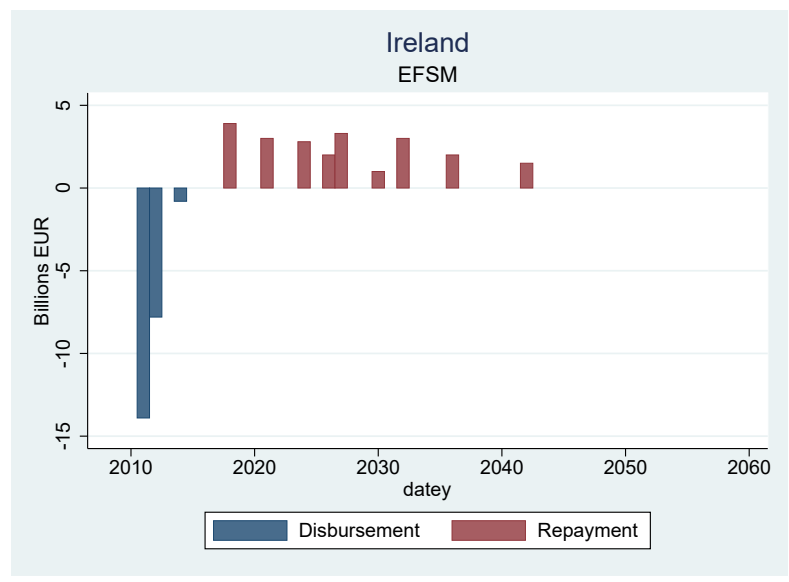

(b) EFSM

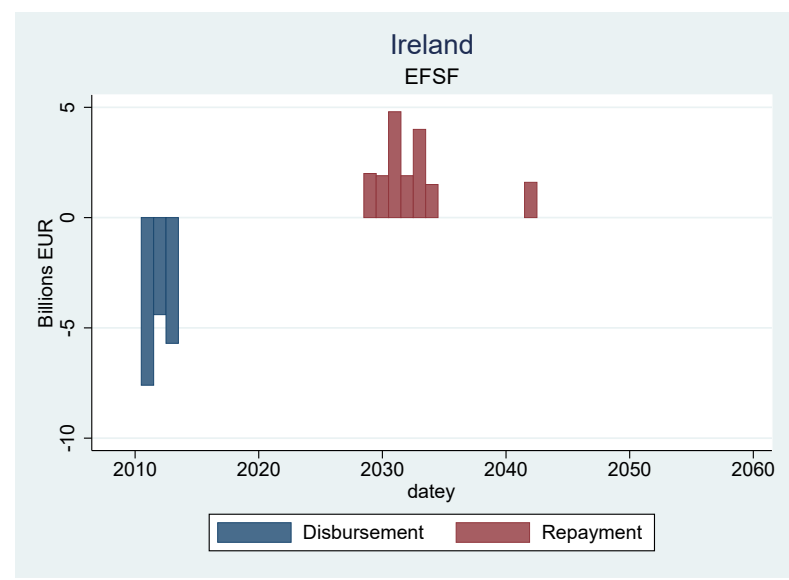

(c) EFSF

Figure 12: Irish Programmes

tranches between March 2012 and November 2013. Sweden offered a loan of $€ 600$ Million in four tranches between June 2012 and November 2013. We do not calculate the size of the transfer for these loans because they are relatively small and becuase details regarding interest payments are difficult to find ${ }^{86}$

Figure 12 plots the disbursements and repayment schedules for Ireland.

\section{G.2.3 Portugal}

Portugal requested aid from the EFSF, the IMF, and the European Union via the EFSM in April 2011 and was approved for a programme in May 2011. Portugal officially exited in June 2014 when they allowed the programme to lapse without taking the last available tranche of funding. The three groups each committed approximately $€ 26$ Billion out of a total of $€ 78$

\footnotetext{
${ }^{86}$ There is detailed information for the United kingdom. For bilateral loans, the interest rate for the UK loans was the "the semi-annual swap rate for Sterling swap transactions..." plus a margin of 229bp per annum. (UK Treasury (2010)) In 2012, the interest rate was reduced to a service fee of 18bp per annum plus the cost of funding. (UK Treasury (2012)) $£ 7,668,903.59$ was rebated to Ireland as a consequence by reducing the interest payment due at the following interest payment date. From other testimonies, we can piece together that the interest rate on Sweden and Denmark loans was tied to the 3-month Euribor rate plus a margin of $100 \mathrm{bp}$. However, there is little other information publicly available at this time.
} 
Billion. (EC (2016))

IMF disbursements amounted to around 2,306\% of Portugal's quota, and were disbursed through the EFF. (IMF (2011a)) Interest payments for IMF loans are provided by the IMF.

EFSF disbursements began in 2011 and ended in 2014. The initial FFA in April 2011 set the terms of the loans, in particular the lending rates and the maximum weighted average maturities. The lending rates for the EFSF were equal to the EFSF Cost of Funding plus a Margin, which in the beginning of the programme (May 2011) was equal to 208bp. The initial maximum weighted average maturity at this time was 7.5 years. In July 2011, the margin was reduced to 0bp and the maximum weighted average maturity was lengthened to 15 years. In June 2013, the maximum weighted average maturity was officially extended to 22 years.

For EFSF loans, the month of annual interest payments for each disbursement is given at the time of the disbursement. To simplify the analysis, we assume that all interest payments are made in March. We set the interest payment for interest periods prior to and including September 2018 equal to the prevailing blended rate of 176bp multiplied by the total outstanding level of debt.

Lending rates for the EFSM were equal to the EU's cost of funding plus, originally in May 2011, a 215bp margin. Initially, the weighted average maturity was 7.5 years. In November 2011 Portugal the average maturities of Portugal's EFSM loan were extended to 12.5 years and margins were eliminated. (EU (2011b)) In 2013, the average maturities were again extended to 19.5 years. (EU (2011a)) We use $3 \%$ as the average cost of funding. ${ }^{87}$

Figure 13 plots the disbursements and repayment schedules for Portugal. The programmes are relatively similar in size, however the repayment schedule is much more front-loaded for the IMF programme relative to the EFSM and EFSF repayment schedules. For the IMF, full repayment is expected by 2025, however the EFSM and EFSF repayment schedules now extend through 2040.

\section{G.2.4 Cyprus}

Cyprus officially asked for assistance in 2012 and was approved for a programme in May 2013. Cyprus officially exited its programme in March 2016. The program’s total financing envelope was $€ 10$ Billion, with the ESM committing €9 Billion and the IMF committing approximately $€ 1$ Billion through . In total, The ESM disbursed $€ 6.3$ Billion between May 2013 October 2015, while the IMF disbursed all of its commitment. (ESM (2016))

The ESM loans were not amortized, with the lump sum owed at the date of maturity. Interest rates were equal to the cost of funding plus some margin. We use the blended rate taken from the ESM in August 2018 of 91bp applied to the outstanding principal. IMF lending terms are described above.

Cyprus's post-programme surveillance began in September. There have been five such surveillance missions as of October 2018, although as of this time the fifth PPS report has not been released.

Figure 14 plots the disbursements and repayment schedules for Cyprus. The IMF loans are scheduled to be repaid over the period 2020 to 2025, while the ESM loans don't start to be repaid until closer to 2025 . The approximately $€ 0.26$ billion early repayment was done in a bid to reduce debt servicing costs, as Cyprus was able to issue debt a lower interest rate. (CNA News Service (2017))

\section{G.2.5 Spain}

Spain received assistance from only the ESM. Loans were approved in July 2012, with two disbursements in December 2012 and February 2013. The ESM committed $€ 100$ Billion, although only $€ 41.3$ Billion was used. The assistance came in the form of bonds, which were used to recapitalize the banking sector. Spain has made some voluntary early repayments on

\footnotetext{
${ }^{87}$ This number comes from the same statement by Olli Rehn in 2012 as the number for Ireland.
} 


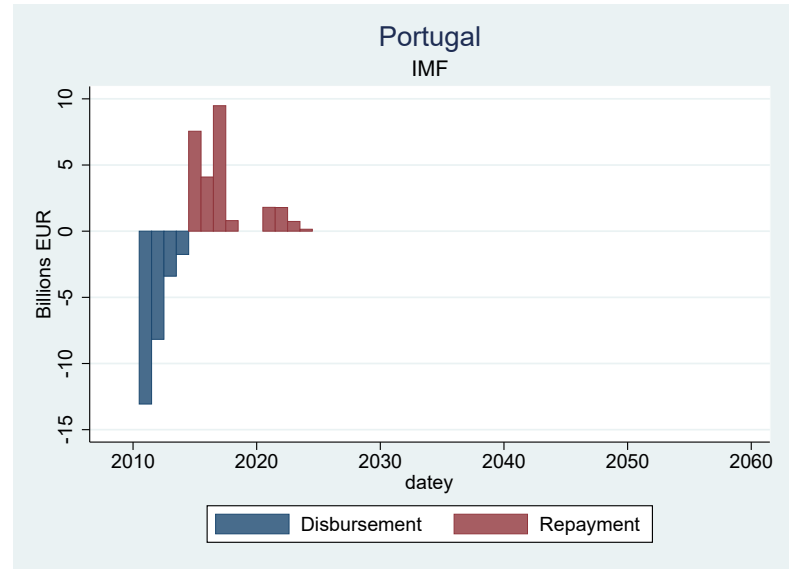

(a) IMF

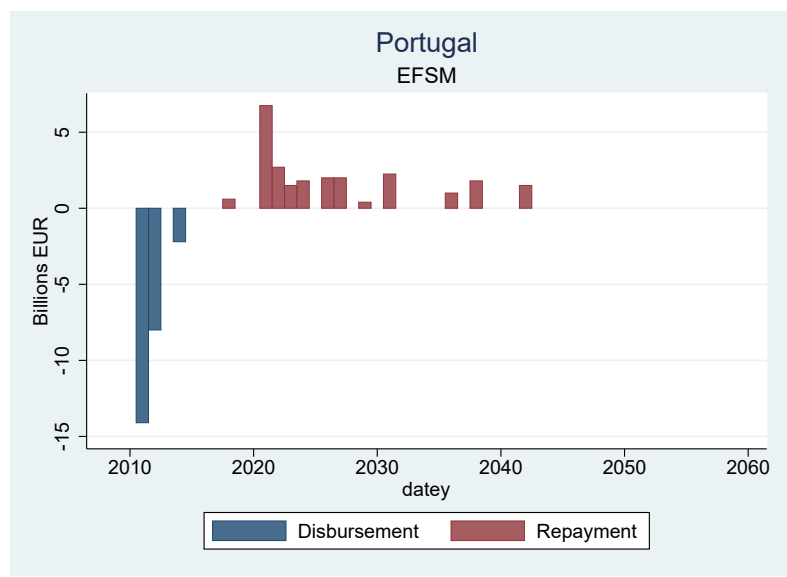

(b) EFSM

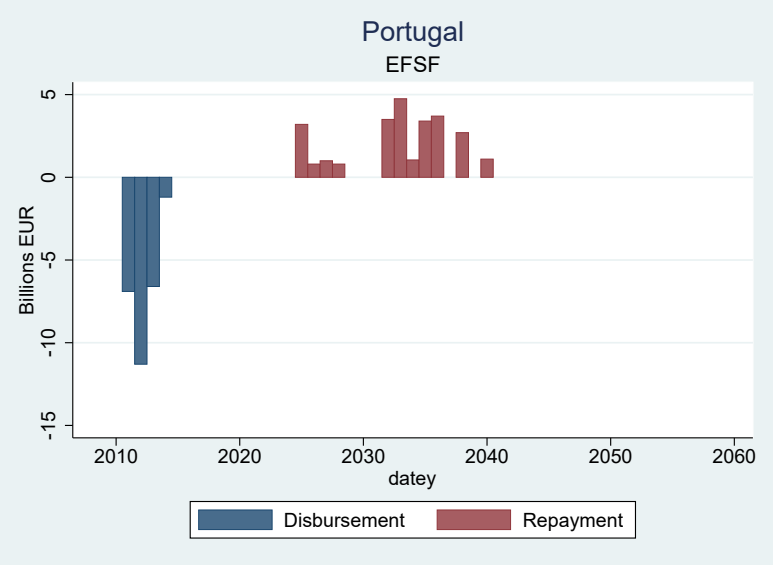

(c) EFSF

Figure 13: Portugal Programmes

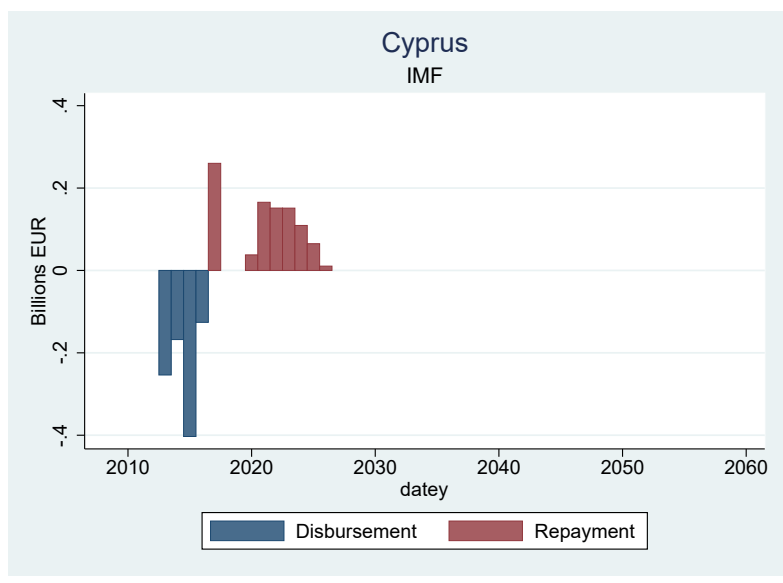

(a) IMF

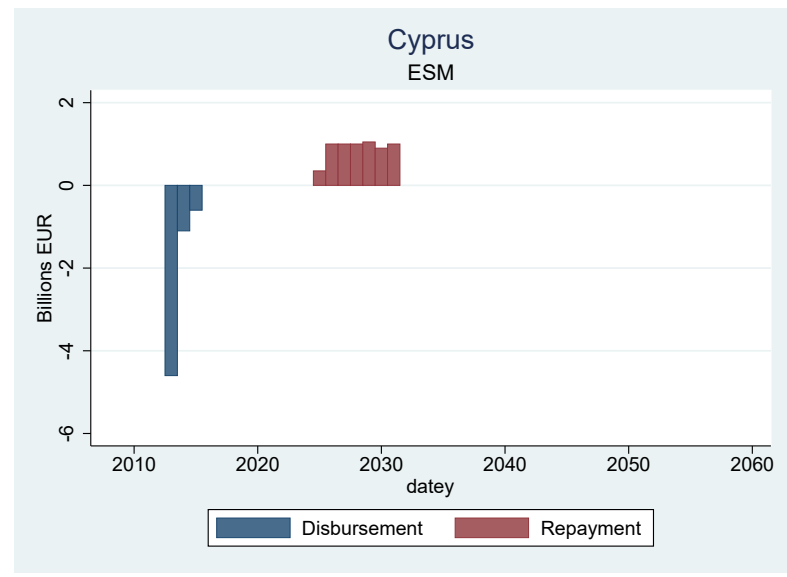

(b) ESM

Figure 14: Cyprus Programmes 


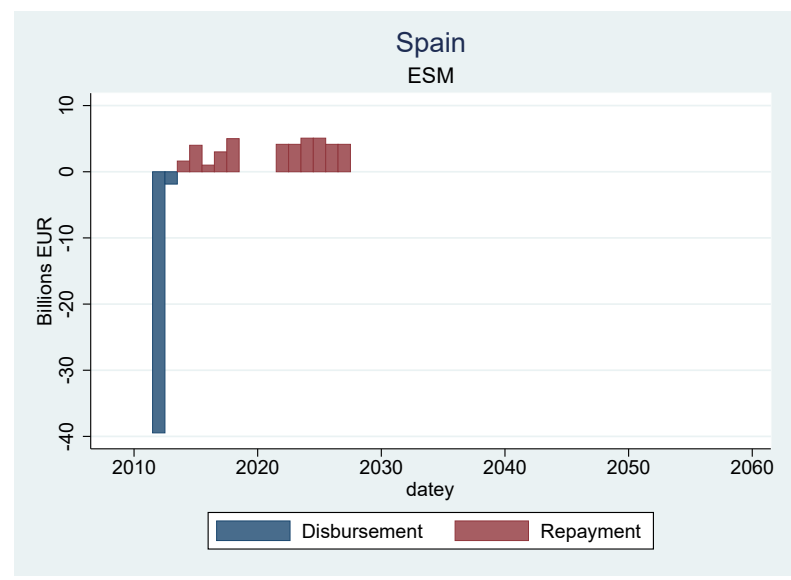

(a) ESM

Figure 15: Spain Programme

these loans. (ESM (2013)) Otherwise, we use the blended rate taken from the ESM in August 2018 of 111bp applied to the outstanding principal. Figure 15 plots the ESM assistance to Spain as of August 2018.

Spain's post-programme surveillance began in March 2014. There have been ten such surveillance missions as of October 2018, with the eleventh scheduled for Spring 2019.

\section{G.3 Other European Programmes}

\section{G.3.1 Hungary}

Talks regarding financial assistance to Hungary began as early as October 2008, when IMF Director Dominique StraussKahn issued a statement discussing the issues facing Hungary. By the end of the month, both the IMF and the EC issued press releases and formal recommendations for Hungary to receive medium-term assistance. (IMF (2008c),EU (2008a)) This assistance was formally granted whith the IMF Executive Board's approval of a maximum of SDR10.5 bn (approximately $€ 12.5 \mathrm{bn}$ ) the EC's decision providing a maximum of $€ 6.5$, both in Early November. (IMF (2008a), EU (2008b)) These loans were conditional on Hungary implementing a number of structural policies, such as expenditure ceilings and expanded deposit insurance programs.

Assistance from the EC was under its medium-term balance of payments program. ${ }^{88}$ The realized EC loans were comprised of three installments given over the course of December 2008 to July 2009, each with a maturity between three and six years. ${ }^{89}$ For the IMF, approximately SDR7.6 bn was disbursed through the SBA between November 2008 and September 2009 and was repaid between February 2012 and August 2013.

From the IMF, Hungary received approximately $€ 8.2$ billion (SDR 7.6 billion) through the SBA. As explained above, these loans are typically around three years, have interest payments tied to the basic rate of charge, and are conditional on structural reforms occurring. Repayment was on schedule through August 2013, at which point Hungary chose to repay early obligations due in 2013 and 2014 in order to generate interest savings. The data series for IMF disbursements, repayment, and interest come from the IMF website. This data is in SDR, and are converted to EUR at the prevailing

\footnotetext{
${ }^{88} \mathrm{We}$ focus on actual disbursements, so the second round of assistance in July 2012, which did not result in any assistance, is excluded from our analysis.

${ }^{89}$ The original agreement stipulated a maximum of five installments over at most two years with a weighted average maturity of 5 years. The MoU only mentioned four installments.
} 


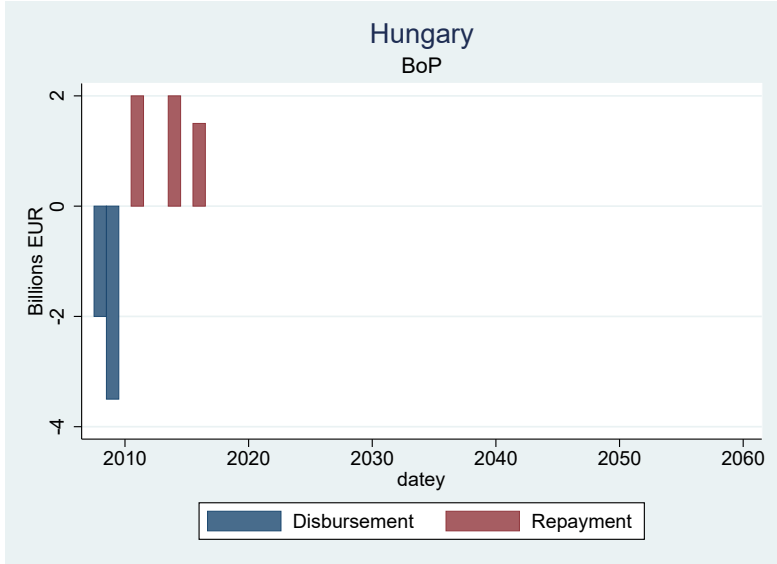

(a) BoP

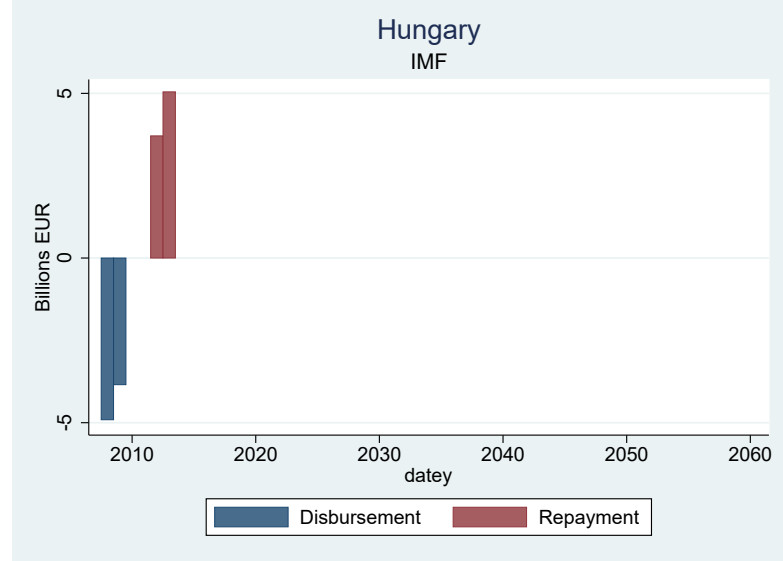

(b) IMF

Figure 16: Hungary Programme

monthly exchange rate using an average of the daily rates. As Hungary repaid its loans by the end of 2013, no projections of repayment/interest or forecasted exchange rates are used.

Although $€ 1$ billion of loans were authorized from the World Bank, none were realized.

Post-programme assistance began in April 2011 and ended in November 2014. There were six review missions in total. As of November 2014, Hungary had repaid more than $70 \%$ of its EU loan, and hence was not subject to post-programme surveillance.

Figure 16 plots the disbursement and repayment schedules for Hungary. The repayment schedule for Hungary ended in 2013, while the Balance of Payment programme ran through 2016. Note that Hungary's first repayment was

\section{G.3.2 Latvia}

Latvia came under financial pressure around the same time as Hungary. As early as November 2008, Latvia had requested aid from the EC and other lending institutions. (IMF (2008d)) Such assistance was formalized in January 2009 when a total of $€ 7.5 \mathrm{bn}$ was made available. This programme was in large part designed to maintain the exchange rate peg between the Latvian Lat (LVL) and the Euro. Of this amount, $€ 3.1 \mathrm{bn}$ came from the EC, SDR1.5 bn (approximately $€ 1.7 \mathrm{bn}$ ) came from the IMF through the SBA, €1.9 bn came from the Nordic countries (Sweden, Denmark, Finland, Estonia, and Norway), and the remainder came from the World Bank, the European Bank of Reconstruction and Development, the Czech Republic, and Poland. (EU $(2009 a, b)$ ) For the EC, financial assistance came in four installments for a total of $€ 2.9$ bn between February 2009 and October 2010. For the IMF, approximately SDR1 bn was disbursed between 2008 and 2010 and was repaid in 2013.

The repayment schedule for the EC is constructed using the PPS mission reviews and information from the EC website. We set the repayment date of the first disbursement to be March 2014 and the repayment date of the second disbursement to be January 2015 to match the information from the EC website. ${ }^{90}$ For the third disbursement, we assume it will be repaid in lump sum in March 2019. For the fourth and final disbursement, we assume a constant amortization over the period 2020-2025. These last two disbursements match the information provided in the PPS mission reports. ${ }^{91}$

Interest payments for the EC BoP programme are calculated using an interest rate of $3.2 \%$ on the outstanding balance

\footnotetext{
${ }^{90}$ See Financial assistance to Latvia

${ }^{91}$ These reports document repayment in LVL until PPS 4 in January 2014, when Latvia formally joined the Eurozone and replaced its currency with the Euro. As usual, we report all results in Euro using prevailing exchange rates.
} 


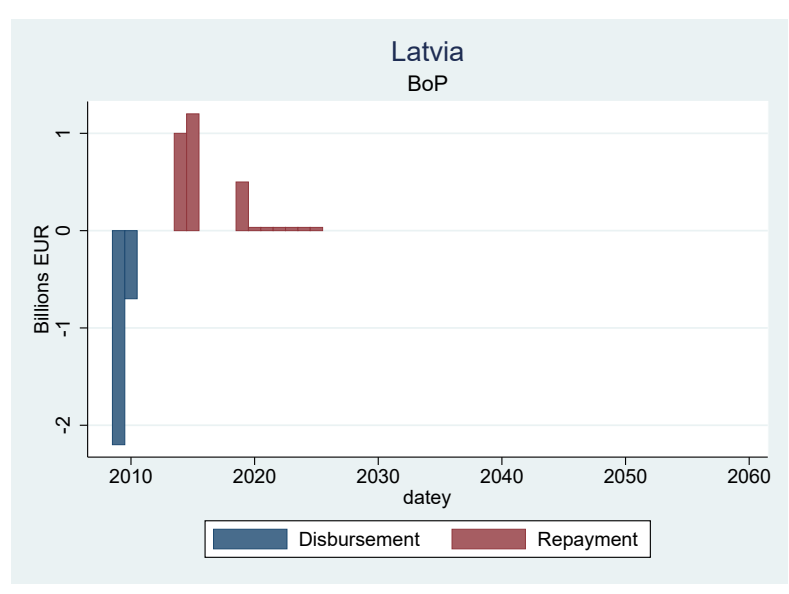

(a) $\mathrm{BoP}$

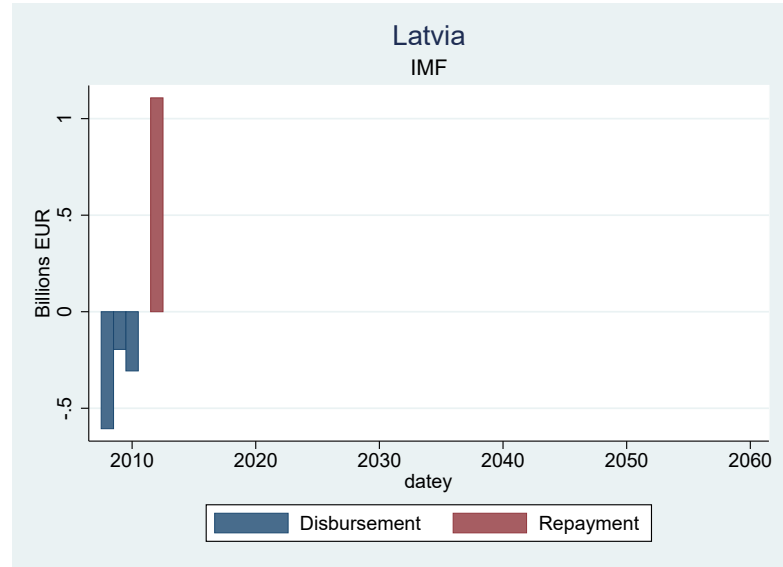

(b) IMF

Figure 17: Latvia Programme

until repayment. We use the values in EUR to calculate the levels of outstanding debt.

For the IMF, there were six planned series of disbursements, however only the first four were actually released. These disbursements occurred in December 2008 (the initial agreement), August 2009, February 2010, and August 2010. (IMF (2008d), IMF (2008b), IMF (2009), IMF (2010c), IMF (2010d), IMF (2011b), IMF (2011c)) As for repayments, Latvia made a series of early repayments to the IMF in 2012. In September 2012, Latvia made an early repayment of obligations due in 2012-14. (IMF (2012b)) Latvia repaid its obligations early by announcing in December 2012 its intent to repay in 2013 the obligations that would have been due in 2015. (IMF (2012a)) Officially, these loans were repaid in December 2012, and as such all IMF reimbursals are in 2012. As Latvia repaid its loans by the end of 2012, no projections of repayment/interest or forecasted exchange rates are used.

Figure 17 plots the disbursement and repayment schedules for Latvia. For the Balance of Payments programme, most repayment was in 2014 and 2015, although there are some minor payments scheduled through 2025. For Latvia, as mentioned above, all repayment was officially complete by 2012 .

\section{G.3.3 Romania}

Romania, the final Non-Eurozone country we study, also experienced financial pressures in mid-2009. Assistance was formalized in May 2009 when a maximum of $€ 20$ was made available, with $€ 5$ bn from the EC through the balance of payments programme, SDR11.443 bn (approximately $€ 12.95 \mathrm{bn}$ ) from the IMF through the SBA, $€ 1$ bn from the World Bank, and $€ 0.5$ bn each from the European Investment Bank (EIB) and the European Bank for Reconstruction and Development (EBRD). ${ }^{92}$ (EU (2009c)) We focus in this paper on the Balance of Payments programme and the IMF.

Romania entered three BoP programmes between 2009-2015, however only the first programme of 2009-2011 saw realized disbursements. Post-programme surveillance commenced in October 2015 and consisted of three surveillance missions (May 2016, March 2017, and November 2017). Romania exited post-programme surveillance in April 2018 following repayment of $70 \%$ of its EU loan. We set the repayment and interest rate schedule according to the EC's post-programme

\footnotetext{
${ }^{92}$ Note that this is technically only Programme 1, with two more programmes (2011-2013 and 2013-2015) later. However, the 2011-2013 and 2013-2015 programmes were approved on a precautionary basis, and featured no disbursements by the IMF or the EC. The disbursements by the EIB and EBRD continued through 2012, but are small and not taken into account in our analysis. We also do not calculate the transfer from the World Bank.
} 


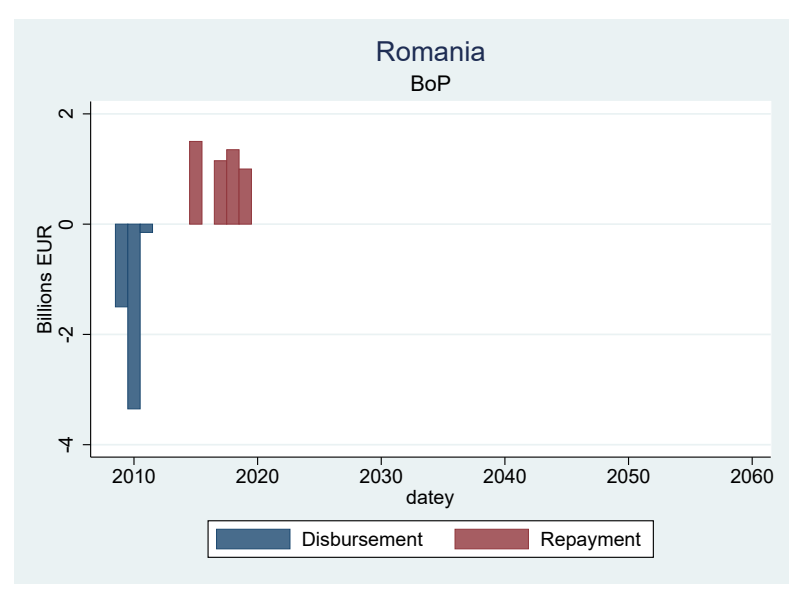

(a) $\mathrm{BoP}$

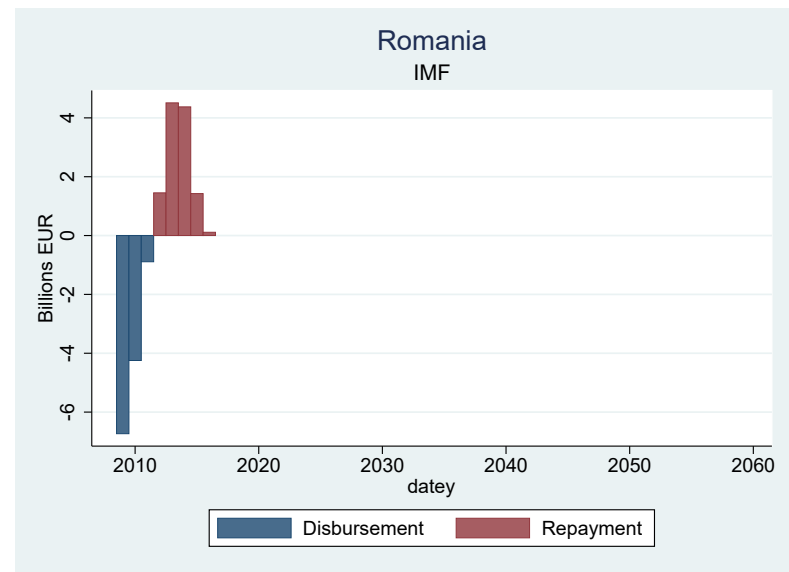

(b) IMF

Figure 18: Romania Programme

evaluation. (EC (2015)) The interest rate is approximately 3\%. We set the repayment dates to be the same as the issuance date for each loan. For interest, we assume interest is paid in same quarter the loan is disbursed beginning the following year until, and including, the repayment date. Interest payments are calculated using an interest rate of $3.2 \%$ on the outstanding balance.

Romania was approved for assistance from the IMF in May 2009 through the SBA..$^{93}$ Romania received financial assistance over six disbursements including May 2009 (the initial agreement), September 2009, February 2010, July 2010, September 2010, and January 2011. ${ }^{94}$ In March 2011, Romania was approved for the seventh disbursement and a new SBA, however these were precautionary and never drawn upon. IMF Lending terms for the SBA are described above in the section on Greece. The data series for IMF disbursements, repayment, and interest come from the IMF website. This data is in SDR, and are converted to EUR at the prevailing monthly exchange rate using an average of the daily rates. As Romania repaid its loans by the end of 2016, no projections of repayment/interest or forecasted exchange rates are used.

Figure 18 plots the disbursement and repayment schedules for Romania. The balance of payment programme has slightly longer durations, with repayment between 2014 and 2019, while the IMF only ran through 2016.

\section{H Methodology}

To estimate total transfers $T r_{t}^{i, j}$ for lender $i$ to borrower $j$ at time $t$, we calculate the difference between the present value of the sequence of net transfers discounted at some benchmark internal rate of return and the present value of the sequence of net transfers discounted at its actual internal rate of return. By definition, this latter term is zero, and so we can write the transfer as

$$
\operatorname{Tr}_{t_{0}}^{i, j}=\sum_{t=t_{0}}^{T} \frac{1}{(1+\bar{r})^{t}} N T_{t}^{i, j}
$$

where $T$ is the date of the last net transfer flow (always a repayment). $\bar{r}$ is the (risk-free) discount or reference rate at time $t$. In practice, we set this discount rate to the internal rate of return on the IMF's lending for borrower $j$ during the Eurozone

\footnotetext{
${ }^{93}$ Romania is no stranger to using the SBA programme via the IMF. In particular, Romania received assistance via the SBA between October 2001 and October 2003, and a precautionary SBA ending in June 2006. (IMF (2007))

${ }^{94}$ The February 2010 combined both the second and third disbursements.
} 
crisis. $N T_{t}^{i, j}$ are net transfers from lender $i$ to borrower $j$ at time $t$.

We follow Joshi and Zettelmeyer (2005) and construct net transfers as

$$
-N T_{t}^{i, j}=R_{t}^{i, j}-D_{t}^{i, j}+i_{t-1}^{i, j}\left(D^{o}\right)_{t-1}^{i, j}+\ldots+i_{t-\tau}^{i, j}\left(D^{o}\right)_{t-\tau}^{i, j}
$$

where $\tau$ denotes the maturity of each disbursement. $D^{o}$ is the outstanding balance remaining on each disbursement. Then, the internal rate of return $i r r^{i, j}$ is the value that sets the sequence of net transfers to zero. The series of net transfers $N T_{t}^{i, j}$ is also used to calculate the size of the present discounted value of the transfer.

To calculate the internal rate of return, we follow Joshi and Zettelmeyer (2005). We begin by establishing a lending cycle for each country-lender pair. A lending cycle is a sequence of disbursements, repayments, and interest payments between a lender and a borrower during which the level of outstanding debt is positive. Unlike Joshi and Zettelmeyer (2005), who in some cases have multiple lending cycles per country-IMF pair, we only have one lending cycle for each country as, once a country requested assistance, they have since maintained an outstanding balance.

We make two key assumptions when calculating the internal rates of return. The first key assumption is that the current specification of repayments and interest rates will coincide with the realized outcome, and there will be no more debt renegotiations. Any changes to the current agreement that makes the terms more favorable for Greece, such as delaying interest payments or extending the overall maturity, would result in a larger transfer than we calculate. The second key assumption is that for loans with variable interest rates that depend on the international institutions borrowing rate, we assume that they can roll over debt at the same interest rate. Whether the current environment featuring low global interest rates is here to stay is beyond the scope of this paper, but if global interest rates were to rise, both the IMF and the Europeans lenders would most likely be affected similarly. Hence, it is unlikely that these changes in the interest rate are a source of concern in our estimation.

\section{Time-Varying NPV for Greece}

In this section, we outline the evolution of the Greek debt programmes by rescue fund. This provides the background information regarding why the NPV for Greece had changed so much over time. It also provides sources for where we take forecasts of repayment from.

In calculating the NPV over time, we use equation H.1 and calculate the size of the transfer for each $s \in\left\{t^{\text {start }}, t^{\text {start }}+\right.$ $1, \ldots, T-1, T\}$, where $t^{\text {start }}$ is defined as the quarter of the start of each programme and $T$ is defined as 2018Q3. Expanding on Equation H.1, we therefore write the size of the net present value of the series of as of time $s$ :

$$
T r_{s}^{i, j}=\sum_{t=s}^{T} \frac{1}{\left(1+\bar{r}_{s}\right)^{t}} N T_{s, t}^{i, j}, \quad s \in\left\{t^{\text {start }}, t^{\text {start }}+1, \ldots, T-1, T\right\}
$$

where $N T_{s, t}$ denotes the expected net transfer of the series as of time $s$ :

$$
N T_{s, t}=E_{s}\left[R_{t}^{i, j}-D_{t}^{i, j}+i_{t-1}^{i, j}\left(D^{o}\right)_{t-1}^{i, j}+\ldots+i_{t-\tau}^{i, j}\left(D^{o}\right)_{t-\tau}^{i, j}\right]
$$

By using this notation, note that for $t>s$, then we use the realized disbursements, repayments, and interest payments at time $t$.

The "risk-free" rate $\bar{r}_{s}$ in Equation I.1 is the internal rate of return for the expected sequence of net transfers to the IMF as of time $s$. Hence, the risk-free rate we use to discount the sequence of transfers is time varying as well. 
To further understand this exercise, consider the following example. In December 2012, there was an official debt relief agreement reached between the EFSF and Greece that included, among other things, a smoothing of the repayment profile by Greece to extend the weighted average maturity of the programme (this agreement is discussed in more detail below). This change affects the expectation of future repayments by shifting repayment schedules $R$ further into the future. As an example, assume away interest payments and suppose that all disbursements have been made. Suppose a repayment of $€ 1$ bn that was originally set for January 2030 is now moved to January 2040. In the language above, this means that initially, we have ${ }^{95}$ :

$$
N T_{2012 Q 4, J a n 2030}=E_{2012 Q 4}\left[R_{J a n 2030}\right]=1 N T_{2012 Q 4, J a n 2040}=E_{2012 Q 4}\left[R_{J a n 2040}\right]=0
$$

In the next quarter, following the release of details regarding the repayment schemes, we now have

$$
N T_{2013 Q 1, \operatorname{Jan} 2030}=E_{2013 Q 1}\left[R_{\text {Jan } 2030}\right]=0 N T_{2013 Q 1, \operatorname{Jan} 2040}=E_{2013 Q 1}\left[R_{J a n 2040}\right]=1
$$

Hence, the sequence of net transfers used to calculate the size of the transfer has been adjusted.

\section{I.1 Greek Loan Facility}

While assistance was formally requested in April 2010, no funds were disbursed at this time. On May 9, 2010 the IMF agreed to a Stand-By Agreement (SBA) with Greece. On May 18, 2010, the euro-area Member states disburse the first installment of their pooled loans to Greece. From the beginning, the full amount of the programme was expected to be disbursed. Therefore, we assume that, beginning in May 2010, investors expected the programme to run its fully scheduled course. This implies that, for our quarterly NPV series, Q2 of 2010 is the first observation.

The full schedule of disbursements is set out on page 27 of Occasional Papers 61 (EC (2010a)). In each subsequent review (Occasional Papers 68, 72, 77, 81, 87) there is a similar table that lists the expected disbursement schedul (EC (2010,a,c, $2011 a, b, c)$ ). For all quarters up to and including Q3 of 2011, we use this table to forecast future disbursements. However, with the introduction of the EFSF in mid-2011, occasional paper 87 only lists the first six tranches as planned disbursements. As these reviews were quarterly, we assume in October 2011 the EFSF is expected to take over all future loans, and that only the first six tranches are expected to be part of the the GLF package to Greece. Therefore, we use this abbreviated forecast beginning in Q4 of 2011.

As for repayments and interest, we use the realized repayment schedule as soon as the loan is disbursed. However, for loans not yet disbursed, we begin by using the requirements set out in the Euro Loan Facility Act and its amendments. Under the original terms, the repayment schedule was to mirror that of the IMF's SBA with a three year grace period followed by repayment of constant maturity over eight quarters. According to the original Euro Area Loan Facility Act (dated in May 2010), the loan terms were five years. We therefore assume that for each disbursement, the loans are amortized over the eight quarters beginning after the three year grace period. Interest payments for this period are tied to the 3-month Euribor rate with a margin of 300bp for the first three years and 400bp for the last two years. This affects the forecasts up to and including 2011Q2.

In the Euro Area Loan Facility Act of June 2011, the grace period was extended to four years and six months. The term of each loan was also extended to ten years. We therefore assume that, following this period, future loans have a constant amortization over the five and a half years (22 quarters) after each grace period. ${ }^{96}$ As for realized loans, a detailed amended schedule is included in the Act. Additionally, the margin was lowered to 200bp for the first three years and 300bp

\footnotetext{
${ }^{95}$ I suppress the $i$, for the EFSF, and $j$, for Greece for clarity

${ }^{96}$ For the 2011Q3, 2011Q4, and 2012Q1 forecasts, this only affects the forecasted disbursements of $€ 8.7$ bn in July 2011 and $€ 5.8$ bn in November 2011.
} 
following. These two changes affect calculations for loan schedules beginning in Q3 of 2011. This amendment also revises the repayment dates for the original loans.

In the Euro Area Loan Facility Act of February 2012, the grace period was again extended to ten years. The terms were extended to fifteen years. At this point, all six loans had been disbursed, and the EFSF programme was scheduled to begin soon. Hence, we only need worry about the realized loans. As for realized loans, a detailed amended schedule is included in the Act. The margin was lowered to $150 \mathrm{bp}$ for all periods. These two changes affect calculations for loan schedules beginning in Q2 of 2012.

In the Euro Area Loan Facility Act of December 2012, the terms were extended to thirty years. For realized loans, a detailed amended schedule is included in the Act. The margin was lowered to 50bp for all periods. These two changes affect calculations for loan schedules beginning in Q1 of 2013. Note that this was the last agreement related to GLF funding, and so we use this forecasted repayment schedule for all future periods.

\section{I.2 European Financial Stability Fund}

The European Financial Stability Facility Act of 2010 created the EFSF, although loans were not extended to Greece until March 2012.

For forecasted disbursements, beginning with EC (2012b) in March 2012, forecasts include the additional funding for an overall $€ 144.7$ billion. ${ }^{97}$ We therefore begin our EFSF series in Q1 2012 using the series from this paper as our forecast. We also use this paper for the Q2 and Q3 forecasts. However, note that there were actually more disbursements in Q1 and Q2 of 2012 then expected. I subtract the difference from the end of the forecasted time series. ${ }^{98}$ Occasional Paper 123 (the first review) in December 2012 details all of the disbursements in 2012, and also forecasts the month of each tranche for the second disbursement in Q1 2013, as well as a quarterly forecast series (EC (2012b)). This quarterly series also updates the actual disbursements from 2012. We therefore use this series as the forecasted series for Q4 2012.99,100 The forecasts for Q2 and Q3 of 2013 use the same forecast as Q1 of 2013. However, at the end of Q3 it was apparent that there would be no disbursements that quarter even though 3.4 was expected. We simply assign this 3.4 to Q4. ${ }^{101}$ Occasional Paper 148 came out in May 2013, so we use its forecast starting in Q2 2013. Occasional Paper 159 came out in July 2013, so we use its

\footnotetext{
${ }^{97}$ Table 19 on Page 56.

${ }^{98}$ The first occasional paper forecasted 74.0/29.6 in Q1/Q2. The actual disbursements were 72.1/37.5, which is $€ 6$ billion more. For the 2012Q2 forecast, this means that the Q2, Q3, and Q4 disbursements in 2014 are reduced to zero, and the Q1 disbursement is reduced from 10.7 to 8.9. This is repeated for the 2012 Q3 forecast. Note that the 72.1 includes the $€ 35$ billion for collateral that was returned early, as explained below, and is eliminated from our forecasts completely beginning in 2012Q3.

${ }^{99}$ Note that there is a slight difference between this series and our series. In their series, they assign the early April tranches to Q1, and we assign them to Q2. This accounts for the difference between the 40.5/33.5 in Q1/Q2 in the Occasional Paper and the 37.1/36.7 in our series.

${ }^{100}$ Using the Internet Archive Wayback Machine, we can view the dates of disbursements and download the EFSF Newsletters (which seem to be quarterly). This is what we use to fill the actual disbursements in Q2 and Q3 2012. The big difference seems to be that there was a slight delay in releasing some of the funds relative to expectations, and so the actual disbursement schedule was not as frontloaded as expected. This may somewhat affect our estimates of the internal rates of return between 2012 Q1 and 2012 Q2, since we assume that the Q1 forecast uses the Occasional Paper's quarterly series, but the Q2 series uses the actual disbursements as of May 2012 (the first available date from the Wayback Machine). Recall that when using quarterly forecasts, we assume the disbursements take place at the end of the quarter.

${ }^{101}$ There is also an error in that the 2013 Q1 disbursements are assigned to Q4 in Occasional Paper 123. We correct this by adding the 14.8 expected in $\mathrm{Q} 1$ to the 4.2 forecasted in order to keep the total constant. This is somewhat corrected in Occasional Paper 148, although at this point the realized disbursements from Q1 2013 were included, so the Q1 total is only 12.0
} 
forecast beginning in Q3 2013. ${ }^{102}$ Occasional Paper 192 came out in April 2014, so we use its forecast beginning in Q1 2014. Occasional Paper 192 is the last official document, and other than a redelivery of bonds, there were no new disbursements from the EFSF after August 2014. However, in Q1 2014, there was a forecasted $€ 10.2$ billion still to be disbursed, so we carry this forward as before under the assumption that investors always expect the remaining money to be disbursed in the following quarter. ${ }^{103}$ There were two $€ 1$ billion disbursements in July and August of 2014, and so we forecast $€ 1.9$ billion for each subsequent quarter until the programme was formally ended in July 2015. Hence, beginning in Q3 2015, we assume there will be no further disbursements.

There are a number of "gray areas." One gray area is how to deal with the three disbursed tranches of the private sector involvement (PSI) participation, which includes an approximately $€ 29.7$ billion sweetener, $€ 4.8$ billion of accrued interest, and in particular $€ 35$ billion of ECB collateral. This is a gray area because the tranches were disbursed in March and April while the loan modification at the end of 2012 bundles them all being into one loan. However, the EFSF website does state which tranches of each disbursement were assigned to which program, so we assign repayment to be in the same month as the disbursed tranche's month. ${ }^{104,105}$ A second gray area for the EFSF loans is how to handle the $€ 35$ billion given to Greece as collateral in March 2012, but was subsequently returned in July 2012. We assume that for the Q1 and Q2 forecasts in 2012, this $€ 35$ billion was expected to be used and paid back accordingly. Then, beginning in Q3, we assume that the sequence of transfers includes the fact that all $€ 35$ billion was repaid early. A third gray area is how to handle to handle the $€ 7.2$ billion made available for bank recapitalization in January 2013. We do not assign this as a loan in January, as it does not appear the Greek government called upon it at that time. This contrasts with Occasional Paper 148, which lists this 7.2 billion as a realized disbursement in Table 7 and Table 9. In Occasional Paper 159, Q1 2013 disbursements are reduced down to 4.8 from 12.0, but it is still included in Table 7 as it was drawn upon in May 2013. We therefore list is as disbursed in May 2013. Another gray area concerns how to deal with "roll-over loans." For now, we assume that they are repaid instead of rolled over. ${ }^{106}$

For realized repayments, other than the $€ 35$ billion listed above, there has only been a $€ 10.9$ billion repayment. This repayment includes $€ 7.2$ billion from the bank recapitalization listed above as well as $€ 3.7$ billion of the loan tranche in December 2012 ( $€ 16$ billion), both in February 2015.

For forecasted repayments, we follow the EFSF's repayment scheme. ${ }^{107}$ Initially, most loans have full repayment on a single maturity date, while others have linear amortization after 10 year grace period. For forecasted loans that have not yet been disbursed, we assume that they will be repaid in lump sum 15 years following disbursement. ${ }^{108}$ This assumption is made because the initial terms of the EFSF stipulated a minimum of a 15 year repayment scheme in July 2011. As for the month of repayment, it is unclear in most cases what the Principal Repayment Dates are. Hence, for all loans, we assume

\footnotetext{
${ }^{102}$ For Q4 2013, we use Occasional paper 159. As before, we take the difference between what is actually disbursed and what is forecasted, and assume it will be distributed the following quarter.

${ }^{103}$ In practice, this means that, because $€ 6.3$ billion was disbursed in April 2014, then we forecast $€ 3.9$ billion in Q3 2014 .

${ }^{104}$ The web site lists a 10 year grace period followed by a maturity. We therefore assume a linear amortization following the grace period. This results in a 20 year amortization period for the PSI sweetener. The accrued interest is repaid in lump sum after 15 years.

${ }^{105}$ Note again that this only affects the 2012 forecasts, as beginning in 2013 the loans are combined into one, which we assume to be disbursed in March (see below).

${ }^{106}$ Rollover loans include Disbursement 3, Tranche 2. Beginning in 2017, this loan is fully amortized between 2051 and 2056.

${ }^{107}$ When possible, we use the repayment scheme from the EFSF websites at the time of the forecasted internal rate of return.

${ }^{108}$ Some loans had longer maturities. Others, such as those to be used for bank recapitalization, did not have a schedule for repayment. This is because they were funded with loans issued by the EFSF and such loans were scheduled to be rolled over. We assume 15 years for these disbursement. For the $€ 7.2$ billion disbursement in 2013 , it was repaid early.
} 
the annual amortization on the anniversary of the disbursements. ${ }^{109}$

Interest payments are calculated using the EFSF blended rate prevailing at that quarter. ${ }^{110}$ We apply the average blended rate over the quarter prevailing at the time of the forecast forward until the outstanding debt balance is equal to zero. This is equivalent to assuming that all loans have the same interest rate.

There were four modifications to the original loan agreement. In December 2012, maturities were extended by 15 years. Additionally, interest payments were deferred for 10 years and rolled into a new loan. It does not look to be have been updated on the EFSF website until after January 2013. Hence, we assume that this modification affects the forecast being in Q1 2013. ${ }^{111}$ In January 2017, two important changes were made. ${ }^{112}$ First, there was a smoothing of the repayment profile. Maturities were extended back to 32.5 years. ${ }^{113}$ Second, the step-up margin of 200 basis points on the $€ 11.3$ billion tranche was waived. This tranche was issued in December 2012. These two measures therefore affect forecasts beginning in Q1 of $2017 .^{114}$

\section{I.3 European Stability Mechanism}

Greece first requested ESM support in July 2015, so we begin our series for Greek ESM assistance in 2015Q3. The total financing envelope is $€ 86$ billion. For forecasted disbursements, we begin by assuming that the total envelope will be disbursed, although eventually the ESM reports that not all funding will be needed.

The first approved tranche was for $€ 16$ billion from August 2015 through the end of 2015, so we take the actual disbursements as the forecasted disbursements for that year. Additionally, €25 billion was available for bank recapitalization, however only $€ 5.4$ billion was ever drawn upon. ${ }^{115}$ This is consistent with the first tranche proposal of August 2015, although they only give a maximum date for which disbursements must be made by. There is little information about forecasted disbursements following this date. We therefore make assumptions on forecasted disbursements. First, of the $€ 86$ bn envelope, in $2015 € 26$ bn was expected to be disbursed, as explained above. This leaves approximately $€ 60$ bn to be disbursed in the years following. For the $2015 \mathrm{Q} 3$ forecast, we assume that all $€ 25$ bn of the bank recapitalization will be disbursed eventually. We assume that the $€ 60 \mathrm{bn}$ will be disbursed evenly through 2018 . This means that $€ 5$ bn is forecasted to be disbursed each quarter for the 2015Q3 forecast. We do not assume that the $€ 25$ bn for bank recapiltalization will be

\footnotetext{
${ }^{109}$ An exception occurs if the date given for the final maturity is different than the disbursement. In all of these cases, we use the listed date of the final maturity.

${ }^{110}$ This data is available from Corsetti, Erce and Uy (2017), who graciously made their data available.

${ }^{111}$ The following changes are made: i. the PSI and Accrued Interest are combined and amortized over 20 years through 2042. The combined amount listed on the website is 34.6, which is a slight overestimate of the 34.5 that was actually disbursed. We use the actual disbursement to calculate repayment so as not to overestimate repayment. (Note that this only affects the accrued interest, and also results in the March/April tranches being combined into one. We follow this by having all be due in March of each year beginning in 2023.); ii. The €5.9 billion changed to 2047 from 2032 ; iii. The $€ 3.3$ billion changed to 2041 from 2027; iv. The amortization period of the $€ 25$ billion for bank recapitalization changed from $2023-2032$ to 2034-2039 and 2043-2046; v. The €4.2 billion changed to 2042 from 2027; vi. The €1 billion changed to 2040 from 2027.

${ }^{112}$ We do not consider the reduction of interest rate risk to be as important. While this certainly would constitute a transfer to Greece, it is not obvious how to model it.

${ }^{113}$ Almost all maturities were affected. The new maturities are the current ones listed on the EFSF website.

${ }^{114}$ The modifications were discussed as early as Q4 2016. Because the maturity extension mostly affects the long horizon, the Q1 2017 number would be a close approximation to the Q4 2016 number.

${ }^{115}$ Note that of the $€ 10$ billion for bank recapitalization, only $€ 5.4$ billion was drawn upon in December. We assume that the full $€ 10$ billion was forecasted to be drawn upon in December for the 2015Q3 forecast, but beginning in 2015Q4 we assume that none of this amount, nor the remaining $€ 15$ billion will be drawn. This is because, beginning in the first compliance report, there is no forecasted series for the disbursement of the remaining bank recapitalization funds as they are expected to be unused.
} 
disbursed for the 2015Q4 and 2016Q1 forecasts.Instead, these forecasts will only have $€ 66.4 \mathrm{bn} .{ }^{116}$ We then take the $€ 45$ bn (86 - 19.6) remaining for the 2015Q4 and 2016Q1 forecasts and assume that it will be fully disbursed by the end of 2018 . Therefore, $€ 3.75$ bn for the 2015Q4 and 2016Q1 forecasts. ${ }^{117}$ We do so by assuming a constant disbursement amount for each quarter, which seems to match the long-term forecasts of the ESM in the later compliance reports.

The first compliance report was completed in June 2016, and we use this as the basis for our 2016Q2 forecast (EC (2016b)). Although Greece was originally forecasted to receive a second tranche of $€ 11.2$ billion between December 2015 and June 2016, there were no disbursements until June 2016 due to "[ $t$ ]he long delay in completing the first review." 118 From the first compliance report in June 2016, we see that this tranche was reduced from $€ 11.2$ billion to $€ 10.3$ billion. For the forecast, we assume that the tranches will be distributed in Q2 and Q3 of 2016 as listed in the Compliance Report. ${ }^{119}$ We then use the compliance report to build the forecast forward through 2018. Note that now, the ESM assumes that $€ 19.6$ bn of the original $€ 86$ bn will be unused, so we continue to not include this amount in our forecasts. We also use the forecast from the first compliance report as our assumed forecast for 2016Q3, 2016Q4, and 2017Q1 by applying forward the undisbursed forecasts to the following quarter.

The second compliance report was completed in June 2017, and we use this as the basis for our 2017Q2 forecast (EC $(2017 b)) .{ }^{120}$ In this report, the ESM now assumes that $€ 27.4$ bn of the original $€ 86$ bn financing envelope will go unused, which gives a total forecasted disbursed amount of $€ 58.6 \mathrm{bn}$. We also use this forecast as our assumed forecast for 2017Q3 and 2017Q4 by applying forward the undisbursed forecasts to the following quarter.

The third compliance report was completed in March 2018, and we use this as our 2018Q1 forecast (EC (2018b)). In this report, the ESM again assumes that $€ 27.4$ bn of the original $€ 86$ bn financing envelope will go unused, which gives a total forecasted disbursed amount of $€ 58.6 \mathrm{bn}$. The ESM assumes that the remaining $€ 11.7 \mathrm{bn}$ of this amount will be disbursed in July 2018, so we include that forecast. ${ }^{121}$

The fourth compliance report was first issued in June 2018 and updated in July 2018. We use this as our 2018Q2 forecast (EC (2018a)). At this point, $€ 46.9$ bn had been disbursed. Here, the ESM anticipates lending slightly more for the final disbursement in August 2018 of $€ 15 \mathrm{bn}$, which brings the total back up to around $€ 61.9 \mathrm{bn}$. Note that this forecast is for a disbursement of July. For the 2018Q2 forecast, we therefore assume a date of July. ${ }^{122}$ For the 2018Q3 forecast, we assume the final disbursement of $€ 15$ bn will be given in August 2018, which is the end of the programme.

Repayment of disbursed amounts is given on the ESM website, and we assume that Greece will repay all debts where listed. For undisbursed amounts, we assume that they carry 15 year maturities with no amortization, which is around 5 years less than what the disbursed amounts have, and around half of what the maximum average maturity is allowed to be in the Financial Assistance Facility Agreement. There was an early repayment of $€ 2$ Billion in February 2017 coming from the sale of assets. ${ }^{123}$ Using the wayback machine, these repayments were applied to the final tranches in 2058 and 2059 of each disbursed loan, which we use as well.

According to the ESM website, the blended interest rate has been rising steadily over the lifetime of the programme. For this reason, interest payments are again calculated using the ESM blended rate prevailing at that quarter. We apply the

\footnotetext{
${ }^{116}$ Recall that $€ 5.4$ bn was disbursed, so we subtract the remainder, $€ 19.6 \mathrm{bn}$, from the envelope

${ }^{117}$ Note that for the 2016Q1 forecast, we add the forecasted amount that wasn't disbursed in 2016Q1 to 2016Q2, assuming that the ESM wants to disburse the loans as soon as possible.

${ }^{118}$ First Compliance Report, Page 16.

${ }^{119}$ First Compliance Report, Table 5.

${ }^{120}$ Table 5 of the report displays the forecast.

${ }^{121}$ This number comes from the fact that the ESM writes that the cash buffer for Greece is expected to be insufficient.

${ }^{122}$ There is some debate as to whether the forecast should be July or August, as the Eurogroup statement on June 22, 2018 forecasts August as well. We choose July to be consistent with the methodology throughout this exercise.

${ }^{123}$ The National Bank of Greece had to sell a subsidiary, Finansbank, as part of the conditions for receiving bank recapitalization loans.
} 
average blended rate over the quarter prevailing at the time of the forecast forward until the outstanding debt balance is equal to zero. This is equivalent to assuming that all loans have the same interest rate. Note that the Corsetti, Erce and Uy (2017) data on blended rates only goes forward to August 2015, the date of the first ESM disbursement. Therefore, we use the ESM website to approximate the increase of interest rates through the current $1.62 \%$.

Other than the short-term financial assistance in January 2017, there do not seem to be any substantial revisions to the ESM's loan agreements. This short-term agreement mainly focused on EFSF loans, described above, but for the ESM they included modifications to the interest rate scheme that should reduce forecasted ESM payments. Specifically, backto-back loans held by Greek banks were exchanged for long-term fixed notes and cash; swap agreements by the ESM to stabilize the cost of funding charged to Greece, and matched funding for future disbursements. As it is not immediately clear how to factor these modifications into our calculations, we ignore them. Additionally, the ESM exchanged floating rate notes for cash, which affected the repayment profile. We implement this change beginning in 2018Q1 using the forecasted repayment scheme from the ESM website available June 25, 2018. This does not affect the total amount of disbursements, only the repayment profile by reducing interest rate risk. The forecasted repayments were not available on the ESM website immediately, and we use the available data from June 2018.

JUNE 2018: This is because modifications to these loans would involve negotiations with the private sector. Second, for the ESM programme, the step-up margin related to the debt buy-back tranche was eliminated. This step-up margin had been temporarily waived, but now was abolished. The third major change, which is not included in our calculations, is the transfer of approximately $€ 2$ billion in profits from the ESM segregated account to Greece.

\section{I.4 International Monetary Fund}

Greece first requested IMF support in the form of a Stand-By Agreement (SBA), and was approved on May 9, 2010, so we begin our series in 2010Q2. Beginning in March 2012, Greece moved from an SBA to an Extended Fund Facility (EFF). The key difference between the two is that the EFF features a longer duration of support and longer maturities for the loans than the SBA, but the spreads over the 3-month SDR rate are identical. We end our forecast series in 2016Q1, when the EFF was cancelled. ${ }^{124}$

For forecasted disbursements, we mostly rely on IMF publications. For forecasts in 2010Q2, we use the forecasted request for funding. ${ }^{125}$ For forecasts in 2010Q3, we use Occasional Paper 68 in August 2010 (EC (2010)). For forecasts in 2010Q4, we use Occasional Paper 72 (EC (2010c)). For forecasts in 2011Q1 and 2011Q2, we use Occasional Paper 77, For forecasts in 2011Q3, we use Occasional Paper 81 (EC (2011b)). ${ }^{126}$ For forecasts in 2011Q4, we use Occasional Paper 87 (EC (2011a)). ${ }^{127}$ However, this paper was published during the transition from Programme 1 and the GLF to Programme 2, which involved the EFSF.

This was also the time when the IMF switched from using the SBA to the EFF. At this point, with Programme 2 in full effect, the IMF was projected to make $€ 28$ bn in equally phased disbursements over four years. As with the SBA, EFF disbursements would not be made without a round of reviews. The first/second reviews were published in December 2012. For the first three quarters, we use the proposed disbursement schedule from the March 2012 statement, which

\footnotetext{
${ }^{124}$ In July 2017, Greece requested SBA funding. We do not include this in our forecasts.

${ }^{125}$ Table 7 of the Staff Report on Request for Stand-By Arrangement (IMF (2010a)).

${ }^{126}$ For this forecast, Occasional Paper 81 was written in July 2011 and there was also a forecasted disbursement in that same month. The Occasional Paper was not worried about this disbursement, and it was actually disbursed in July. However, there is also a forecasted disbursement in September, which did not actually occur. For this reason, this forecast is not as of the end of the quarter, like the others, but more as of the middle.

${ }^{127}$ Like the forecast before, this will take place in the middle of the quarter as there is a forecasted disbursement in November which doesn't actually occur until December.
} 
forecasts $€ 1.6$ bn each quarter through 2016Q1. We also use this forecast for 2012Q2 and 2012Q3. However, after the $€ 1.6$ bn in March was disbursed, there was not another disbursement until December 2012. As there do not appear to be any other IMF communications during this time period, we therefore "roll forward" each $€ 1.6$ bn until December under the assumption that investors think this will be disbursed as soon as possible. For 2012Q4 we use Occasional Paper 123 to make our forecast. ${ }^{128}$ For the 2013Q1 forecast, we use the IMF's first/second review of the EFF, published in December 2012, to make the forecast. There was a disbursement in January 2013 following completion of these reviews, and we assume that this was forecasted in December for the 2012Q4 forecast. There is also a forecasted disbursement in February 2013. We leave this one in, but note that it was never actually made. For the 2013Q2 forecast, we use the EFF Third Review in June 2013. The forecasts did not change, but there was a disbursement of $€ 1.8$ bn For the 2013Q3 forecast, we use the EFF Fourth Review in July 2013. Note that this is only one month later, but it resulted in the release of the next disbursement in July. The next actual disbursement was not until June 2013, so for the 2013Q4 and 2014Q1 forecasts, we roll forward the forecasted amounts to match this realization. For the 2014Q2 forecast, we use the EFF Fifth Review in June 2014. This June 2013 would be the final IMF disbursement, but the EFF program was not cancelled until January 2016. As such, we maintain the forecasts until 2016Q1 by rolling forward the anticipated amounts. The 2016Q1 forecast is the final forecast.

For actual repayments, we use the data available from the IMF website. Because there have been no modifications to the disbursements, these are accurate at the time of disbursement. To calculate projected repayments of a series not yet disbursed, we use the fact that, up until March 2012, the IMF was using the SBA. This means that the loans had a three year grace period before maturity repayment, and following this point they were then repaid over a two year span. Taken together, the SBA loans were expected to be fully repaid in exactly 5 years. We take this same approach for forecasted SBA loans, and assume that they will be repaid, after a three year grace period, over a two year period, quarterly, with a constant amortization. As for EFF loans, which began to be used as of the 2012Q1 forecast, these has much longer maturities and so had a four year grace period. They are then repaid at a semi-annual rate and are forecasted to be fully repaid over the next 6 years. Taken together, the EFF loans were expected to be fully repaid in exactly 10 years. We take thsi approach for forecasted EFF loans, and assume they will be repaid, after a four year grace period, over a six year period, semi-annually, with a constant amortization. Principal repayments for both SBA loan and EFF loans are assumed to be in the three/six month intervals beginning after the disbursement date.

For interest rates, the IMF lends at the market-related interest rate, which is the basic rate of charge. This interest rate is calculated by taking the market-determined Special Drawing Rights (SDR) interest rate and adding a margin of $100 \mathrm{bp}$. Added to this charge is a 200bp surcharge for all amounts above $187.5 \%$ of quota, which after three years rises to $300 \mathrm{bp}$. For all disbursed loans, the IMF gives a projected interest payment schedule, and we use this whenever possible. Otherwise, we use Greece's quota to calculate the interest rate (on all outstanding debt), (SDR1.1 bn). We use the rate of charge prevailing in the last day of the sample as our estimate of future interest rates. This is almost certainly a lower bound (see Figure 19), so in practice our estimate of the internal rate of return is also a lower bound.

In practice, only two events move the internal rate of return substantially. First, the shift from using the SBA to the EFF and the introduction of Programme 2 affected both the amount of disbursements and the expected interest payments. Second, the IMF programme was officially cancelled in January 2016, eliminating all future disbursements and with them repayments and interest.

\footnotetext{
${ }^{128}$ It looks like the EFSF assumed that the first and second reviews would be disbursed on schedule (although they were not) in Q4. Then, they assumed $€ 1.8$ bn going forward, which is what is in the first/second review. This is a result forecasting fewer reviews, since the November 2012 review waas skipped.
} 


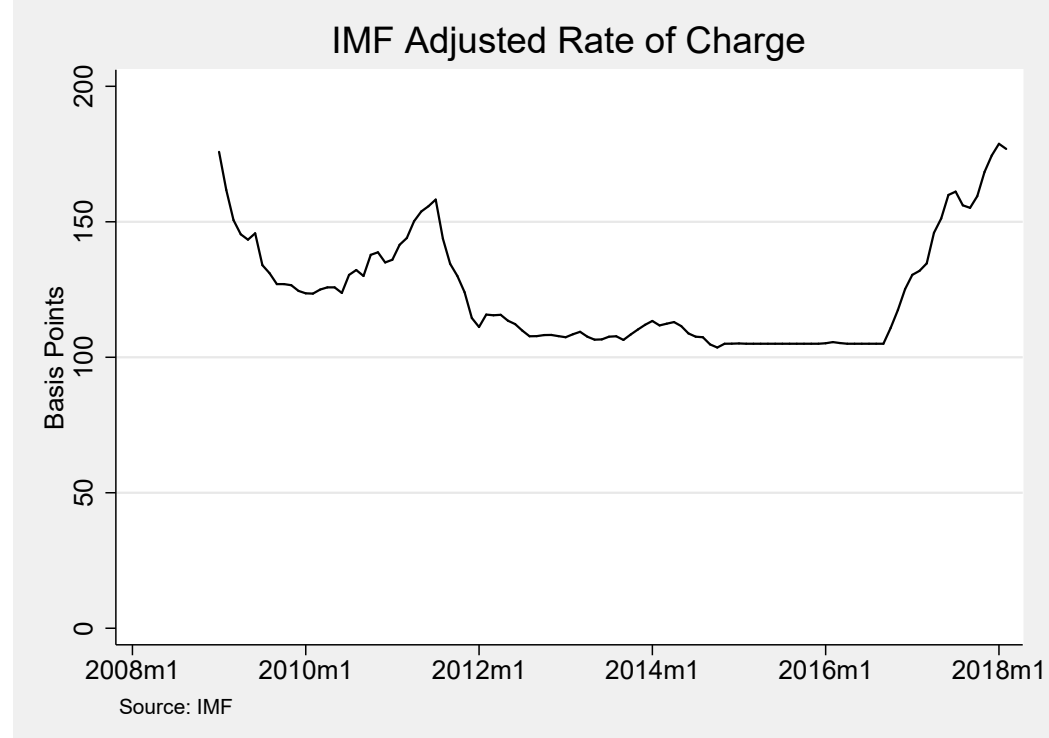

Figure 19: Basic Rate of Charge

\section{I.5 Time-Varying NPV and IRR by Entity}

Using 1, we can calculate the size of the transfer to Greece by each entity. We first calculate net transfers for each discounting each series of net transfers, using equation H.2. We then discount this series at the IMF internal rate of return. Figure 20 shows the evolution of the internal rates of return while Figure 21 shows the size of the transfer. 


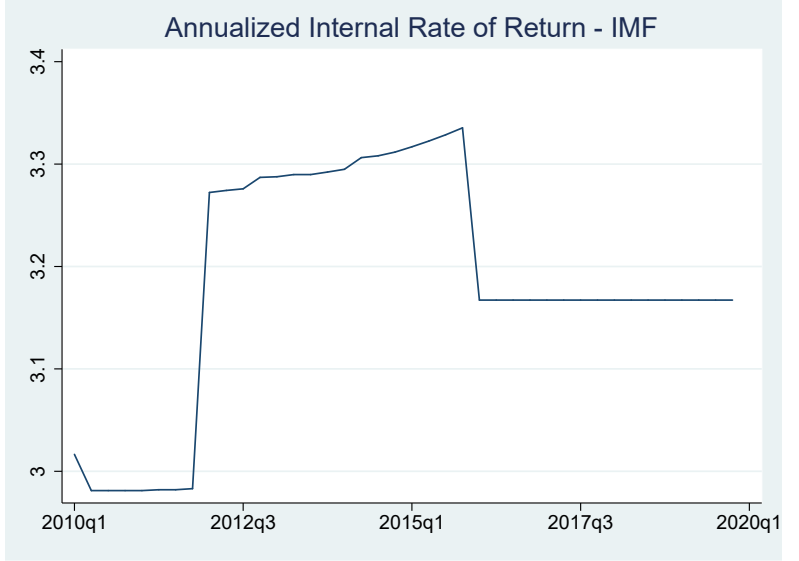

(a) IMF

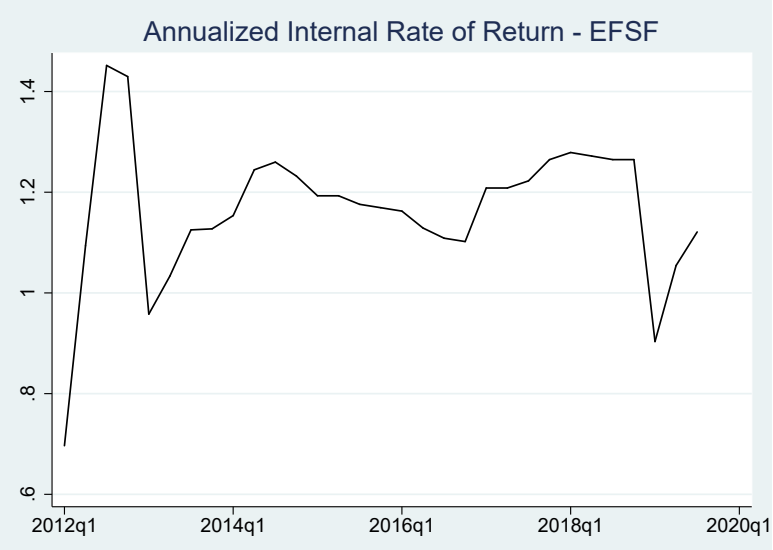

(c) EFSF

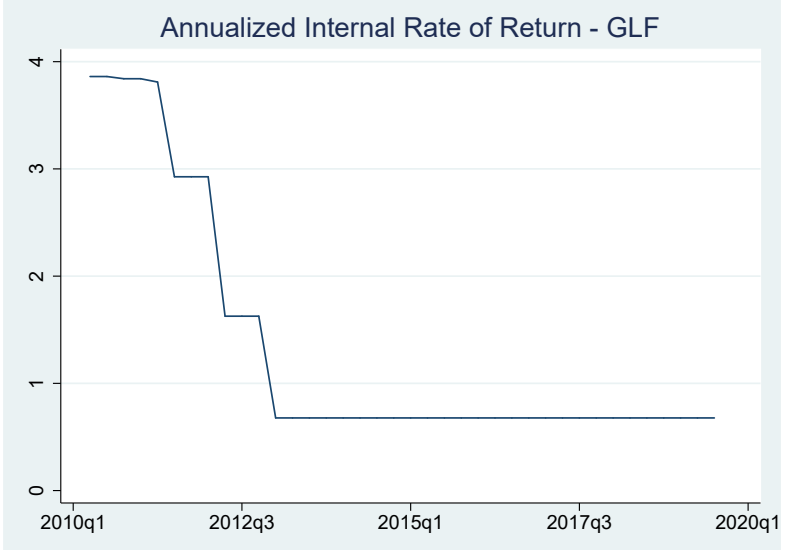

(b) GLF

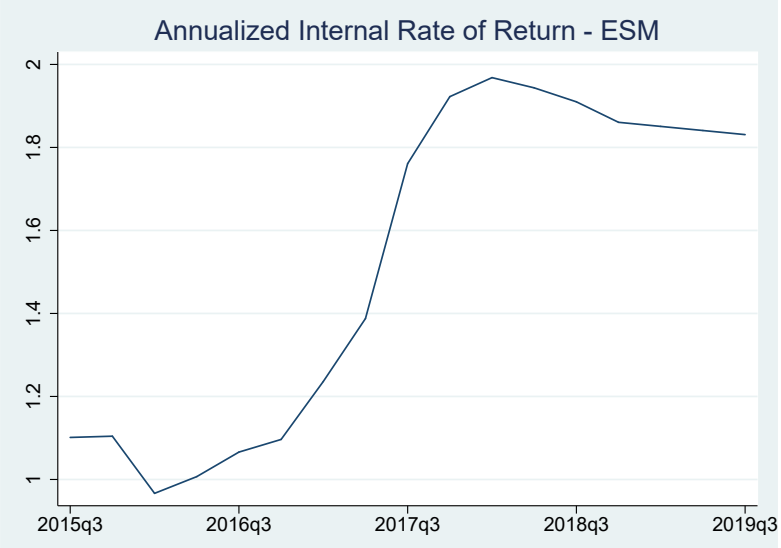

(d) ESM

Figure 20: IRR's by Lender 


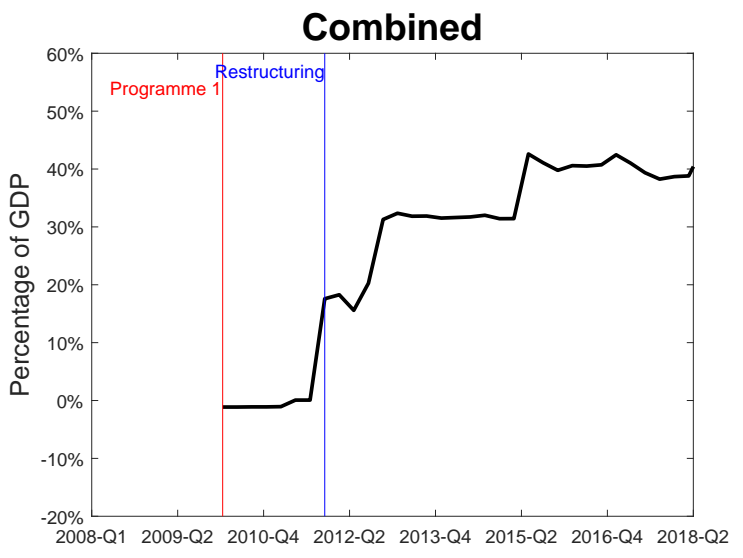

(a) NT Combined

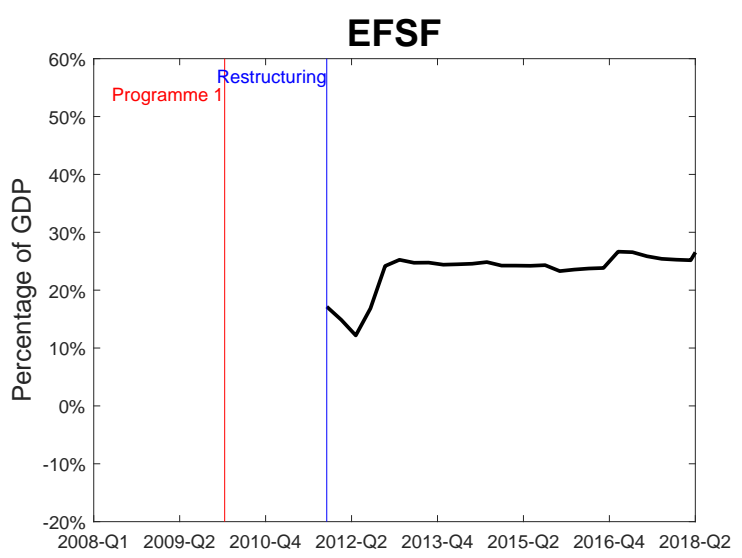

(c) NT EFSF

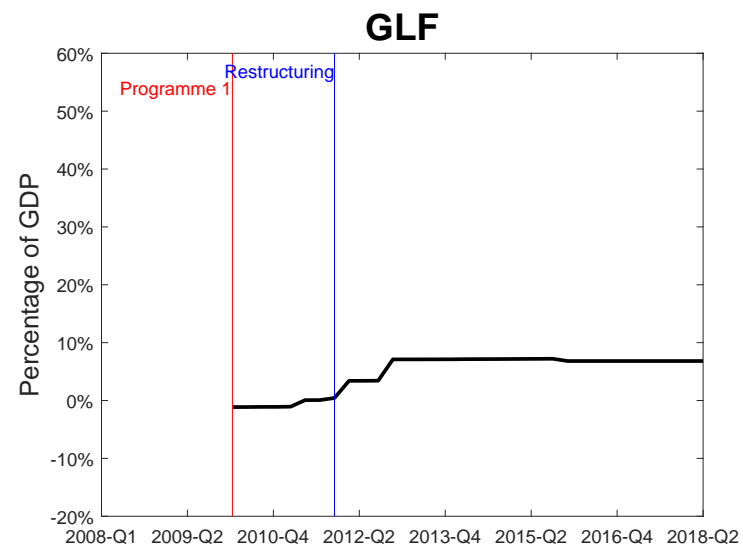

(b) NT GLF

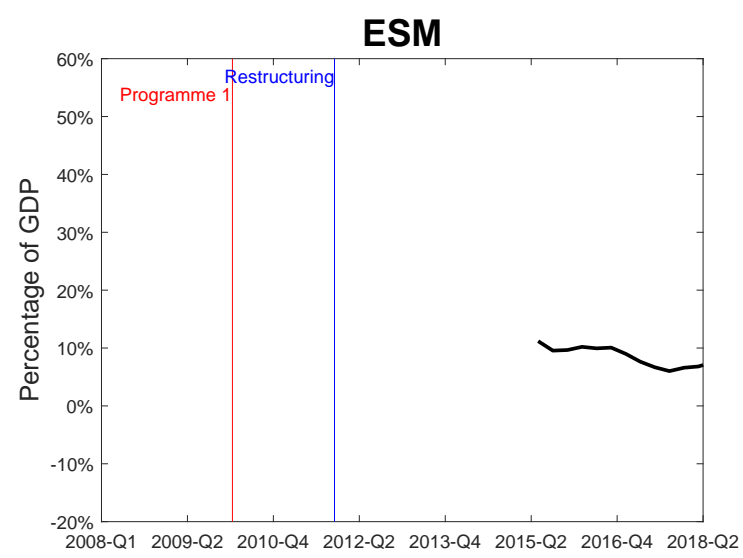

(d) NT ESM

Figure 21: Net Transfers by Lender 


\section{References for Online Appendix}

Blustein, Paul. 2015. "Laid low: The IMF, the euro zone and the first rescue of Greece." Centre for International Governance Innovation CIGI Paper Series 61.

CNA News Service. 2017. “Cyprus makes early payment on IMF loan.” cyprus-mail.com [Online; posted 17-July-2017].

Corsetti, Giancarlo, Aitor Erce, and Timothy Uy. 2017. "Official Sector Lending Strategies During the Euro Area Crisis." Centre for Macroeconomics (CFM) Discussion Papers 1720.

Du, Wenxin, Joanne Im, and Jesse Schreger. 2018. "The U.S. Treasury Premium.” fournal of International Economics, 112(C): $167-181$.

EC. 2010a. "The Economic Adjustment Programme for Greece." European Commission Occasional Papers 61.

EC. 2010b. "The Economic Adjustment Programme for Greece - First Review." European Commission Occasional Papers 68.

EC. 2010c. “The Economic Adjustment Programme for Greece- Second Review." European Commission Occasional Papers 72.

EC. 2011a. "The Economic Adjustment Programme for Greece- Fifth Review." European Commission Occasional Papers 87.

EC. 2011b. "The Economic Adjustment Programme for Greece- Fourth Review." European Commission Occasional Papers 81.

EC. 2011c. "The Economic Adjustment Programme for Greece- Third Review." European Commission Occasional Papers 77.

EC. 2012a. "The Second Economic Adjustment Programme for Greece." European Commission Occasional Papers 94.

EC. 2012b. "The Second Economic Adjustment Programme for Greece - First Review." European Commission Occasional Papers 123.

EC. 2012c. "The Second Economic Adjustment Programme for Greece - Fourth Review." European Commission Occasional Papers 192.

EC. 2015. "Balance of Payments Assistance Programme - Romania, 2013-2015." European Commission.

EC. 2016a. "Ex Post Evaluation of the Economic Adjustment Programme - Portugal 2011-2014." European Commission Institutional Papers 40.

EC. 2016b. "The Third Economic Adjustment Programme for Greece - First Compliance Report.” European Commission Compliance Reports 1.

EC. 2017a. "Post-Programme Surveillance Report - Second Report." European Commission Institutional Papers 54.

EC. 2017b. "The Third Economic Adjustment Programme for Greece - Second Compliance Report." European Commission Compliance Reports 1.

EC. 2018a. "The Third Economic Adjustment Programme for Greece - Fourth Compliance Report." European Commission Compliance Reports 1. 
EC. 2018b. "The Third Economic Adjustment Programme for Greece - Third Compliance Report." European Commission Compliance Reports 1.

EFSF. 2014. “Second Amendment Agreement.” European Financial Stability Fund.

EFSF. 2015. “Third Amendment Agreement.” European Financial Stability Fund.

ESM. 2013. “Conclusion of ESM Financial Assistance Programme for Spain: An Overview.” European Stability Mechanism.

ESM. 2016. "Conclusion of ESM Financial Assistance Programme for Cyprus: An Overview." European Stability Mechanism.

ESM. 2017. “Short-Term Debt Measures for Greece, Explainer.” European Stability Mechanism.

EU. 2008a. "Council recommendation (EU) no 716/2008." Council of European Union.

EU. 2008b. “Council regulation (EU) no 112/2008.” Council of European Union.

EU. 2009a. “Council regulation (EU) no 289/2009.” Council of European Union.

EU. 2009b. “Council regulation (EU) no 290/2009.” Council of European Union.

EU. 2009c. "Council regulation (EU) no 459/2009." Council of European Union.

EU. 2011a. "Council regulation (EU) no 323/2013." Council of European Union.

EU. 2011b. "Council regulation (EU) no 344/2011." Council of European Union.

EU. 2011c. "Council regulation (EU) no 673/2011.” Council of European Union.

EU. 2011d. "Council regulation (EU) no 77/2011." Council of European Union.

EU. 2013a. "Council regulation (EU) no 0336/2012." Council of European Union.

EU. 2013b. “Council regulation (EU) no 313/2013.” Council of European Union.

Eurogroup. 2010. "Euro Loan Facility Act of 2010."

European Commission. 2012. "Parliamentary questions - Answer given by Mr Rehn on behalf of the Commission." 29 June 2012.

IMF. 2007. "Staff Report for the 2007 Article IV Consultation.” International Monetary Fund.

IMF. 2008a. "Press Release: IMF Executive Board Approves 12.3 Billion Euro Stand-By Arrangement for Hungary." International Monetary Fund.

IMF. 2008b. "Press Release: IMF Executive Board Approves $€ 1.68$ Billion (US\$2.35 Billion) Stand-By Arrangement for Latvia." International Monetary Fund.

IMF. 2008c. "Press Release: Statement by IMF Managing Director Strauss-Kahn on Hungary." International Monetary Fund. IMF. 2008d. "Statement by IMF Managing Director Strauss-Kahn on Latvia." International Monetary Fund. 
IMF. 2009. "Press Release: IMF Completes First Review Under Stand-By Arrangement with Latvia and Approves $€ 195.2$ Million Disbursement." International Monetary Fund.

IMF. 2010a. "Greece: Staff Report on Request for Stand-By Arrangement." International Monetary Fund.

IMF. 2010b. "IMF Executive Board Approves €22.5 Billion Extended Arrangement for Ireland." International Monetary Fund.

IMF. 2010c. "Press Release: IMF Completes Second Review Under Stand-By Arrangement with Latvia and Approves $€ 200.3$ Million Disbursement.” International Monetary Fund.

IMF. 2010d. "Press Release: IMF Completes Third Review Under Stand-By Arrangement with Latvia and Approves $€ 105.8$ Million Disbursement.” International Monetary Fund.

IMF. 2011a. "IMF Executive Board Approves an €26 Billion Extended Arrangement for Portugal." International Monetary Fund.

IMF. 2011b. "Press Release: IMF Completes Fourth Review Under Stand-By Arrangement With Latvia." International Monetary Fund.

IMF. 2011c. "Press Release: Statement by the IMF and EC on the Fifth and Final Review to Latvia." International Monetary Fund.

IMF. 2012a. "Press Release: IMF Statement on Latvia's Announcement about Early Repayment to the IMF." International Monetary Fund.

IMF. 2012b. "Press Release: Latvia Makes Early Repayment to the IMF." International Monetary Fund.

IMF. 2016. "Conditionality Factsheet.” International Monetary Fund.

IMF. 2017. “The IMF’s Extended Fund Facility.” International Monetary Fund.

Joshi, Priyadarshani, and Jeromin Zettelmeyer. 2005. “Implicit Transfers in IMF Lending, 1973-2003." IMF Working Paper 05/8.

UK Treasury. 2010. “Credit Facility for Ireland Provided by The Commisioners of Her Majesty’s Treasury.”

UK Treasury. 2012. "Amendment to the Credit Facility for Ireland Provided by The Commisioners of Her Majesty’s Treasury." 